\title{
Southwestern United States Carbon Sequestration Training Center
}

\author{
Final Technical Report
}

November 16, 2009 through December 31, 2012

WORK PERFORMED UNDER AGREEMENT

\author{
DE-FE0001731 \\ SUBMITTED BY \\ New Mexico Institute of Mining and Technology \\ Petroleum Recovery Research Center, New Mexico Tech \\ 801 Leroy Place \\ Socorro, New Mexico, 87801 \\ University of Utah \\ Grants and Contracts Accounting \\ 201 South President's Circle, Room 406 \\ Salt Lake City, Utah 84112-9020 \\ Subcontractors: \\ Texas Agrilife Research \\ Office of Sponsored Research Services \\ 400 Harvey Mitchell Parkway South, Suite 300 \\ College Station, Texas 77845-4375
}

\section{PRINCIPAL INVESTIGATOR}

\author{
Robert Lee \\ Telephone (575) 835-5408 \\ Fax (575) 835-6031 \\ lee@prrc.nmt.edu \\ Prepared by Co-PI's
}

Andrew Campbell (NMT), Telephone (575) 835-5327, campbell@nmt.edu

Brian McPherson (U of U), b.j.mcpherson@utah.edu

Tarla Petersen (TAMU), tarlarai@gmail.com

May 2013

SUBMITTED TO

U.S. Department of Energy

National Energy Technology Laboratory

William O’Dowd

William.ODowd@netl.doe.gov 


\section{Disclaimer}

This report was prepared as an account of work sponsored by an agency of the United States Government. Neither the United States Government nor any agency thereof, nor any of their employees, makes any warranty, express or implied, or assumes any legal liability or responsibility for the accuracy, completeness, or usefulness of any information, apparatus, product, or process disclosed, or represents that its use would not infringe privately owned rights. Reference herein to any specific commercial product, process, or service by trade name, trademark, manufacturer, or otherwise does not necessarily constitute or imply its endorsement, recommendation, or favoring by the United States Government or any agency thereof. The views and opinions of authors expressed herein do not necessarily state or reflect those of the United States Government or any agency thereof. 


\begin{abstract}
The Southwest $\mathrm{CO}_{2}$ Training Center was initiated in November 2009 in response to the need to develop a generation of workers with expertise in carbon capture, utilization and storage (CCUS). Three universities ran the Training Center cooperatively: New Mexico Tech, the University of Utah and Texas A\&M University. The overall approach of the Training Center was to conduct education and outreach at a wide range of educational levels, including K-12 students and teachers, undergraduate and graduate students, professionals, and the general public. Key activities included: (1) Outreach targeted development of a video game (Carbon Bond) for middle-school students. (2) A summer program for high-school students. (3) Training for K-12 educators in Utah with a program by the Keystone center on "the Climate Status" and two offerings of a Masters of Science Teaching class at New Mexico Tech (NMT) on Climate and Carbon Sequestration. (3) Development and approval of an undergraduate curriculum for a concentration in CCUS for geology majors offered at the Earth and Environmental Science Department at NMT. This included a new course in Carbon Sequestration Science and a field course in Reservoir and Caprock Geology. (4) A new graduate-level course in CCUS was developed and offered via distance education to students at the University of Utah (U of $U$ ), NMT and the University of Texas at El Paso (UTEP). (5) Professional training via a reservoir modeling class, opening up the university courses to professionals, and conducting three webinars on outreach and public perception in CCUS.

Overall we offered $60 \mathrm{CEU}$ credits and 2,598 hours of professional training. A business plan was developed to continue the Training Center's CCUS education into the future. This involves a collaborative agreement with Schlumberger Carbon Services using the expertise and on-line materials developed by the Training Center for a commercial professional development website.
\end{abstract}




\section{TABLE OF CONTENTS}

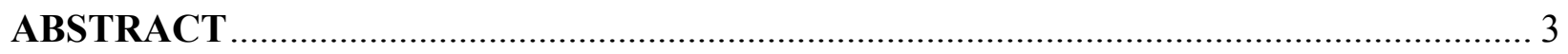

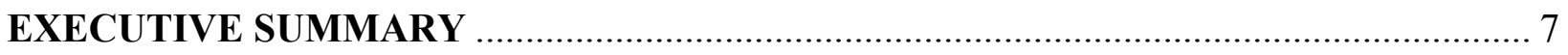

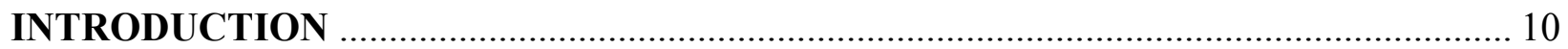

IMPLEMENT AN ORGANIZED SPONSORSHIP DEVELOPMENT PLAN .................... 11

BusineSS Plan AND CoMmERCIALIZATION STRATEGY ...................................................... 11

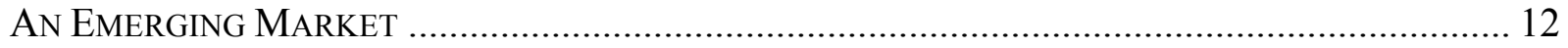

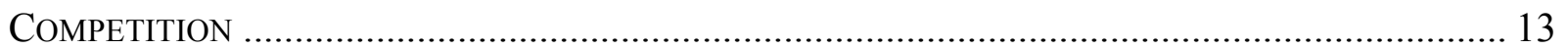

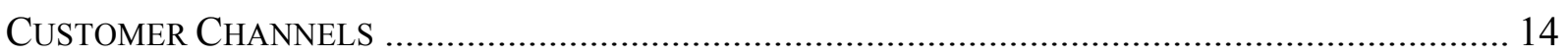

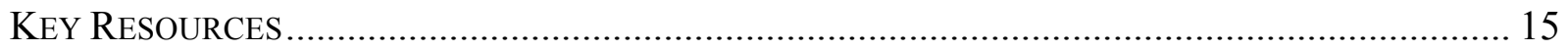

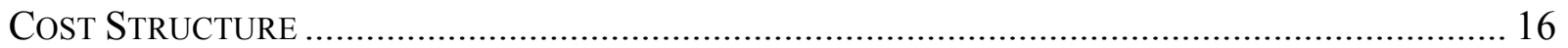

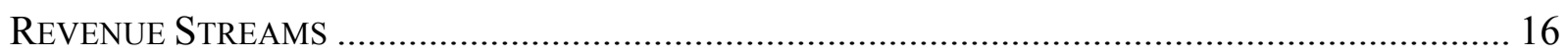

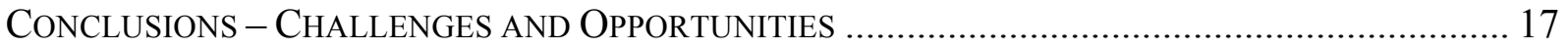

SECONDARY SCHOOL CCUS EDUCATION AND TRAINING ………………............... 19

Secondary Teacher Training, Salt Lake City, December 9-10, 2010 ............................. 19

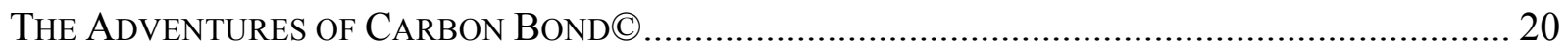

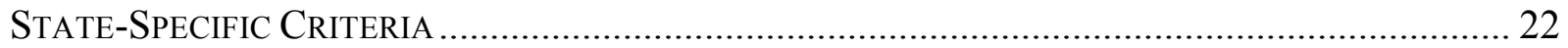

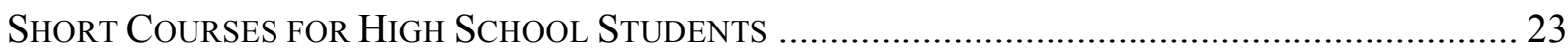

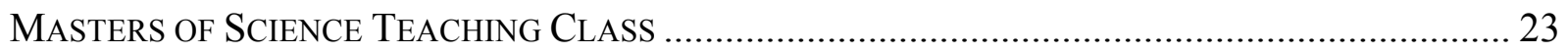

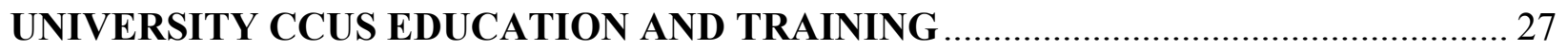

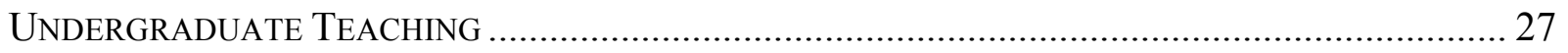

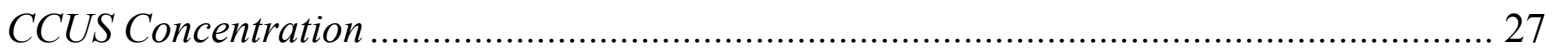

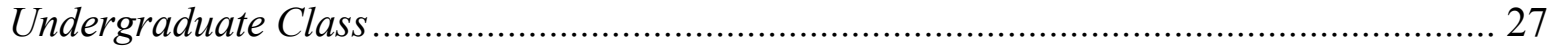

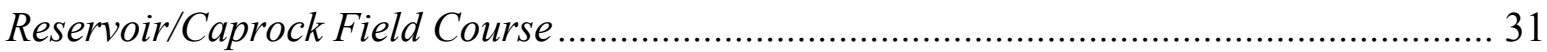

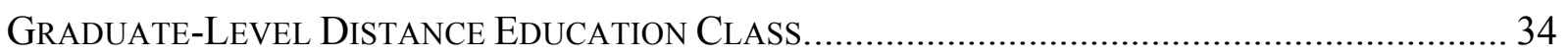

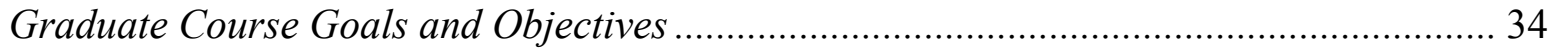

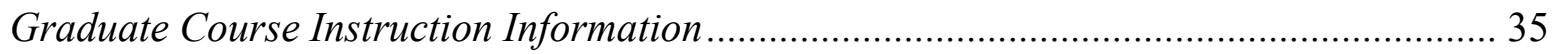

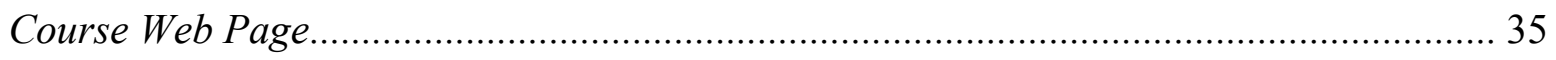




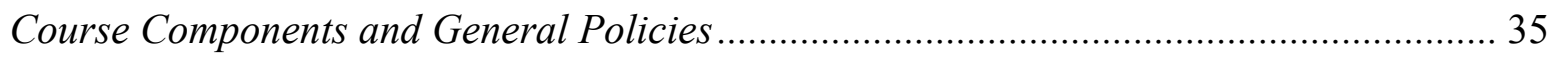

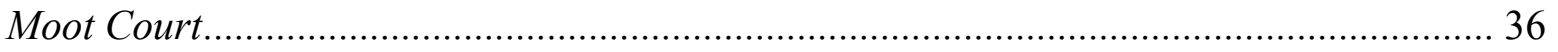

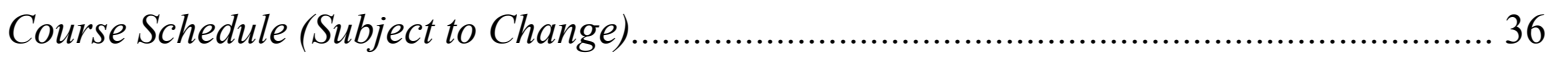

PROFESSIONAL CCUS EDUCATION AND TRAINING ………………....................... 40

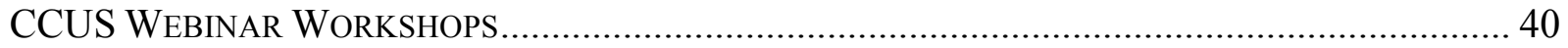

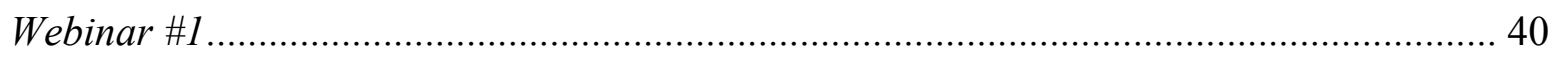

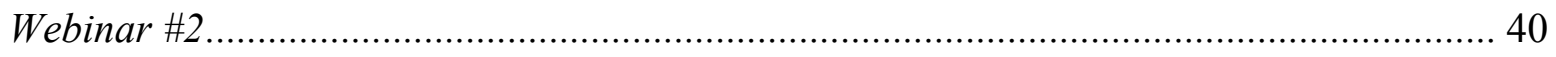

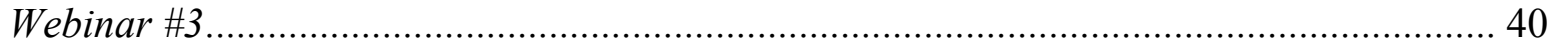

SWTC Professional Short Course 1: OCtOBer 26-27 2010 ….......................................... 41

REGIONAL/BASIN TECHNOLOGY TRANSFER SERVICES ..................................... 42

TRAINING CENTER WEBSITE AND LISTSERVS ………………………................... 43

PLANNING AND MANAGEMENT OF THE REGIONAL TRAINING PROGRAM ...... 44

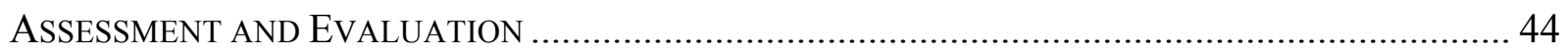

RESEARCH CONFERENCES AND PUBLICATIONS ...................................................................... 45

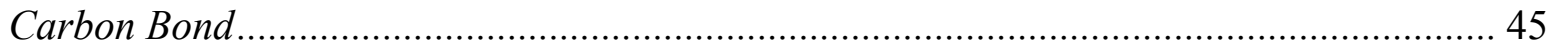

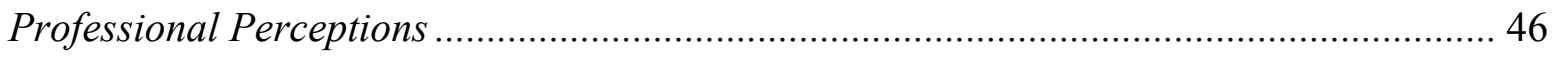

The Use and Utility of YouTube Videos as an Outreach Medium for Carbon Capture, and Sequestration Information ……………....................................................................... 48

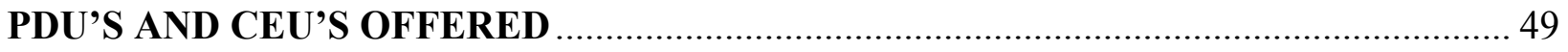

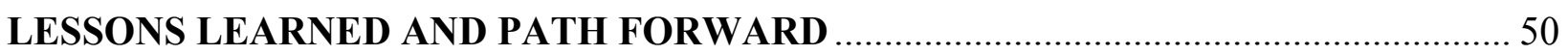

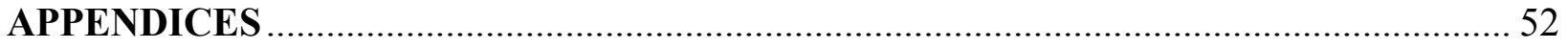

A. Complete CaProck Services Business Plan ………………................................... A-1

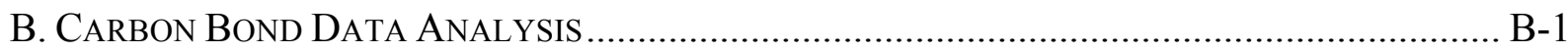

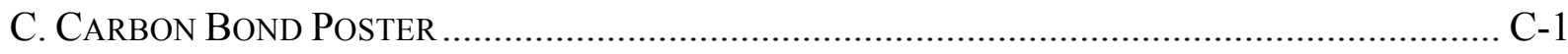

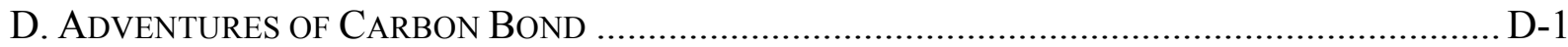

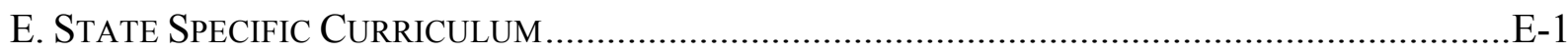

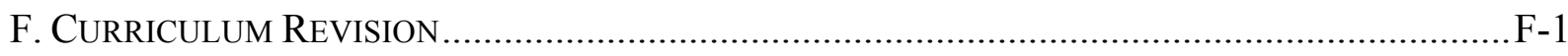

G. TREndS Training Center Education and Training Survey Data Report ............. G-1

H. CCS UNDERGRADUATE ClaSS SURVEY ................................................................... H-1 


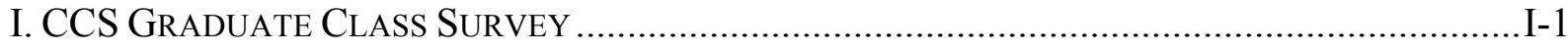

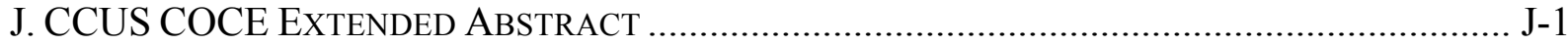

K. The Use and Utility of YouTUBe Videos …......................................................... K-1

L. PDU AND CEU DOCUMENTATION ........................................................................ 


\section{EXECUTIVE SUMMARY}

The Southwest $\mathrm{CO}_{2}$ Training Center started in November 2009 for the purpose of training a new generation of workers in the field of carbon capture, utilization and storage (CCUS). Our approach was to address a broad range of the educational spectrum. Activities included K-12 education, an undergraduate college curriculum, graduate classes, teacher training, and professional development classes. A Continuing Education (CEU) training session was offered for 30 teachers in Salt Lake City, Utah in conjunction with the Keystone Center utilizing their Climate Status Investigations curriculum for middle school students designed to address the issue of global climate change. We conducted pilot testing of The Adventures of Carbon Bond $\odot$ as an educational tool for secondary education about CCUS (created by Feldpausch-Parker and Peterson) designed for 6th -8th graders. Testing included 193 students from Michigan, Texas and North Carolina. We completed a review of state-specific curricula to identify where CCUS education could contribute to the curriculum and we suggested where The Adventures of Carbon Bond could fit within state standards in relation to the results of our pilot data. A three-day short course on geology for CCUS was developed for high-school students and offered in the summers of 2011 and 2012 for a group of over 30 at-risk students who were in an Upward Bound summer program at New Mexico Tech. The class included lectures labs, demonstrations, laboratory exercises and field trips. We also offered an intensive class in the Masters of Science Teaching program at New Mexico Tech. This two-week, two-credit class, which was offered in 2011(0 students), 2012 (3 students), and 2013 (7 students), focused on teaching climate change, CCUS, and the relevant geology to middle and high school teachers.

The Southwest $\mathrm{CO}_{2}$ Training Center engaged in a number of activities to instruct undergraduate students in topics related to CCUS. These included: (1) development of a new undergraduate concentration in CCUS, (2) teaching an upper-level undergraduate class "Carbon Sequestration Science", and (3) teaching a three-day field course focused on reservoir rocks and caprocks. More information on these activities is provided in the following sections. The New Mexico Tech Earth and Environmental Science Department developed an option for CCUS, which included core earth science classes, as well as additional courses in petroleum engineering, chemistry, hydrology, and mathematics. In addition, all students were required to take a capstone class "Carbon Sequestration Science". This class was taught at the upper-level (senior/junior), with all students required to have taken at least a year of calculus, chemistry and 
physics, but with only a few geology prerequisites in order to encourage non-majors to take the class. We succeeded in this respect, as many petroleum engineering students (over half the class) enrolled. Class included a three-day field trip to two Southwest Partnership field sites in New Mexico and Utah. The second offering of the class (Spring 2012) was canceled due to low enrollment, reflecting a limited pool of interested students. Our graduate-level college class was offered in fall semesters of 2010 (14 students) and 2012 (23 students). This class joined classrooms at NMT and $U$ of $U$ via distance education (with some students from UTEP logging on individually). The class covered an introduction, geology, geochemistry, flow modeling, and societal impacts of CCUS.

A CCUS simulation professional short course was held at the University of Utah on October 26-27, 2010. The training course (18 students) was convened by Dr. Brian McPherson and taught by code development staff from the Pacific Northwest National Laboratory. For the sake of simplicity, we offered training with only one simulation package, STOMP, a multifluid subsurface flow and reactive transport simulator, developed at the Pacific Northwest National Laboratory (PNNL). In addition The Southwest $\mathrm{CO}_{2}$ Training Center ran a three-day reservoir/caprock field course (10 students) in the Moab, UT area August 15 - 17, 2012. The course was taught by Peter Mozley and Andrew Campbell (New Mexico Tech), and Jason Heath (Sandia National Laboratories). The course examined reservoir and caprock lithologies and seal bypass structures (faults, dikes etc.) that could affect the subsurface flow of $\mathrm{CO}_{2}$. A portable permeameter was used to provide real-time data for the students on lithologic and structural controls on permeability.

The plan for sustaining CCUS training after the end of the contract was developed by the University of Utah (Dr. Brian McPherson) and USTAR (Ryan Streams) in collaboration with Schlumberger Carbon Services. Caprock Carbon Services is a comprehensive program that promotes and supports the adoption of Carbon Capture, Utilization and Storage (CCUS) practices though training and tailored project support for a diverse set of energy development stakeholders. Caprock Carbon Services benefits from having the branding and training experience of Schlumberger's NExT practice, which will allow Caprock to focus on CCUS without struggling to compete in the mature, developed marketplace of professional technical training. The lowered barriers to market entry will prove invaluable in helping Caprock Carbon Services deliver its product of high-quality CCUS training services. 
During the award period we pursued diverse activities to promote CCUS training and education. Most, but not all, of these activities were very successful, and many, but not all are likely to be continued in the future. The instructor who taught the MST classes has indicated that student response was enough to justify teaching it again, which he plans to do. We had good enrollments in all of the classes, except when we attempted to teach our undergraduate capstone course the second time, and too few students enrolled to justify teaching it. We feel this was due to a somewhat limited pool of interested students, and if we offer it again in a few years we anticipate a better enrollment. Our undergraduate field course on reservoir and caprock geology was also extremely successful (based on student reviews and enthusiasm in the field), and will continue to be taught in the future, perhaps every other year. Unfortunately, our undergraduate option in CCUS was not successful, in that in three years no students signed up for it, probably due to the current lack of jobs in CCUS. Our most successful course was the semester-long graduate level CCUS class, which was offered twice for a total of 38 students at 3 different universities. This course impacted their knowledge of, and ability to work in, the CCUS field. Our webinars and on-site professional short course were very successful. Student feedback showed that the participants felt an overall improvement in their understanding of the topic. During our research into the demand for future CCUS training we discovered that our original plan of having our graduate-level class available on-line for professional development was not a good business model due to low demand. Therefore the plan for Caprock services is more tailored to the needs of industry. 


\section{INTRODUCTION}

Our overall approach was to generate early interest in, and increase the number of workers available to, the CCUS industry by developing and implementing academic programs, specialized classes, continuing education, professional development, and public awareness. We think of this approach as filling the "pipeline" of future CCUS professional across the educational spectrum. The program included outreach and recruitment activities for secondary education students and science teachers, as well as multi-disciplinary undergraduate and graduate courses and curricula. The website and electronic based tools were used to inform and to incorporate pertinent industry developments and professional education opportunities. A business plan was written to identify opportunities for growth and possible target markets and includes a long-term strategy for a sustainable program by collaborating with an established industrial partner. The following actions increase the likelihood that the training program will be sustainable subsequent to the funding period: (1) The undergraduate and graduate level classes are in university course catalogs and there are sufficient faculty to continue to teach the classes as long as there is student interest. (2) The graduate level class was developed as a distance education class, which will be particularly easy to teach in the future as all the materials are in place and can be accessed by students at different universities, thus increasing demand. (3) The Masters of Science Teachers course is within the framework of New Mexico Tech's normal summer course offerings and will continue with appropriate demand. (4) The business plan ensures that should sufficient interest arise we will quickly use the education and training materials already in place for professional education and development

This report summarizes the accomplishments made during the contract period. Written material was supplied by Danielle Endres, Tarla Rai Peterson, Andrea Feldpausch-Parker, and Megan O'Byrne for the outreach activities, Peter Mozley for the undergraduate activities, Bruce Harrison for the MST classes, and Ryan Streams and Brian McPherson for the Business plan. These materials were assembled by Andrew Campbell and Peter Mozley. 


\section{IMPLEMENT AN ORGANIZED SPONSORSHIP DEVELOPMENT PLAN}

The plan for sustaining CCUS training after the end of the contract (Fig. 1) was developed by the University of Utah (Dr. Brian McPherson) and USTAR (Ryan Streams) in collaboration with Schlumberger Carbon Services (IM) and NExT. This replaces our original strategy of using the content developed from the graduate-level course as a series of on-demand modules for continuing education on a professional development web-site. USTAR conducted a series of interviews prospective end-users (such as legal firms, energy industry companies, educators, consultants and technical researchers). The overwhelming conclusion based on these interviews was that online video courses were not the preferred delivery for professional training. Instead, we found the strong preference among end-users is live, multi-day training workshops.

\section{Business Plan and Commercialization Strategy}

The University of Utah and USTAR developed a new commercial training entity known as Caprock Carbon Services. This was done in collaboration with Schlumberger Carbon Services and NExT (Network of Excellence in Training - a subsidiary of Schlumberger) and all parties are currently negotiating a working partnership. Caprock Carbon Services is a comprehensive program that promotes and supports the adoption of Carbon Capture, Utilization and Storage (CCUS) practices though training and tailored project support for a diverse set of energy development stakeholders. The complexity of CCUS projects requires expertise in a variety of fields - policy, geology, physics, chemistry, legal, environmental, financial, risk, etc. Currently, no comprehensive program exists to address the full range of issues associated with CCUS. This presents a barrier to CCUS implementation. Without a comprehensive program to educate, motivate and support stakeholders, the complexity of CCUS projects will remain an obstacle for commercial application.

Caprock Carbon Services is currently developing a partnership with Schlumberger. This partnership will have the unique benefit of allowing Caprock to concentrate on its CCUS training niche, while enjoying the broader reach of its partner organization's training programs. CCUS has traditionally been too narrow of a focus for larger training organizations to dedicate their efforts. With this partnership, Schlumberger is able to expand their educational portfolio, increase its available resources for teaching and gain access to the expertise of Dr. McPherson's 
carbon science team without dedicating extensive resources of its own to developing a CCUS training practice.

Caprock Carbon Services benefits from having the branding and training experience of Schlumberger's NExT practice, which will allow Caprock to focus on CCUS without struggling to compete in the mature, developed marketplace of professional technical training. The lowered barriers to market entry will prove invaluable in helping Caprock Carbon Services deliver its product of high-quality CCUS training services. See Appendix A for the complete business plan.
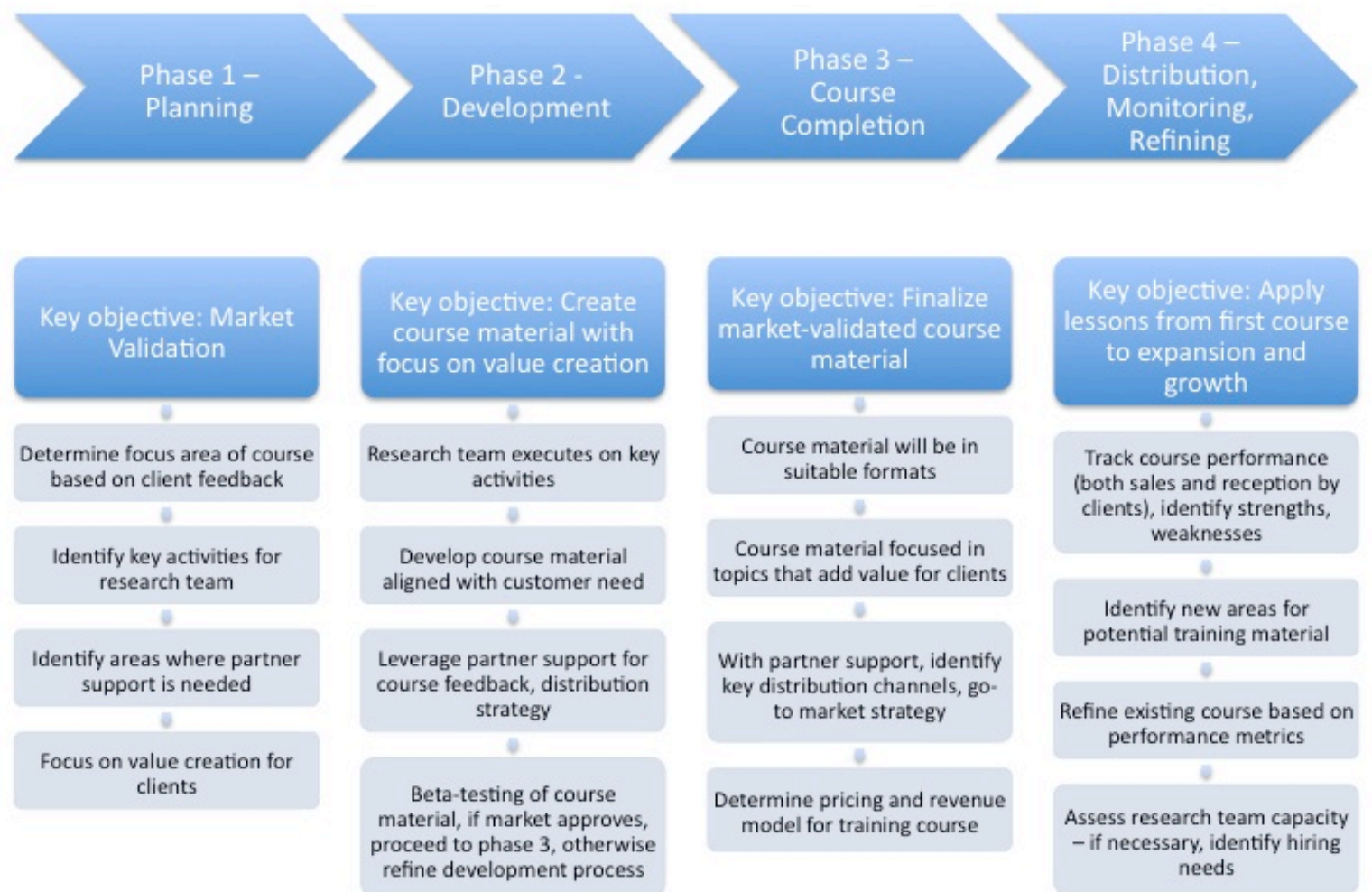

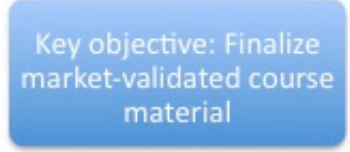

Course material will be in suitable formats

Course material focused in topics that add value for clients

With partner support, identify key distribution channels, goto market strategy

Determine pricing and revenue model for training course

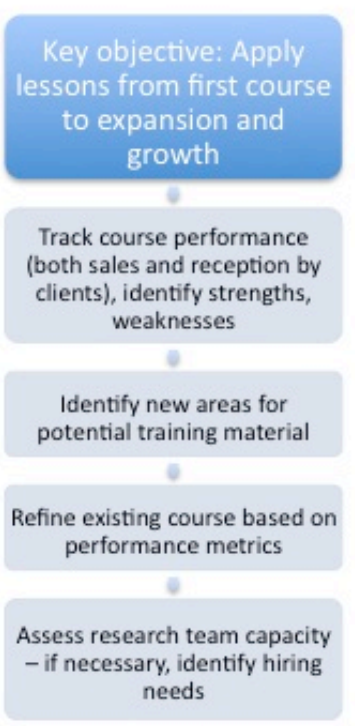

Figure 1. Strategy for development of a commercial professional training center based upon Southwest $\mathrm{CO}_{2}$ Training Center materials and expertise.

\section{An Emerging Market}

Currently, CCUS practices focus on sequestration of carbon dioxide in mature oilfields. $\mathrm{CO}_{2}$ injection, a process also known as enhanced oil recovery (EOR) is already common practice and its importance to oil production has been growing rapidly in recent years. As of 2009, the global value of the enhanced oil recovery market was $\$ 62.5$ billion and is projected to reach $\$ 1.3$ trillion by 2015 (Source: SBI Energy - EOR Worldwide Market Analysis). Investment in new 
technology has been a fundamental piece of the oil and gas industry. The oil and gas industry's investment in research and development reached \$3.4 billion in 2006 (Source: Ernst \& Young Investment 2006). Given the growing value of the EOR market and the industry's commitment to investment in R\&D, Caprock Carbon Services is well-positioned to deliver value-driven services in a growing sector.

Oil and gas producers are increasingly conscious of their carbon emissions. Although there are no current national regulations on carbon emissions, producers are still seeking ways to limit emissions. In the event that carbon emission regulations are enacted, this practice would become even more important

\section{Competition}

The Society of Petroleum Engineers, which has over 100,000 members worldwide (Source: SPE Membership 2011) and offers a variety of technical training, currently has no offerings on CCUS or EOR technology. Similarly, the American Petroleum Institute, which has over 500 corporate members including the super-major oil producers, offers no training in CCUS or EOR. Additionally, major commercial training organizations like Schlumberger's NExT program, or Nautilus World do not currently offer CCUS focused training. Caprock Carbon Services stands to satisfy this niche market.

Caprock Carbon Services will have consulting and service role with its customer base. We are an outside organization brought in to provide expertise in our CCUS niche. Our role is to be the experts on CCUS. Customers will look to us to distill the key issues relating to CCUS, provide them with information, training and project support. Our partnership with Schlumberger will allow us to quickly and accurately customize our services to client needs. Their extensive expertise in professional education in the oil and gas fields will be a tremendous asset. Our most important customers:

- Geologists and engineers for small to medium oil and gas producers

- Project management personnel

- Legal teams involved in CCUS

- Project financing and risk assessment teams

Stakeholders we will target in the future include:

- Policymakers 
- Environmental groups

- University-level academia targeting geology and engineering students

- $\mathrm{K}-12$ teachers and students

\section{Customer Channels}

We will reach our target customer base by offering our product as part of a suite of training services through our partner organization. By offering our services as part of a broader training program or project support program, we can broaden interest in our services. There may be other channels we choose to use, depending on the nature of our training material. If we choose to use video short courses like the one in development, we may use online continuing education websites as a potential channel for reaching our audience.

The number of organizations dedicated to CCUS services is limited and people actively seeking these services won't have many choices. The key will be to create a channel that brings interest and attracts market segments that may not initially think of CCUS project support. By using a broader training program offered by our partners at Schlumberger as a foot in the door, we can offer our services once they have already established a relationship with our partner. As noted above, CCUS projects are complex and require expertise in a variety of fields. In order to be a go-to resource on the subject, we need to develop a team that has expertise in these different areas. We need experts on land law, mineral law, environmental regulations, permitting, site characterization, geology, geochemistry, geophysics, etc. We have expertise in some areas (notably geomechanics and computer modeling) but we will need to round out our team in other areas. This will require hiring top-tier talent.

Initial training efforts will focus on these core expertise areas of geomechanics and computer modeling. After we develop training in these areas, we can think about ways to deliver additional value to clients (expanded training methods, tailored services, etc.). Building relationships with partners and potential clients will be another key activity. We will rely on seamless cooperation to move our services through our partner company to the clients. They will need to understand what exactly we can provide and we will need to understand how they approach training and project support. 


\section{Key Resources}

Caprock Carbon Services' primary resource is its human capital. Our geoscience and modeling expertise is our core strength. The talent we hire to provide expertise in other areas of CCUS will be a key resource once they are a part of the team. In order to deliver on our mission of providing high-end training and tailored project support to CCUS undertakings, we will require a highly capable team.

- Both hiring this team and connecting with clients will require a strong professional network to bring together new partners, find project applications and identify potential stakeholders.

- Another key resource will be credibility and brand recognition. Our partnership with Schlumberger will be a tremendous asset in that respect.

- Our primary financial obligation will be to provide resources needed to create our training programs, cover travel expenses and compensation.

Our key partners include:

- CCUS research team

- NExT

- University of Utah

- Southwest Partnership Universities

Our primary key partner is our CCUS research team. Currently, our team consists of carbon management researchers at the University of Utah and New Mexico Tech. This team may also include other scientists from the other Southwest Partnership Universities in the future. Their expertise is the real source of value for Caprock Carbon Services. Their technical knowledge and modeling capabilities will likely be the most valuable asset from the clients' perspective. They will be supplying a substantial portion of our ability to add value.

Another key partner is Schlumberger's NExT training program. Our relationship with them will be vital for identifying potential clients and potential projects, establishing name recognition with customers and providing further expertise in CCUS. Schlumberger will also be able to provide us with a framework for creating a training program that caters to clients' needs. Their extensive experience in providing training for the oil and gas industry would become a valuable resource for Caprock Carbon. 
The University of Utah, New Mexico Tech, or another University in the Southwest Partnership may be a source of human capital. As identified earlier, our value to clients depends on our ability to provide expertise. By drawing on the talent of these and other universities, we may be able to add some complementary personnel.

\section{Cost Structure}

Human capital is our most important resource; our salary costs will be our most important expenditures (Table 1). Salary costs will remain fixed once hiring is complete.

- Elements like credibility, brand recognition, etc. will not be major costs given our plan to partner with an existing firm. The primary cost associated with these resources will be whatever revenue-sharing model we decide on with our partner organization. Depending on how we choose to structure our training, we will have costs associated with training material production (i.e. recording, encoding, web-hosting, etc.) and with project support (travel, IT resources for video conferencing, etc.)

Our team's current position at the University of Utah may allow for sharing of resources like office space, computing, etc. This will need to be refined further, but it may allow us to avoid significant investment in computer modeling capabilities, new office space and similar expenses.

\section{Revenue Streams}

Potential customers will be most willing to pay for services and training tailored to specific projects. There appears to be little interest in general education-style training.

- Currently, technical training courses for oil and gas engineers are offered in 2-5 day formats, typically offered at $\$ 2,500-\$ 5,000$ for the course.

- These courses focus in high-end, technical training and target high-value professionals. In order to be competitive with existing training material, Caprock Carbon Services will need to offer a similarly high-end product.

In order to maximize value creation, our services will need to be tailored to individual clients' needs. In addition to offering short courses on CCUS:

- We will need to explore long-term project support that caters to individual teams' needs and addresses the challenges of unique projects. This training approach, which discussed during an informal conversation with Schlumberger, would require further clarification on the revenue structure. 
Table 1. Profit and Loss Projection (3 Years) for the Training Center

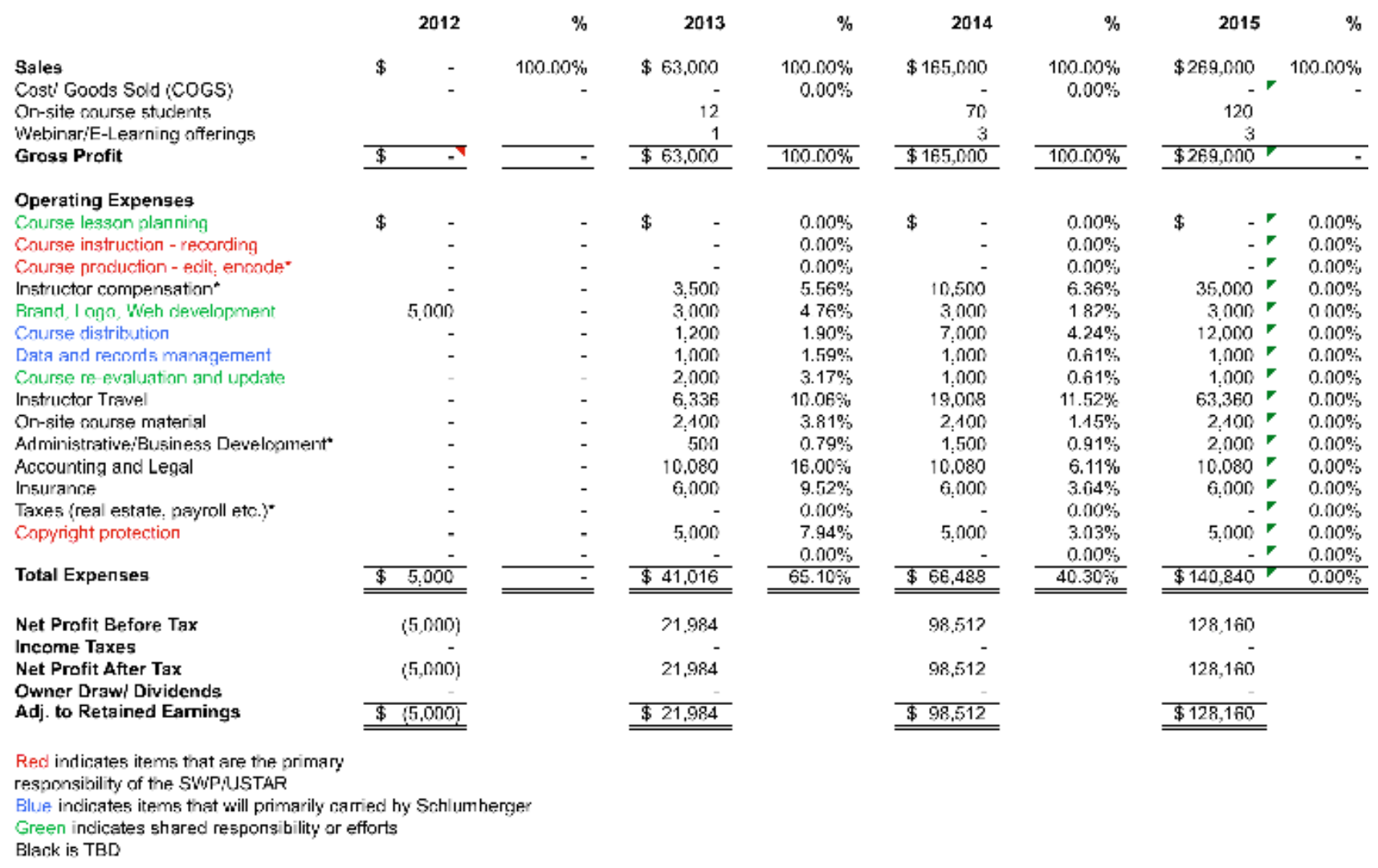

\section{Conclusions - Challenges and Opportunities}

The overarching direction of Caprock Carbon Services is a partnership with NExT. Given the narrow focus of a CCUS training center, partnering with a larger training and service provider appears to offer the best chance of commercial viability. Both NExT and the Caprock Carbon Services team remain optimistic about the opportunity to establish a mutually beneficial working relationship that furthers CCUS training, knowledge and expertise.

Currently, challenges remain that will need to be addressed before a partnership is established. The primary reason for this is because this is a completely new project for the University of Utah. There are many remaining questions on how to handle ownership, licensing, intellectual property and conflict of interest. Without an existing framework, resolving many of these issues will be difficult for the University of Utah. However, we remain engaged in discussions with the Technology Commercialization Office, the University Conflict of Interest Committee, leadership at the College of Engineering and the University's General Counsel. As 
we resolve these issues, we will be able to move forward with delivering high-quality technical training based on the work done by the Southwest Partnership. The revenue potential for this self-sustaining, commercial training center is discussed in Table 1. 


\section{SECONDARY SCHOOL CCUS EDUCATION AND TRAINING}

Our efforts in secondary school education have two main goals: 1) creating awareness of CCUS issues and knowledge, and 2) sparking student interest in science and engineering topics of CCUS. Efforts were directed both toward students and secondary teachers who will have a long lasting influence by incorporating CCUS topics into their classrooms. We succeeded in attracting teachers to three teacher-centered classes, and in attracting high-school students to two 3-day short courses. We also completed development of the Carbon Bond game for engaging younger students.

\section{Secondary Teacher Training, Salt Lake City, December 9-10, 2010}

Based on our review of the state specific criteria, we determined that the Keystone Center's "Climate Science Investigations" curriculum provided an excellent set of teaching modules for junior high school and high school students about CCUS. We contracted with the Keystone Center (Keystone, CO) to offer a "Climate Status Investigations" teacher training in Salt Lake City, UT at the McGillis School. The Climate Status Investigations is a curriculum for middle-high school students designed to "broaden the scope and quality of national science education with a balanced, non-biased, comprehensive, and interdisciplinary approach to the study of an issue pivotal to our students' generation - global climate change" (Keystone Center, 2009). The curriculum was developed in partnership with the U.S. Department of Energy and the National Energy Technology Laboratory. All participants in the teacher training received a copy of the full curriculum to use in their classes.

The training course filled to its maximum of 30 teachers quickly and there were 8 teachers on the waiting list. Teachers who participated in the training event came from schools in American Fork (2), Bingham (1), Harrisville (2), Kaysville (3), Kearns (1), Layton (2), North Ogden (1), Riverton (6), Salt Lake City (4), West Jordan (7), and West Valley City (1) from the counties of Davis, Salt Lake, Utah and Weber. The training was offered at no cost for the participants, and included covering the costs of transportation, and substitute teachers. All of the teachers received 13 hours of re-licensure points that can be used towards applying for a teaching license renewal in the State of Utah. We asked Keystone to investigate ways that teachers could also get University Credit or USOE Credit/Professional Staff Development Credit. As a result, teachers had the opportunity to receive one semester upper-level university credit issued from 
Utah State University for participation in the training at a subsidized rate (\$30.00). Eleven teachers received University Credits. Teachers also received a set of lesson plans and other materials from the Keystone Center that can be used in their classrooms.

Out of this training, 18 teachers signed up to be on the Southwest $\mathrm{CO}_{2}$ Training Center list serve for K-12 teachers and 13 signed up to participate in the pilot tests for The Adventures of Carbon Bond 2.0 game.

Teachers expressed interest in future trainings, field trips with researchers from EGI at Utah sites, and other curriculum materials. Due to teacher interest in, and the waiting list for the course, there is high demand for another Keystone training or other training opportunities for teachers in Utah.

\section{The Adventures of Carbon Bond $\mathbb{C}$}

In addition to the Keystone curriculum, our review of the state specific curriculum and educational needs revealed an absence of interactive gaming tools for teaching about CCUS. We developed The Adventures of Carbon Bond $\odot$ as a teaching module targeted to junior high school students (grades 6-8). The Adventures of Carbon Bond $\odot$ is an interactive video game for teaching about CCUS. Video games have often been trivialized as a medium that does not warrant further critical attention. Yet video games, as educational tools have the power to persuade and educate in ways that traditional mediums do not. ${ }^{1}$ Video games, therefore, are not only persuasive, but also hold the potential to transform the way we think about the world. Indeed, according to Chang "more environmentally realistic games could affect our understanding of real-world environmental issues, either by implicitly or explicitly modeling different forms of our individual and collective environmental agency" (p. 60). ${ }^{2}$

The Adventures of Carbon Bond $\odot$ is an internet-based videogame geared toward teaching students about climate change and geologic CCS as a mitigation strategy. Players have

\footnotetext{
${ }^{1}$ Bogost, I, Persuasive games: The expressive power of video games. MIT Press, Cambridge, (2007a); Gee, JP, Stories, probes, and games. Narrative Inquiry. 21(2): 353-357 (2011); Konzack, L, Rhetorics of computer and video game research. In J. P. Williams and J. H. Smith (Eds.), The players' realm: studies on the culture of video games and gaming. McFarland \& Company, Inc., Jefferson, pp. 110-130 (2007); Pötzsch, H, Borders, barriers and grievable lives: the discursive production of Self and Other in film and other audio-visual media. NORDICOM Review. 32(2): 75-94 (2011).

${ }^{2}$ Chang, AY, Games as environmental texts. Qui Parle: Critical Humanities and Social Sciences. 19(2): 57-84 (2011).
} 
the opportunity to learn (1) the basic science of climate change; and (2) the science and technology behind geologic CCS, which is an important option for mitigating climate change but is still not well understood within the public realm. ${ }^{3}$ The storyline of the game focuses on a main character, Carbon Bond, who is on a mission to save the planet by capturing as many rogue $\mathrm{CO}_{2}$ molecules as possible and sequestering them in an underground formation. Being a $\mathrm{CO}_{2}$ molecule, Bond separates himself from anthropogenic $\mathrm{CO}_{2}$ at the beginning of the story by claiming to be "naturally formed" through the carbon cycle, thus distinguishing for players the difference between natural $\mathrm{CO}_{2}$ and $\mathrm{CO}_{2}$ from industrial operations. Bond's adventures take him from the smokestacks of an integrated gasification combined cycles power plant, to the stormy coasts of the Gulf of Mexico (impacted by increased storm intensity related to climate change), and finally to a $\mathrm{CO}_{2}$ storage facility in the Southern Rockies where the Greenhouse Gas Gang (anthropogenic GHGs) is locked away. This overarching narrative begins with the assumption that climate change is a factual problem that needs to be solved, offers CCS as a technological solution to mitigating climate change, and positions players to be a part of the solution by capturing and sequestering $\mathrm{CO}_{2}$ molecules. Following a melodramatic frame, the game presents anthropogenic $\mathrm{CO}_{2}$ as the villain and players (through the game persona of Carbon Bond) as the heroes. The game is made up of four progressive gaming activities interspersed throughout the melodramatic narrative: (1) a shooting activity, using a "Goo Gun," to capture members of the Greenhouse Gas Gang at a local power plant; (2) a driving activity with the goal to avoid collision with storm debris while hauling the gang to prison; (3) a storage activity to imprison the gang in an underground formation; and (4) an entrance exam into the National Energy Technology Laboratory as a secret agent like Carbon Bond. This final activity tests players on their knowledge of the carbon cycle, GHGs, energy production, rock formations, and climate change. If enough points are earned, players can print their own badges. The video game provides opportunities for students: to (1) learn through activities presented within a social/environmental context; (2) define a problem and create solutions; and (3) transition from being a fictitious hero to a real life hero.

\footnotetext{
${ }^{3}$ Feldpausch-Parker, AM, Communicating carbon capture and storage technologies: opportunities and constraints across media. Unpublished doctoral dissertation, Texas A\&M University, College Station, TX. (2010); Johnsson, F, Perspectives on $\mathrm{CO}_{2}$ capture and storage. Greenhouse Gases: Science and Technology. 1(2): 119-133 (2011); Moutenet, JP, Bedard, K and Malo, M, Public awareness and opinion on CCS in the province of Québec, Canada. Greenhouse Gases: Science and Technology. 2(2): 126-135 (2012).
} 
We conducted pilot testing of The Adventures of Carbon Bond $\mathbb{C}$ as an educational tool for secondary education about CCUS (created by Feldpausch-Parker and Peterson; see http://trpetersonlab.tamu.edu/Games/TheAdventuresOfCarbonBond.swf and http://trpetersonlab.tamu.edu/Games/Jeopardy.swf).

The testing protocol included portions for both teachers and students. Teachers were asked to 1) review curriculum on CCUS geared toward youth; and 2) participate in an interview ( 2 hours max) discussing the materials and their potential application. Students were asked to: 1) fill out a pre-activity questionnaire; 2) play the game, The Adventures of Carbon Bond (link provided above); and 3) fill out a post-activity questionnaire. These questionnaires were designed to evaluate knowledge acquired from activity participation. IRB approval was received from Texas A\&M University to conduct this study.

We tested the game in Michigan, Texas, and North Carolina. We had a total of 193 students $\left(6^{\text {th }}-8^{\text {th }}\right.$ grade $)$ and 3 teachers participate in the testing.

We completed data analysis on the student questionnaires from our pilot test (for results, see Appendix B). We presented our data on a poster at the $11^{\text {th }}$ Annual Carbon Capture and Sequestration Conference (Pittsburg, PA, April 30-May 3, 2012; see Appendix C). The poster was voted the top 5 paper/poster from the conference. The paper, "Rise of the Hero: How the Creation of a Fictitious Hero could Overcome the Melodrama that is Climate Change and Carbon Sequestration" was published in the proceedings from the conference. The paper was revised, submitted, and accepted for publication in Greenhouse Gases: Science and Technology (see Appendix D). The early view version is available at: http://onlinelibrary.wiley.com/doi/10.1002/ghg.1298/abstract

\section{State-Specific Criteria}

In May 2010, we completed an initial review of state specific curricula to identify where CCUS education could fit (for results and discussion, see Appendix E). As noted above, we adopted teaching modules already created by Keystone Center's "Climate Science Investigations" curriculum. Then we identified where The Adventures of Carbon Bond could fit into these curricula. Finally, we revised our report in November 2012 to suggest where The Adventures of Carbon Bond could fit within state standards in relation to the results of our pilot data (see Appendix F). 


\section{Short Courses for High School Students}

We conducted three-day short courses for 30 high-school students in the summers of 2011 and 2012. The courses were done in conjunction with New Mexico Tech's Upward Bound program, which is dedicated to helping first-generation college-bound and/or low-income high school students prepare for college by providing them with the academic, personal, and professional skills they need to overcome their obstacles and succeed. The format for the class was morning lectures, followed by afternoon laboratories or field trips. Laboratory exercises included a Google Earth exercise investigating changes in ice volume through time, and exploring the impact of changing sea level using NOAA's Sea Level Rise and Coastal Flooding Impacts visualization web site. The field trips focused on the geology of reservoir rocks and caprocks. The last exercise was a debate of the pros and cons of various approached to reducing greenhouse gasses.

\section{Masters of Science Teaching Class}

This two week, two-credit class, which was offered in 2011 (0 students), 2012 (3 students), and 2013 (7 students), focused on teaching climate change, CCUS, and relevant geology to middle and high-school teachers. In 2013 the seven MS students in the class were a diverse group of currently active teachers in either middle or high school classes. Five were from New Mexico, one from Colorado and one from Texas. The participating teachers were from: El Paso TX-General Science, Los Lunas NM-General Science \& Math, Durango CO- Biological Sciences, South Valley NM- Chemistry, Belen NM-Math, Rio Rancho NM-Biology, and Shiprock NM-general Science. None of the MST teachers were earth science teachers; their background in geology was minimal before the class. The students found the field trips to be very useful to complement the classroom reviews of geological principles.

Significant time was set aside for group work on development of curricula for teaching of $\mathrm{CO}_{2}$ sequestration. The teachers said this was very helpful as they were able to see what each other was working on and see what could be incorporated into their own program. They all agreed that being able to have developed a complete curriculum in the class made it much more likely that they will use it in their classroom. Given the success of this class, we will likely offer it again after the end of the project. Table 2 shows the schedule for the class with the associated teaching materials. These materials are available at:

http://www.ees.nmt.edu/ acampbel/Grad\%20Class/ 
Monday

AM: Introduction to MST class, context overview of the $\mathrm{CO}_{2}$ sequestration activities at NM Tech (ARC) PowerPoint: Intro to CCS-ST 589

Overview of climate change and $\mathrm{CO}_{2}$ sequestration class PowerPoint: Geo rev 1(BH)

PM: Computer lab activity: Glacier changes from Google earth imagery

PowerPoint: Google Earth Lab 1

Tuesday

AM: Field trip to La Jencia Mesa: Overview of Rio Grande Rift structures, identification of different types of sedimentary rocks, identification of rock characteristics, seal and reservoir characteristics identified in the field

PM: Review of Geology 1: Rock cycle, minerals and rocks. PowerPoint: Geo rev 2

Review of world climate system. PowerPoint: Climate 1

Wednesday

AM: Review of Geology 2: Sedimentary Rocks

PowerPoint: Georev 3

Review of Geology 3 : Metamorphic rocks.

PM: MST students were working in computer lab beginning to develop curricula for class project

Thursday

AM: Field trip to San Lorenzo Canyon: Identification of geologic structures, anticlines, characteristics of sedimentary rocks, Rio Grande Rifting history.

Review of Geologic record of past climate changes

PowerPoint: Paleoclimateology 1 Geologic History 


\section{Table 2. Continued.}

PM: Geology exercise in lab, identification of common rock forming minerals and different rock types. An abbreviated Geology 101 Rocks \& mineral lab

Friday

AM: Introduction to $\mathrm{CO}_{2}$ sequestration, natural sinks and sources of $\mathrm{CO}_{2}$.

PowerPoint: GeoSequest 3 (Reseal)

PowerPoint: Res-Seal

Potential sequestration options identified. PowerPoint: Methods of sequestration

PM : Discussion with class participants

Teaching climate change in schools. Coordinating with existing classes. Meeting curriculum requirements

Monday

AM: Review of Geologic $\mathrm{CO}_{2}$ sequestration

PowerPoint: Geosequest 2 (storage mechanisms)

Review of modern climate change indicators

PowerPoint : Climate Rev 2

PM : Class room activities, Properties of $\mathrm{CO}_{2}$ gas, dry ice experiments, mini permeameter, teaching activities for porosity and permeability (ARC)

Tuesday

AM: Field trip to Fite Ranch to observe 1 ma year soil with $2 \mathrm{~m}$ thick $\mathrm{CaCO}_{3}$ (calcic) horizon.

PM: Review of $\mathrm{CO}_{2}$ sequestration in soils. PowerPoint: Soil C Sequestration

Climate change review. PowerPoint: Climate 2

Curriculum development in lab 


\section{Table 2. Continued.}

Wednesday

AM: Preliminary review of curricula development projects: This was helpful as everyone was able to see what each other were doing and opportunities for synergistic activities and sharing and identified.

PM: Curriculum development in the lab

Thursday

AM: Field trip to Quebradas: Sedimentary rocks, reservoir and seal characteristics, geologic structures, fractures, faults, folds. Precipitation of Barite along faults.

PM: Review of Geologic structures: types of faulting, folding controls on $\mathrm{CO}_{2}$ sequestration PowerPoint: Geo Rev 4

Friday

AM: Presentation of classroom activities and curricula developed by participating MST teachers. 


\section{UNIVERSITY CCUS EDUCATION AND TRAINING}

Our university level training was intended to interest students in careers in CCUS and to introduce the necessary skills needed to work in this field. We were able to attract both geology and petroleum engineering students to four college-level courses (i.e., an undergraduate CCUS class, a reservoir/caprock field class, and a graduate CCUS class that was taught twice). Enrollment in these four courses was a total of 49 students. We set up an undergraduate concentration in CCUS at New Mexico Tech, but were unable to attract any students to opt for this concentration.

\section{Undergraduate Teaching}

The Southwest $\mathrm{CO}_{2}$ Training Center engaged in a number of activities to instruct undergraduate students in topics related to CCUS. These included: (1) development of a new undergraduate concentration in CCUS, (2) teaching an upper-level undergraduate class "Carbon Sequestration Science", and (3) teaching a three-day field course focused on reservoir rocks and caprocks. More information on these activities is provided in the following sections.

\section{CCUS Concentration}

The New Mexico Tech Earth and Environmental Science Department has a number of degree options, which require students to take certain classes depending on the option. We developed an option for CCUS, which included core earth science classes, as well as additional courses in petroleum engineering, chemistry, hydrology, and mathematics (Table 3). In addition, all students were required to take an upper-level (capstone) class "Carbon Sequestration Science", which is described in the next section. The option was approved by the Institute Senate and included in the New Mexico Tech course catalog.

\section{Undergraduate Class}

The undergraduate class was taught at the upper-level (senior/junior), with all students required to have taken at least a year of calculus, chemistry and physics prior to enrolling. We only listed a few geology prerequisites in order to encourage non-majors to take the class. We succeeded in this respect, as many petroleum engineering students (over half the class) enrolled. The instructors were New Mexico Tech professors Andrew Campbell, Peter Mozley, and Mark Person, with additional guest lecturers from Los Alamos National Laboratories and Sandia 
National Laboratories. The principal topics covered are listed in Table 4. We divided most class periods into two segments: an initial lecture followed by a laboratory or discussion. All students were required to produce a short video on a topic related to CCUS. These videos were linked to the SWP Training website at the end of the semester. Students were also required to attend a two day (weekend) field trip, which visited several SWP study sites in New Mexico and Utah. The class was taught in the spring semester of 2011, with 11 students enrolled. We offered the class again in 2012, but too few students enrolled to justify teaching it. Given that comments from students, both informal and on our teaching evaluations, were extremely positive, we feel that the low enrollment in 2012 reflects a limited pool of interested students. 
Table 3. Courses Required for the Earth and Environmental Science CCUS Option at New Mexico Tech

\begin{tabular}{|l|}
\hline $\begin{array}{l}\text { NMT General degree requirements (includes } 1 \text { year calculus, chemistry and physics as } \\
\text { well as humanities) }\end{array}$ \\
\hline EES Core classes \\
\hline any ERTH 100 level class and lab \\
\hline ERTH 201 (Bio) \\
\hline ERTH 202 (Surface) \\
\hline ERTH 203 (Crust) \\
\hline ERTH 204 (Whole Earth) \\
\hline ERTH 205 (Earth Science Practicum) \\
\hline ERTH 390 (General Geochemistry) \\
\hline ERTH 325 (Near Surface Geophysics) \\
\hline ERTH 330 (Global Change Hydrology) \\
\hline ERTH 468 (Evolution of Earth) \\
\hline ERTH 483 (Intro to Field Mapping) \\
\hline Option requirements \\
\hline PETR 101 (Intro to Petro. Engineering) \\
\hline ERTH 370 (Formation Evaluation) \\
\hline ERTH 440 (Hydrological Theory and Field Methods) \\
\hline ERTH 447 (Depo. Systems \& Basin analysis) \\
\hline ERTH 460 (Subsurface and Petroleum Geology) \\
\hline ERTH 484 (Surficial Mapping) \\
\hline ERTH 485 (Metamorphic and Advanced Structure Mapping) \\
\hline ERTH 424 (Sedimentary Petrography) \\
\hline ERTH 4 XX (Carbon Sequestration Science) \\
\hline HYD $507 / 4$ XX (Hydrogeochemistry) \\
\hline CHEM $331+331$ L (P-Chem) \\
\hline MATH 283 (Statistics)or 382 +382L (Probability) \\
\hline
\end{tabular}


Table 4. Topics Covered in the New Mexico Tech Undergraduate Class

\begin{tabular}{|c|c|}
\hline \multirow{2}{*}{\multicolumn{2}{|c|}{$\begin{array}{l}\text { Lecture } \\
\text { Intro to course and CCUS (PSM, ARC) }\end{array}$}} \\
\hline & \\
\hline \multicolumn{2}{|l|}{ Course organization, etc. } \\
\hline \multicolumn{2}{|l|}{ Why CCUS? } \\
\hline \multicolumn{2}{|l|}{ Top climate skeptic arguments and class assignments } \\
\hline \multicolumn{2}{|l|}{ Sequestration options (ocean, land, geologic) } \\
\hline \multicolumn{2}{|l|}{ Overview of geologic (EOR, CBM, basalt, sln aqu, oil fld) } \\
\hline Paleoclimate record(PSM, ARC) & The Great Climate Debate (PSM, ARC) \\
\hline Earth's climate record & Pro and con arguments for anthro \\
\hline Causes of climate change & Mozley/Campbell are "climate skeptics" \\
\hline $\mathrm{CO}_{2}$ Capture Technology (ARC) & Discussion: Writing, Science lit. (PSM) \\
\hline Types of capture, costs issues & Types of literature \\
\hline \multirow[t]{2}{*}{ Discussion of possible paper topics, our expectations } & Use of on-line databases \\
\hline & Style issues, discussion \\
\hline Trapping Mechanisms (PSM, MP) & Discussion: Capture Technology literature \\
\hline \multicolumn{2}{|l|}{ Trapping geometries (structural, stratigraphic) } \\
\hline \multicolumn{2}{|l|}{ Mineral/solution trapping } \\
\hline \multicolumn{2}{|l|}{ Coal trapping } \\
\hline \multicolumn{2}{|l|}{ Oil (EOR) trapping } \\
\hline \multicolumn{2}{|l|}{ Capillary trapping/relative permeability } \\
\hline \multicolumn{2}{|l|}{$\underline{\mathrm{P}-\mathrm{Chem} \text { of } \mathrm{CO}_{2}(\mathrm{ARC})}$} \\
\hline Reservoirs/Seals (PSM) & $\underline{\text { Rock Lab (PSM, GP) }}$ \\
\hline Controls on $\mathrm{P} \& \mathrm{P}$ & Reservoir and seal lithologies \\
\hline \multicolumn{2}{|l|}{ Depositional environments } \\
\hline \multicolumn{2}{|l|}{ Best reservoirs and seals } \\
\hline \multicolumn{2}{|l|}{$\underline{\text { Seals }(\mathrm{JH})}$} \\
\hline \multicolumn{2}{|l|}{ Advanced methods of estimating caprock integrity } \\
\hline$\underline{\mathrm{CO}}_{2}$ "experiments" (ARC) & Mid-term Exam \\
\hline
\end{tabular}


Table 4. Continued.

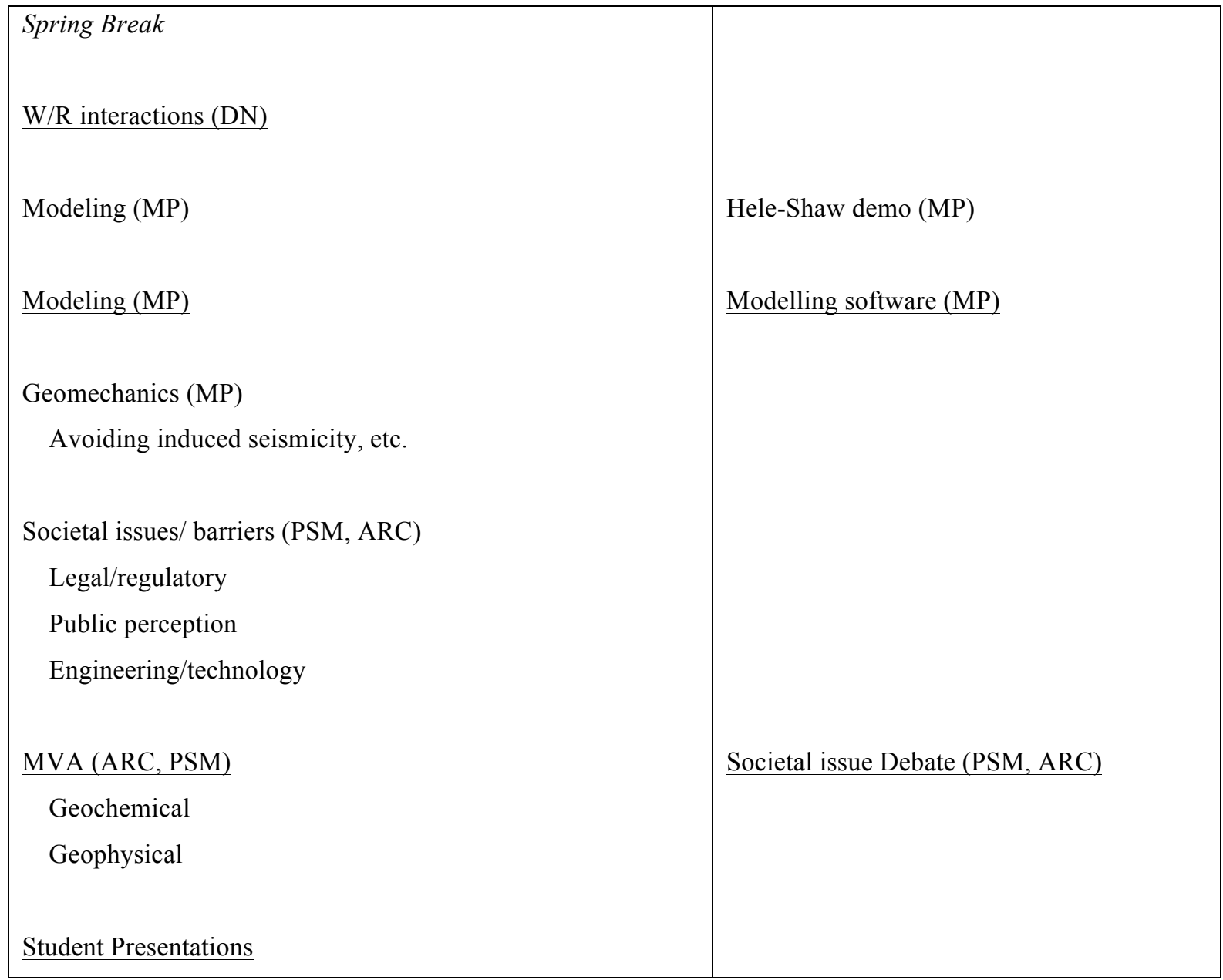

\section{Reservoir/Caprock Field Course}

The Southwest $\mathrm{CO}_{2}$ Training Center ran a three-day reservoir/caprock field course in the Moab, UT area August $15-17,2012$. The course was taught by Peter Mozley and Andrew Campbell (New Mexico Tech), and Jason Heath (Sandia National Laboratories). Ten students participated, including three undergraduate and seven graduate students. It was also advertised to professionals for PDU credit. Instruction took place entirely in the field, with short lectures and abundant informal discussion. A portable permeameter was used to provide real-time data for the students on lithologic and structural controls on permeability (Figs. 2 and 3). In addition, rocks at many of the field sites have large and small-scale patterns of mineralization that can be used to infer past focused fluid flow in the rock, allowing participants to directly relate their 
observations to flow characteristics (Fig. 4). We were also able to visit the Little Grand Wash fault, a natural analog for a $\mathrm{CO}_{2}$ leakage site, which included a visit to a $\mathrm{CO}_{2}$ geyser (Fig. 5). The course evaluations for the class were very positive and it will likely be taught again on a yearly or bi-yearly basis.

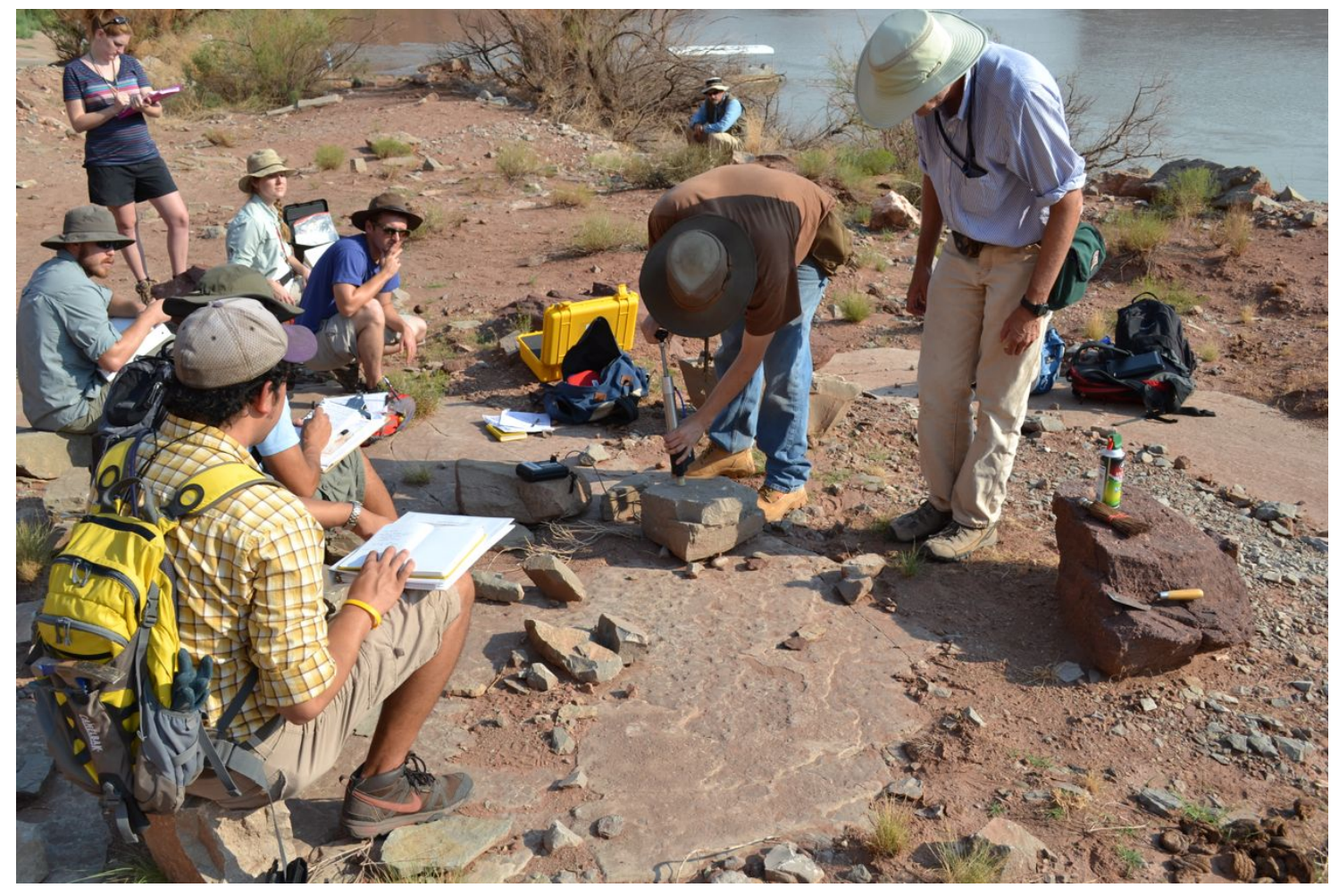

Figure 2. A student uses a field minipermeameter to measure the permeability of a block of limestone in a quarry near the Colorado River. 


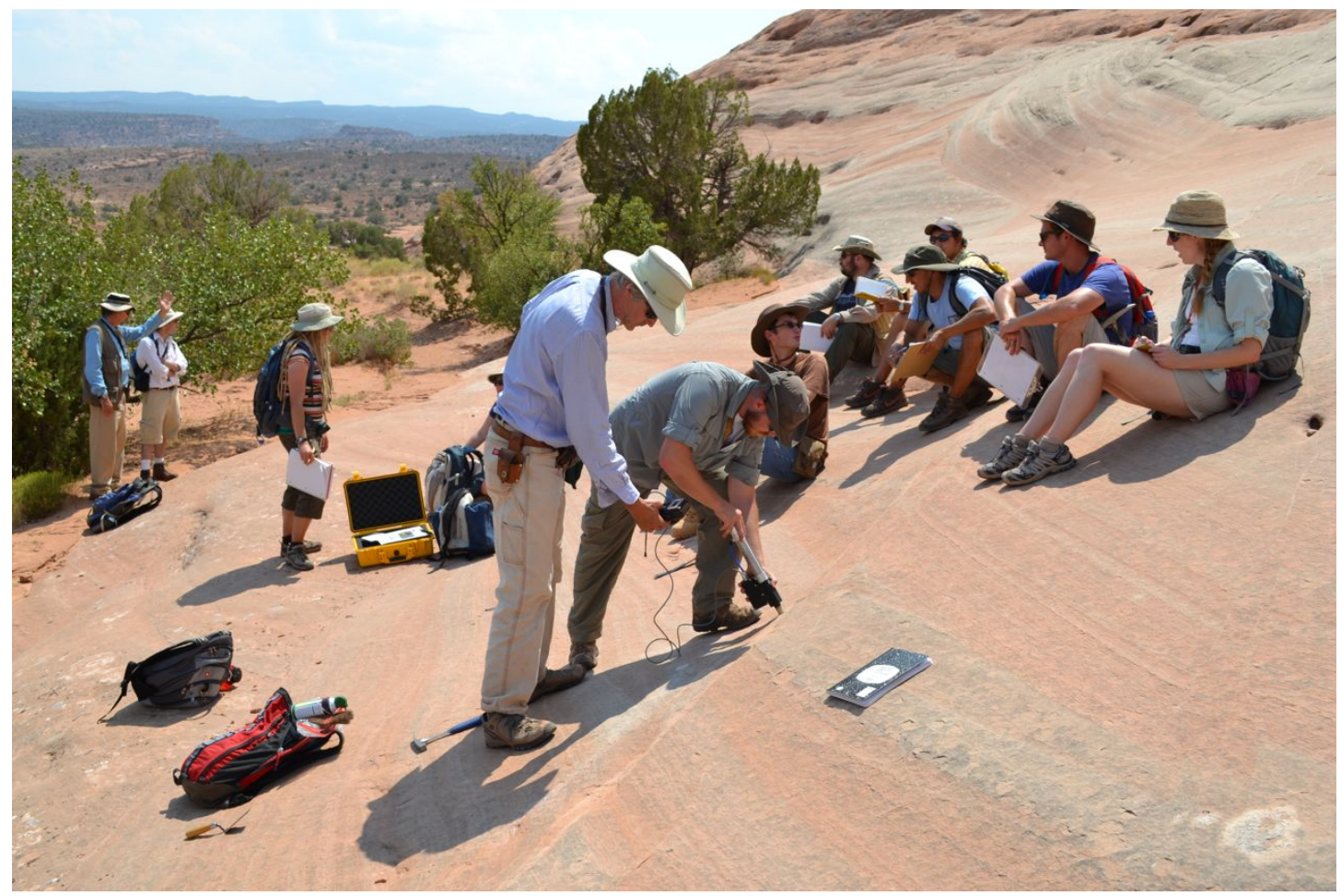

Figure 3. A student measures the permeability of amalgamated deformation bands in the Entrada Formation.

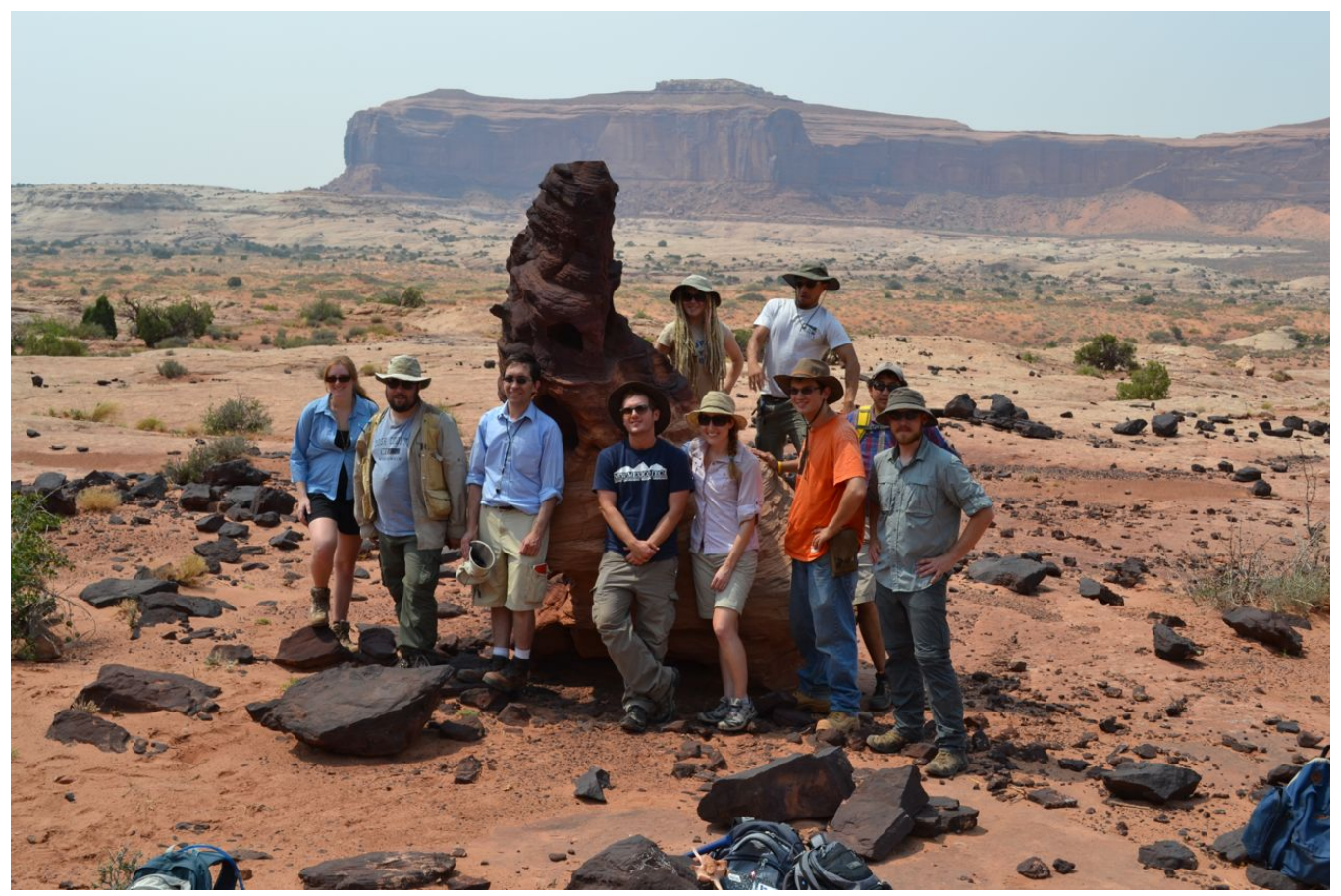

Figure 4. Class members surround a spectacular iron-oxide concretion that records subvertical fluid flow in the Navajo Sandstone. 


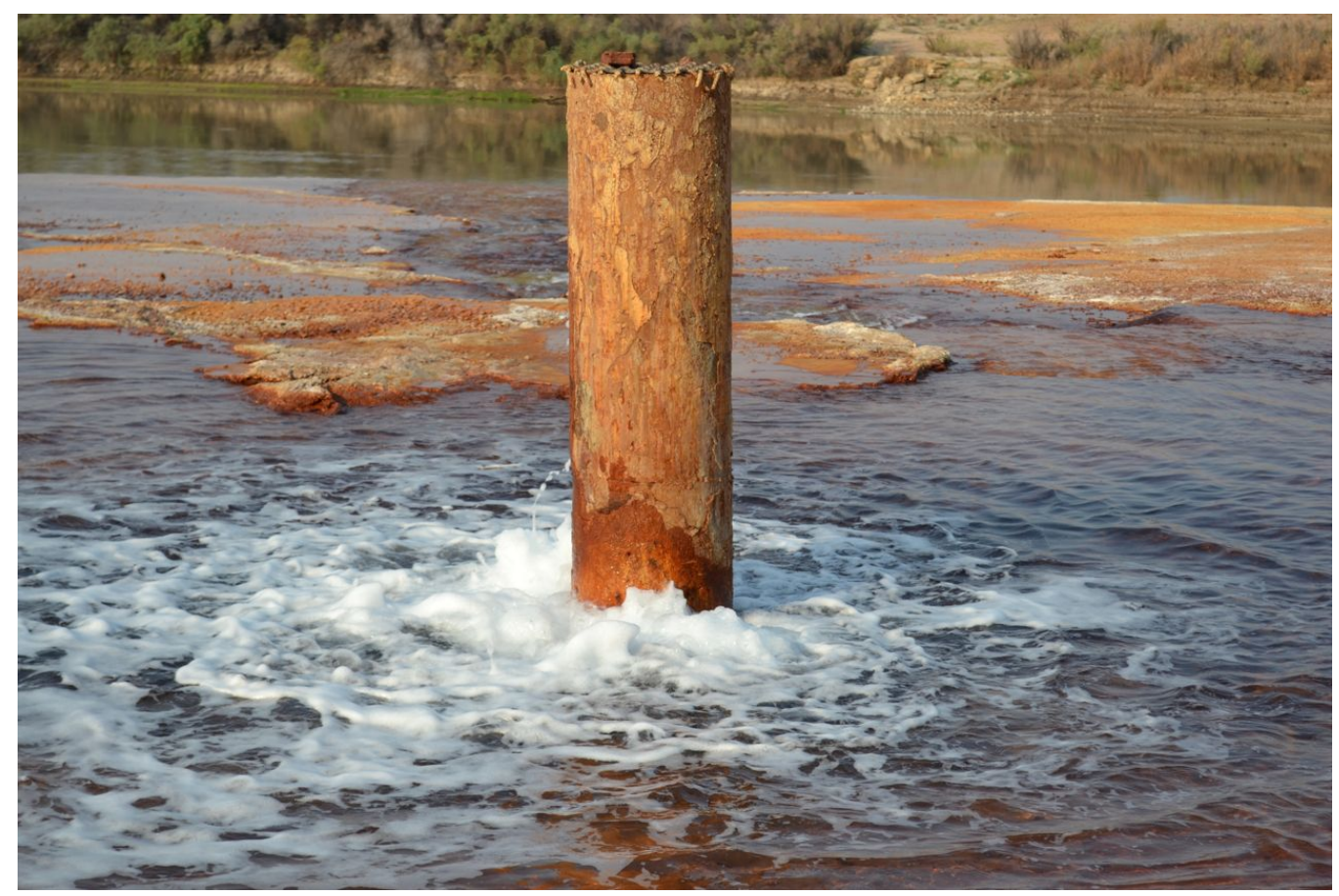

Figure 5. $\mathrm{CO}_{2}$ gas surges from the base of a pipe on top of the Crystal Geyser, a $\mathrm{CO}_{2}$ geyser near Green River, UT.

\section{Graduate-Level Distance Education Class.}

A major activity of the Training Center during the project was development and offering of a graduate course entitled "Carbon Capture and Storage." The course was offered in the fall semesters of 2010 and 2012 (late August through early December of those years).

The course is tailored for professional level education, for advanced post-graduate students and/or industry professionals. A unique aspect of this course is that it was co-taught at two regional universities, New Mexico Tech and the University of Utah, and was available on the Internet. The course was graduate level at both universities, but undergraduates were permitted to enroll. It was offered as Geology 571 at New Mexico Tech and as Civil and Environmental Engineering 7920 at the University of Utah. The total enrollment both years was approximately 50\% M.S. students and 50\% Ph.D. students.

\section{Graduate Course Goals and Objectives}

The goals of this course were to: (1) create a broad academic foundation of carbon capture and sequestration (CCUS), with the primary emphasis on geologic sequestration, that prepares students for continuing education, leading to greater professional competency, and (2) 
provide students with the fundamental knowledge and tools necessary to perform design of CCUS systems for professional practice.

A more practical objective was for material developed as part of the course to serve as the primary basis for professional short courses. The graduate course was divided into individual "modules," including: (1) climate change, (2) general aspects of CCUS, (3) geology, (4) chemistry, (5) modeling, and (6) decision-making factors. These six modules made up what we deem the most critical aspects of CCUS, and thus as part of the 2013 plans for continuing the SWTC, the organization will also offer six different professional short courses based on these modules. All lectures were recorded digitally, and these digital recordings as well as associated teaching materials were used (distilled) to compose these individual short-courses.

Graduate Course Instruction Information

Main Organizers and Instructors:

New Mexico Tech: Andrew Campbell, Professor of Geology

Peter Mozley, Professor of Geology

University of Utah: Brian J. McPherson, Faculty in Civil \& Environmental Engineering

Several guest lecturers were tapped, for sake of specialized training (teaching) of selected topics.

\section{Course Web Page}

All course information is archived and accessible via a web-portal accessible at http://training.southwestcarbonpartnership.org/university/index.html. Students access the web page for copies of lecture summaries and "handouts" (supplemental data or examples, etc.), homework assignments and solutions, in-class example problems and solutions, announcements, additional reading assignments. The full course syllabus includes all course policies.

\section{Course Components and General Policies}

Attendance: Students were expected to attend class and to arrive on time.

Reading Assignments: Students were expected to read assigned reading prior to the corresponding classroom presentation. 
Homework Assignments: Homework consisted of reading assigned journal articles and other materials, and using those materials with a set of teammates to prepare and participate in a series of special team assignments called "moot court proceedings."

\section{Moot Court}

To promote detailed investigation of salient topics, we instigated a set of assignments in the form of mock court proceedings. Many law schools use mock court proceedings, or "Moot Court," to train lawyers with practice court sessions that require everything from pre-trial research to formal arguments and debate. For our graduate course on CCUS, we use Moot Court as a vehicle for students to research a CCUS technology topic and "present a case" about that technology while simultaneously "prosecuting" (or challenging) the weaknesses of competing technologies. For example, the first court date (both years that the course was taught) focused on $\mathrm{CO}_{2}$ separation technologies. Three student teams were formed, with one the "Post-Combustion Team," another the "Pre-Combustion Team," and the third team the "Oxy-Combustion Team." The individual teams were assigned reading materials that summarize $\mathrm{CO}_{2}$-separation technologies, and then required to develop a "defense" of their assigned technology, and to also develop a prosecution (you could consider it a persecution) in the form of a comprehensive critique of the other two technologies. In all Moot Court trials, the team who best develops the most effective arguments for their technology (defense against the other teams' prosecution) and the most effective critiques of the other two technologies will be deemed the winner by majority rule of a jury consisting of the course faculty. We recruited a university attorney to serve as Judge. The Moot Court exercises have proven to be fairly effective, and in both 2010 and 2012, the students indicated that they favor this approach over more traditional homework assignments.

\section{Course Schedule (Subject to Change)}

Table 5 shows the general course schedule for both years, including specific lecturers. 
Table 5. General Course Schedule for the Graduate CCUS Class

\begin{tabular}{|c|c|c|c|}
\hline $\begin{array}{c}\text { Class } \\
\text { Period }\end{array}$ & Module & Topics & Lecturer \\
\hline 1 & Introductory & Technology Test & All \\
\hline 2 & Introductory & $\begin{array}{c}\text { Introductions } \\
\text { Course Scope Overview }\end{array}$ & $\begin{array}{c}\text { All (intro) - McPherson } \\
\text { (overview) }\end{array}$ \\
\hline 3 & Climate Change & $\begin{array}{c}\text { Climate through earth } \\
\text { history }\end{array}$ & Phillips (NMT) \\
\hline 4 & Climate Change & Modern climate and GHG & Reusch (NMT) \\
\hline 5 & CCUS & $\begin{array}{c}\text { Electric Power Plants and } \\
\text { Other } \mathrm{CO}_{2} \text { Sources }\end{array}$ & Campbell (NMT) \\
\hline 6 & CCUS & Terrestrial Sequestration & Jay Angerer (TAMU) \\
\hline 7 & & No Class: Labor Day & \\
\hline 8 & CCUS & $\mathrm{CO}_{2}$ Capture & Adel Sarofim (UU) \\
\hline 9 & CCUS & $\begin{array}{c}\mathrm{CO}_{2} \text { Transport and Geologic } \\
\text { sequestration }\end{array}$ & McPherson (UU) \\
\hline 10 & CCUS & $\begin{array}{l}\text { Geologic sequestration: } \\
\text { Saline, EOR, ECBM }\end{array}$ & McPherson (UU) \\
\hline 11 & CCUS & Trapping mechanisms & McPherson (UU) \\
\hline 12 & & MOOT COURT & \\
\hline 13 & Geology & Intro to geology & Mozley (NMT) \\
\hline 14 & Geology & Sedimentary geology & Mozley (NMT) \\
\hline 15 & Geology & Structural geology & Mozley (NMT) \\
\hline 16 & Geology & Reservoir rocks & Mozley (NMT) \\
\hline 17 & Geology & $\begin{array}{c}\text { Geology of cap rocks and } \\
\text { "stacked systems" }\end{array}$ & Mozley (NMT) \\
\hline 18 & & MOOT COURT & \\
\hline 19 & Geology & Hydrogeology of CCUS & McPherson (UU) \\
\hline
\end{tabular}


Table 5. Continued.

\begin{tabular}{|c|c|c|c|}
\hline 20 & Chemistry & P-chem of $\mathrm{CO}_{2}$ & Grigg (NMT) \\
\hline 21 & Chemistry & $\begin{array}{l}\text { Aqueous Geochem: } \mathrm{CO}_{2^{-}} \\
\qquad \mathrm{H}_{2} \mathrm{O}\end{array}$ & Campbell (NMT) \\
\hline 22 & Chemistry & Carbonate mineralization & Campbell (NMT) \\
\hline 23 & Chemistry & Dissolution vs. precipitation & Campbell (NMT) \\
\hline 24 & Chemistry & Wellbore cements & Carey (LANL) \\
\hline 25 & Modeling & $\begin{array}{l}\text { Intro to modeling and } \\
\text { coupled processes }\end{array}$ & $\begin{array}{c}\text { McPherson (UU) and } \\
\text { Person (NMT) }\end{array}$ \\
\hline 26 & Modeling & $\begin{array}{l}\text { From governing equations } \\
\text { to numerical methods: the } \\
\text { boundary value problem } \\
\text { approach }\end{array}$ & $\begin{array}{l}\text { McPherson (UU) and } \\
\text { Person (NMT) }\end{array}$ \\
\hline 27 & & MOOT COURT & \\
\hline 28 & Modeling & $\begin{array}{l}\text { Multiphase fluid flow } \\
\text { modeling ("H") }\end{array}$ & Han (UU) \\
\hline 29 & Modeling & Thermal processes ("T") & Han (UU) \\
\hline 30 & Modeling & Reactive transport ("C") & McPherson (UU) \\
\hline 31 & Modeling & Mechanical modeling ("M") & McPherson (UU) \\
\hline 32 & Modeling & $\begin{array}{c}\text { Biological considerations } \\
\text { ("B") }\end{array}$ & $\begin{array}{c}\text { Goel (UU) and Boston } \\
\text { (NMT) }\end{array}$ \\
\hline 33 & & MOOT COURT & \\
\hline 34 & Modeling & $\begin{array}{c}\text { Building effective numerical } \\
\text { models of CCUS from } \\
\text { geologic data }\end{array}$ & $\begin{array}{c}\text { Lee (UU) and Person } \\
\text { (NMT) }\end{array}$ \\
\hline
\end{tabular}


Table 5. Continued.

\begin{tabular}{|c|c|c|c|}
\hline 35 & Decision Making & $\begin{array}{c}\text { Review of non-technical } \\
\text { (but critical) aspects of } \\
\text { CCUS }\end{array}$ & $\begin{array}{l}\text { Endres (UU) and } \\
\text { Peterson (TAMU) }\end{array}$ \\
\hline 36 & Decision Making & $\begin{array}{c}\text { Social attitudes and public } \\
\text { Perception }\end{array}$ & $\begin{array}{c}\text { Endres (UU) and } \\
\text { Peterson (TAMU) } \\
\text { Table 5. Continued. }\end{array}$ \\
\hline 37 & Decision Making & $\begin{array}{l}\text { UIC and other important } \\
\text { policy issues }\end{array}$ & Elizabeth Wilson \\
\hline 38 & Decision Making & Economics of CCUS & Walker (UU) \\
\hline 39 & & MOOT COURT & \\
\hline 40 & Decision Making & Liability & $\begin{array}{c}\text { Deo (UU) and } \\
\text { McPherson (UU) }\end{array}$ \\
\hline 41 & Decision Making & Monitoring efficacy & $\begin{array}{c}\text { Deo (UU) and } \\
\text { McPherson (UU) }\end{array}$ \\
\hline 42 & Decision Making & Risk assessment & McPherson (UU) \\
\hline 43 & Decision Making & Risk assessment & McPherson (UU) \\
\hline 44 & & MOOT COURT & \\
\hline 45 & Student Projects & Student presentations & All \\
\hline 46 & Student Projects & Student presentations & All \\
\hline 47 & Student Projects & Student presentations & All \\
\hline
\end{tabular}




\section{PROFESSIONAL CCUS EDUCATION AND TRAINING}

Our professional CCUS educational activities addressed working CCUS professionals through a webinar series focused on outreach and education, a hydrologic modeling short course, and professional training for teachers. The Reservoir and Caprock field school was offered to university students and professionals alike, but no professionals signed up for it. Overall we found it difficult to attract professionals to our offerings.

\section{CCUS Webinar Workshops}

\section{Webinar \#1}

We conducted a Webinar on "Best Practices for Outreach" with Sarah Wade from AWJ, Inc. on April 27, 2011. There were 12 participants including industry partners for SWP, energy related NGOs, National Labs, Geological Survey offices, energy companies, and students at NMT. We garnered these participants by posting an announcement on the website, announcing to the listserv, an email to SWP partners, follow up calls to SWP partners, an email to the NMT Petroleum Technology Transfer Council (PTTC), and an announcement in the NMT undergraduate course. We collected survey data from 7 of the 12 participants of the course.

\section{Webinar \#2}

We offered a Webinar on Best Practices for Community Engagement on October 26, 2011 featuring Francisco Almendra of the World Resources Institute. There were 6 participants (including 2 from government agencies, 2 from the academic sector, and 2 consulting firms). We garnered these participants by posting an announcement on the website, announcing to the listserv, and an email to participants in the first Webinar. We collected survey data from all 6 participants.

\section{Webinar \#3}

We offered a Webinar on CCUS education in K-12 on October 15, 2012 featuring Jeremy Kranowitz of Sustainable America. Kranowitz formerly worked for the Keystone Institute and directed the Climate Science Investigations curriculum on climate change and CCUS. There were 5 participants ( 1 from a government agency, and 3 from the academic sector). We garnered these participants by posting an announcement on the website, announcing to the listserv, an email to participants in the first Webinar, and an announcement in the graduate course. We did 
not collect survey data for this Webinar because we had already completed our analysis of feedback from the first two webinars and incorporated that feedback into this Webinar.

\section{SWTC Professional Short Course 1: October 26-27 2010}

A CCUS simulation professional short course was held at the University of Utah on October 26-27, 2010. The training course was convened by Dr. Brian McPherson (b.j.mcpherson@utah.edu) and taught by code development staff from the Pacific Northwest National Laboratory. This short course provided an introduction to CCUS model simulation analysis. For sake of simplicity, we offered training with only one simulation package, STOMP, a multifluid subsurface flow and reactive transport simulator, developed at the Pacific Northwest National Laboratory (PNNL). Through a combination of lectures and computer laboratory exercises, students were guided through a series of problems, designed to demonstrate specific CCUS scenarios. Students were taught how to prepare input files for flow and reactive transport problems and interpret simulation results, by working with sample problems that vary in complexity and structure. The sample problems were designed to emphasis specific operational modes of CCUS and to serve as prototypes and templates for applications for the students after the course. Lectures described the mathematical models, numerical solution approaches, and code structure, but also covered a series of case study examples. 


\section{REGIONAL/BASIN TECHNOLOGY TRANSFER SERVICES}

We published eight quarterly newsletters (2011-2012) that were disseminated on the Website (http://ccstrend.org/print-materials/index.html) and through the email listservs. The newsletters are all available on the website. The newsletters covered a variety of topics including research updates, reports on training center events, and information about upcoming events. DOE Tech Alerts and Industry News were distributed them on the homepage of the Website (http://ccstrend.org) throughout the duration of the project (Table 6).

Table 6. Schedule of DOE Tech Alerts Posted to the Homepage of the Website

\begin{tabular}{|c|c|c|}
\hline Date & Tech Alerts & Industry News \\
\hline $2 / 2011$ & & 20 \\
\hline $3 / 2011$ & & 13 \\
\hline $4 / 2011$ & & 17 \\
\hline $5 / 2011$ & & 11 \\
\hline $6 / 2011$ & & 8 \\
\hline $7 / 2011$ & & 0 \\
\hline $8 / 2011$ & & 7 \\
\hline 9/2011 & & 5 \\
\hline $10 / 2011$ & & 1 \\
\hline $11 / 2011$ & & 5 \\
\hline $12 / 2011$ & & 1 \\
\hline $1 / 2012$ & 1 & 9 \\
\hline $2 / 2012$ & 2 & 6 \\
\hline $3 / 2012$ & 0 & 15 \\
\hline $4 / 2012$ & 1 & 12 \\
\hline $5 / 2012 \& 6 / 2012$ & 2 & 29 \\
\hline $7 / 2012$ & 3 & 30 \\
\hline $8 / 2012$ & 2 & 20 \\
\hline $10 / 2012$ & 4 & 19 \\
\hline $11 / 2012 \& 12 / 2012$ & 3 & 16 \\
\hline
\end{tabular}

NOTE: We did not track tech alert and industry news in 2011. We were able to retrieve the industry news numbers from the Website archive, but there is not a Website archive for the tech alerts. 


\section{TRAINING CENTER WEBSITE AND LISTSERVS}

Texas A\&M University received a bid for building a website template from Media Solutions at the University of Utah. We participated in weekly teleconferences with Jill Brinton at Media solutions (evaluating and editing template). Megan O'Byrne, Andrea FeldpauschParker, and Israel Parker attended a website management training using Adobe's Dreamweaver software at Media Solutions in Salt Lake City on December 8, 2010. The Website went live in March 2011. Over the course of the project, we updated and organized existing content and news links on the training center Website as well as added new content. The website is available at: http://ccstrend.org.

The Website was named Training and Research in Energy Decision Making (TREND) because this is the logo and acronym created by the team for the Southwest United States Carbon Sequestration Training Center.

We developed two listservs to disseminate information, tech alerts, and newsletters. The first listserv is for professionals (industry, government agency and academics) with a final count of 12 subscribers. The second listserv is for secondary education teachers with a final count of 23 subscribers. 


\section{PLANNING AND MANAGEMENT OF THE REGIONAL TRAINING PROGRAM}

\section{Assessment and Evaluation}

We developed a survey (see Appendices H \& I) to evaluate Training Center education and training efforts. This survey not only serves an evaluative function (so that instructors can make improvements based on student feedback) but also supports research we are conducting on professional perceptions of CCUS. The survey was reviewed and approved by the Institutional Review Boards (IRB) of U of Utah and Texas A\&M U.

After running a pilot test in the Spring 2010 graduate course, we implemented the survey in the following:

- Graduate Course, NMT/Utah, 2010

- Master of Science Teaching Course, NMT, 2011

- ERTH 427 Geological Carbon Sequestration Science, NMT, 2011

- Webinar 1, 2011

- Webinar 2, 2011

We compiled all of the survey data for the webinars (11 respondents), as well as from the undergraduate (13 respondents) and graduate courses (15 respondents). Data collected from three courses and two webinars reflect that the participants felt an overall improvement in their understanding of the topic covered. Course and webinar participants were asked to rate their knowledge of a set of particular questions relating to climate change, CCUS technologies, and public participation on a scale of 1 to 5 , with 1 being no knowledge and 5 being very knowledgeable. Improvements in knowledge were seen in all questions across courses and webinars, save one (teacher survey in 2011, in which the difference between pre and post survey question, "How would you rate your knowledge of social aspects (i.e. economic, political, cultural) of CCUS?" was -0.33). The average of participant improvement in courses was 0.81 (undergrad $=0.86$; graduate $=1.14$; graduate/teacher $=0.42$ ), in the webinars 0.58 (Sarah Wade $=1.25$; Francisco Almendra=0.33). See Appendix G for more detail. 


\section{Research Conferences and Publications}

We have developed and conducted research in three areas. First, we conducted research on The Adventures of Carbon Bond. This included pilot testing in K-12 schools as described above in Task 3. Second, we conducted research on the professional perceptions of CCUS technology. This research included analysis of training survey responses and ethnographic participant observation and interviews at CCUS professional conferences. Third, we conducted research on the effectiveness of YouTube as a medium for CCUS information.

\section{Carbon Bond}

As a result of our research on The Adventures of Carbon Bond (described above), we produced the following products:

- Feldpausch-Parker attended the 91st annual meeting of the American Meteorological Society (AMS) in Seattle, Washington on January 22-27, 2011 where she was part of a small group of communication specialists sponsored by AMS to discuss their research on climate change communication. The theme for the 2011 conference was "Communicating Weather and Climate." Dr. Feldpausch-Parker presented a piece coauthored with Dr. Tarla Peter-son (TAMU), Dr. Danielle Endres (U of Utah), and Megan O'Byrne ( $\mathrm{U}$ of Utah) at the conference discussing the value of educational games as a useful strategy for communicating climate science. The title of the presentation was "Overcoming Climate Skepticism in the Schools: A Case Study of Integrating Climate Change Gaming in the Classroom."

- We presented preliminary data from our testing of the educational video game, The Adventures of Carbon Bond $\odot$, in a poster at the $11^{\text {th }}$ Annual Carbon Capture Utilization and Sequestration Conference (Pittsburgh, PA, April 30-May 3, 2012). The poster was voted the top 5 paper/poster from the conference. The paper, "Rise of the Hero: How the Creation of a Fictitious Hero could Overcome the Melodrama that is Climate Change and Carbon Sequestration" was published in the proceedings from the conference.

- Feldpausch-Parker, A. M., M. O’Byrne, D. Endres, T. R. Peterson, 2012. The Adventures of Carbon Bond: using a melodramatic game to explain CCUS as a mitigation strategy 
for climate change, Greenhouse Gases: Science and Technology. Early view available at http://onlinelibrary.wiley.com/doi/10.1002/ghg.1298/pdf.

- "The Adventures of Carbon Bond: Using a Melodramatic Game to Explain Carbon Capture (CCUS) and Storage as a Mitigation Strategy for Climate Change," abstract accepted for presentation at the 2013 Conference on Communication and the Environment, Uppsala, Sweden, June 2013.

Abstract: In the U.S., policy options for mitigating climate change have been severely limited because of competing ideologies. Opposition to mitigation has successfully framed it as existing outside the realm of fact, instead framing the issue as a melodramatic struggle. While scientists are uncomfortable with melodramatic framing, we argue that melodrama plays on people's tendency to conceptualize issues in these terms and has the capacity to shift debate from the factuality of climate change to mitigation strategies. We developed a video game that uses melodrama to teach youth about climate change and CCUS to create an understanding of $\mathrm{CO}_{2}$ as the villain and humans as heroes through participation in mitigation strategies. We analyzed The Adventures of Carbon Bond $\mathrm{C}$ as a medium for engagement. Using surveys, we demonstrated that students experienced knowledge increases as a result of game play. We conclude by discussing the implications of our findings for productively reframing climate change towards an emphasis on mitigation.

\section{Professional Perceptions}

We completed a literature review of the Science, Technology and Society (STS) scholarly literature and developed an online bibliography for future use. This literature revealed that while much research has examined the public perceptions of CCUS and other technologies, scant research has actually sought to understand the professional perceptions of CCUS technologies.

We gathered qualitative participant observation data on professional perceptions of CCUS technology at the Tenth Annual Carbon Capture and Sequestration Conference in Pittsburgh (May 2011), the Carbon Management Canada 2011 Conference in Calgary (May 2011), and the Eleventh Annual Carbon Capture and Sequestration Conference in Pittsburgh (May 2012). 
We completed preliminary data analysis and produced a report on the survey data for all of the webinars and courses offered through the Training Center (for findings, see Appendixes G, $\mathrm{H}$, and I). This included: two webinars, the graduate level course, the undergraduate level course, and the Master Teaching course. This analysis contributes to assessment of the courses and to our social scientific research on professional perceptions of CCUS.

We have produced the following products:

- "The Deficit Model of Public Outreach and Education: CCUS Professional Talk about Publics," abstract accepted for presentation at the 2013 Conference on Communication and the Environment, Uppsala, Sweden, June 2013.

Abstract: Energy policy by its very nature is a hotly contested topic situated at the nexus of the public and technical spheres of argument demanding communication across those spheres. In this type of cross-sphere controversy, communication scientists and engineers often assume that members of the public are incapable of understanding technical scientific information and that they should simply be educated and informed. While various studies demonstrate the ineffectiveness of this deficit model of communication and introduce new models, our participant observation within a scientific community indicates that it is still a dominant paradigm. In this paper, we use data from our participant observation with Carbon Capture and Storage (CCUS) professionals to describe how their communication about publics not only reifies the deficit model but also highlights new strategies of communication that demonstrate the complexity and ubiquity of the deficit model.

- "Putting the U in Carbon Capture and Storage: Performances of Rupture within the CCUS Scientific Community," abstract accepted for presentation at the 2013 Conference on Communication and the Environment, Uppsala, Sweden, June 2013.

Abstract: This paper examines a rhetorical framing shift from CCUS to CCUS within science and technology professionals' communication, particularly how the professional community responded to this framing shift. Drawing from participant observation, we describe and evaluate the moments of rupture caused by putting the $\mathrm{U}$ in carbon capture and storage. Drawing from the 
theories of terministic screens, rhetorical boundary-work and the cultural performance of social drama, we argue that the framing shift is a breach or rupture in the boundaries of the CCUS professional community that calls forth cultural performances of confusion, acquiescence, and resistance to the framing shift. This theoretical framework has the potential to serve as a powerful heuristic for examination of similar inter-scientific framing shifts. In addition, this paper contributes to contemporary research in rhetoric of science (RoS), social dimensions of CCUS, and environmental communication.

Note: see Appendix J for extended abstract.

The Use and Utility of YouTube Videos as an Outreach Medium for Carbon Capture, and Sequestration Information

We completed an analysis of the effectiveness of YouTube as an outreach medium for CCUS. The report (for findings, see Appendix K, written by graduate student C. Milewski under the supervision of A. Feldpausch-Parker) concluded that CCUS videos posted on YouTube reach a very small public audience. Using this platform to communicate with and/or educate a targeted audience may be more effective 


\section{PDU'S AND CEU'S OFFERED}

The Training Center offered 60 Continuing Education Units of credit and 2,598

Professional Development Units (hours) combined from our various courses (Table 7). Lists of students are in Appendix L.

Table 7. PDU's and CEU's Offered by the Training Center

\begin{tabular}{|c|c|c|c|c|c|c|}
\hline Course Name & $\begin{array}{l}\text { Date of } \\
\text { Course }\end{array}$ & $\begin{array}{l}\text { Number } \\
\text { of } \\
\text { Participants }\end{array}$ & $\begin{array}{l}\text { Number } \\
\text { of CEUs } \\
\text { per } \\
\text { Course* }\end{array}$ & $\begin{array}{l}\text { Number } \\
\text { of } \\
\text { PDHs } \\
\text { per } \\
\text { Course* }\end{array}$ & $\begin{array}{l}\text { Total } \\
\text { CEUs }\end{array}$ & $\begin{array}{l}\text { Total } \\
\text { PDHs }\end{array}$ \\
\hline $\begin{array}{l}\text { Climate Change and } \mathrm{CO}_{2} \\
\text { Sequestration }\end{array}$ & $07 / 02 / 10$ & 0 & 2 & 0 & 0 & 0 \\
\hline Carbon Capture and Storage & $12 / 10 / 10$ & 14 & 0 & 45 & 0 & 630 \\
\hline $\begin{array}{l}\text { CCUS Simulation Analysis } \\
\text { Using the STOMP Simulator }\end{array}$ & $10 / 27 / 10$ & 18 & 0 & 16 & 0 & 288 \\
\hline $\begin{array}{l}\text { Keystone Training: Climate } \\
\text { Status Investigation }\end{array}$ & $12 / 10 / 10$ & 30 & 1 & 0 & 30 & 0 \\
\hline Earth 427 Sequestration Science & $05 / 06 / 11$ & 10 & 0 & 45 & 0 & 450 \\
\hline Intro To CCUS & $06 / 29 / 11$ & 25 & 0 & 0 & 0 & 0 \\
\hline $\begin{array}{l}\text { MST } 589 \text { Climate and } \\
\text { Geological Sequestration }\end{array}$ & $06 / 30 / 11$ & 3 & 3 & 0 & 9 & 0 \\
\hline $\begin{array}{l}\text { Webinar: Guidelines for } \\
\text { Community Engagement in } \\
\text { CCUS projects }\end{array}$ & $10 / 26 / 11$ & 6 & 0 & 0 & 0 & 0 \\
\hline Intro To CCUS & $06 / 29 / 12$ & 32 & 0 & 0 & 0 & 0 \\
\hline $\begin{array}{l}\text { MST } 589 \text { Climate and } \\
\text { Geological Sequestration }\end{array}$ & $08 / 03 / 12$ & 7 & 3 & 0 & 21 & 0 \\
\hline $\begin{array}{l}\text { Geol } 571 \text { Reservoir and Caprock } \\
\text { Field School }\end{array}$ & $08 / 17 / 12$ & 10 & 0 & 15 & 0 & 150 \\
\hline $\begin{array}{l}\text { UU, NMT,UTEP, CCUS } \\
\text { Distance Ed graduate class }\end{array}$ & $12 / 07 / 12$ & 24 & 0 & 45 & 0 & 1080 \\
\hline
\end{tabular}




\section{LESSONS LEARNED AND PATH FORWARD}

During the award period we pursued activities to promote CCUS training and education that were arguably more diverse in approach than any of the other training centers (i.e., a range from k-12 outreach to graduate and professional courses). Most, but not all, of these activities were very successful, and many, but not all are likely to be continued in the future. In the area of K-12 outreach, the development and dissemination of our Carbon Bond video game, the Keystone training, and our Masters of Science Teaching (MST) classes were particularly successful at engaging students and teachers. The Carbon Bond game will be available for use in the future, and continued funding is being pursued to keep it updated. The instructor who taught the MST classes has indicated that student response was enough to justify teaching it again, which he plans to do. However, further Keystone training is unlikely unless additional funding is made available. Our undergraduate and graduate CCUS courses were all well received by the students. We had excellent enrollments in all of the classes, except when we attempted to teach our undergraduate capstone course the second time, and too few students enrolled to justify teaching it. We feel this was due to a somewhat limited pool of interested students, and if we offer it again in a few years we anticipate a better enrollment. Videos produced by faculty and students for this class will continue to be accessible on the Internet. Our undergraduate field course on reservoir and caprock geology was also extremely successful, and will continue to be taught in the future, perhaps every other year. Unfortunately, our undergraduate option in CCUS was not successful, in that in three years no students signed up for it, probably due to the current lack of jobs in CCUS. Should the job market change we may revive the option, but currently it is no longer offered. Our most successful course was the semester-long graduate level CCUS class, which was offered twice for a total of 38 students at 3 different universities. This class offered an in-depth look at the geology, geochemistry, hydrology and social perceptions of CCUS to students, many of whom were engaged in CCUS or petroleum related research. This course impacted their knowledge of, and ability to work in, the CCUS field. Our webinars and on-site professional short course were very successful. Student feedback was compiled from the survey data for the webinars (11 respondents), as well as from the undergraduate (13 respondents) and graduate courses (15 respondents) and show that the participants felt an overall improvement in their understanding of the topic. If these courses continue they will under the auspices of Caprock Carbon Services. We are hopeful that our planned work with Caprock 
Carbon Services will allow us to continue to provide CCUS training to students and professionals. During our research into the demand for future CCUS training we discovered that our original plan of having our graduate level class available on-line for professional development was not a good business model due to low demand. Therefore the plan for Caprock services is more tailored to the needs of industry. However, we have developed content and assembled an excellent group of instructors for this enterprise, which should allow us to continue to utilize the expertise developed for the training center in the future. 


\section{APPENDICES}




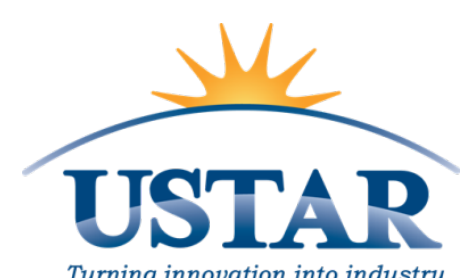

Turning innovation into industry.

\section{SWP}

\section{Caprock Carbon Services}

\section{Business Plan and Commercialization Strategy}

Value Proposition

Caprock Carbon Services is a comprehensive program that promotes and supports the adoption of Carbon Capture, Utilization and Storage (CCUS) practices though training and tailored project support for a diverse set of energy development stakeholders.

\section{Pain}

The complexity of CCUS projects requires expertise in a variety of fields - policy, geology, physics, chemistry, legal, environmental, financial, risk, etc. Currently, no comprehensive program exists to address the full range of issues associated with CCUS. This presents a barrier to CCUS implementation. Without a comprehensive program to educate, motivate and support stakeholders, the complexity of CCUS projects will remain an obstacle for commercial application.

\section{Solution}

Caprock Carbon Services provides the expertise and project support needed to overcome the barriers to adoption of CCUS technology. Caprock Carbon Services will act as a resource for identifying and addressing CCUS adoption challenges by organizing a diverse body of knowledge into a single comprehensive tool. With the understanding that every project is different, Caprock Carbon Services will also provide tailored support so that every project's unique challenges are addressed. This multidisciplinary training system will educate CCUS stakeholders and provide the solutions to allow informed deployment of CCUS technology.

\section{Team}

Dr. Brian McPherson UofU

Principal Investigator Chief Scientific Officer

Ryan Streams USTAR

Business Development

\section{Advisors}

Alan Walker

USTAR/EGI

Director, Eastern Utah

TOIP

Senior advisor, EGI

Dr. Alan Brown

Schlumberger

NAM Technical Training

Coordinator

Contact: Ryan Streams

(435)503-5392

rstreams@utah.gov 


\section{Why Caprock?}

Caprock Carbon Services is currently developing a partnership with Schlumberger. This partnership will have the unique benefit of allowing Caprock to concentrate on its CCUS training niche, while enjoying the broader reach of its partner organization's training programs. CCUS has traditionally been too narrow of a focus for larger training organizations to dedicate their efforts. With this partnership, Schlumberger is able to expand their educational portfolio, increase its available resources for teaching and gain access to the expertise of Dr. McPherson's carbon science team without dedicating extensive resources of its own to developing a CCUS training practice.

Caprock Carbon Services benefits from having the branding and training experience of Schlumberger's NExT practice, which will allow Caprock to focus on CCUS without struggling to compete in the mature, developed marketplace of professional technical training. The lowered barriers to market entry will prove invaluable in helping Caprock Carbon Services deliver its product of high-quality CCUS training services.

\section{An Emerging Market}

Currently, CCUS practices focus on sequestration of carbon dioxide in mature oilfields. CO2 injection, a process also known as Enhanced Oil Recovery (EOR) is already common practice and its importance to oil production has been growing rapidly in recent years. As of 2009, the global value of the Enhanced Oil Recovery market was \$62.5 billion (Source: SBI Energy - EOR Worldwide Market Analysis). Due to persistently high oil prices, the global value of EOR is projected to reach $\$ 1.3$ trillion by 2015 (Source: SBI Energy - EOR Worldwide Market Analysis). Investment in new technology has been a fundamental piece of the oil and gas industry. The oil and gas industry's investment in research and development reached \$3.4 billion in 2006 (Source: Ernst \& Young - Investment 2006).

Given the growing value of the EOR market and the industry's commitment to investment in R\&D, Caprock Carbon Services is well-positioned to deliver value-driven services in a growing sector.

Oil and gas producers are increasingly conscious of their carbon emissions. Although there are no current national regulations on carbon emissions, producers are still seeking ways to limit emissions. In the event that carbon emission regulations are enacted, this practice would become even more important. According to the most recent NATCARB surveys, there is an estimated 143 billion tonnes of $\mathrm{CO} 2$ storage capacity in mature oilfields throughout North America. 


\section{Competition}

The Society of Petroleum Engineers, which has over 100,000 members worldwide (Source: SPE Membership 2011) and offers a variety of technical training, currently has no offerings on CCUS or EOR technology. Similarly, the American Petroleum Institute, which has over 500 corporate members including the super-major oil producers, offers no training in CCUS or EOR. Additionally, major commercial training organizations like Schlumberger's NExT program, or Nautilus World do not currently offer CCUS focused training. Caprock Carbon Services stands to satisfy this niche market.

\section{Knowing our customers}

The Caprock Carbon Services is a comprehensive program for promoting and supporting the adoption of CCUS practices to a diverse set of energy development stakeholders.

\section{Customer Relationships}

Caprock Carbon Services has a consulting and service role with its customer base. We are an outside organization brought in to provide expertise in our CCUS niche. Our role is to be the experts on CCUS. Customers will look to us to distill the key issues relating to CCUS, provide them with information, training and project support. Given the length and complexity of a CCUS project, our relationship will likely be an ongoing one, rather than a one-off transactional relationship.

We will need to develop a rich understanding of our clients' teams, their skills and their needs. Once we have that, we can provide them with tailored training and project support. Our partnership with Schlumberger will allow us to quickly and accurately customize our services to client needs. Their extensive expertise in professional education in the oil and gas fields will be a tremendous asset. Their intimate knowledge of the industry and clients will save use time and allow us to tailor our efforts from the start.

\section{Customer Segments}

Our most important customers:

- Geologists and engineers for small to medium oil and gas producers

- Project management personnel

- Legal teams involved in CCUS

- Project financing and risk assessment teams 
Stakeholders we will target in the future include:

- Policymakers

- Environmental groups

- University-level academia targeting geology and engineering students

- K-12 teachers and students

\section{Customer Channels}

We will reach our target customer base by offering our product as part of a suite of training services through our partner organization. By offering our services as part of a broader training program or project support program, we can broaden interest in our services. There may be other channels we choose to use, depending on the nature of our training material. If we choose to use video short courses like the one in development, we may use online continuing education websites as a potential channel for reaching our audience.

The number of organizations dedicated to CCUS services is limited and people actively seeking these services won't have many choices. The key will be to create a channel that brings interest and attracts market segments that may not initially think of CCUS project support. By using a broader training program offered by our partners at Schlumberger as a foot in the door, we can offer our services once they have already established a relationship with our partner.

\section{Keys to Success}

\section{Key Activities}

As noted above, CCUS projects are complex and require expertise in a variety of fields. In order to be a go-to resource on the subject, we need to develop a team that has expertise in these different areas. We need experts on land law, mineral law, environmental regulations, permitting, site characterization, geology, geochemistry, geophysics, etc. We have expertise in some areas (notably geomechanics and computer modeling) but we will need to round out our team in other areas. This will require hiring top-tier talent.

Initial training efforts will focus on these core expertise areas of geomechanics and computer modeling. After we develop training in these areas, we can think about ways to deliver additional value to clients (expanded training methods, tailored services, etc.) 
Our partnership with NExT will allow Caprock to focus in on its key competencies while relying on their expertise for program support in areas like digital data management and marketing. Given the extensive experience NExT possesses in these fields, it is a natural fit for Caprock to leverage their expertise.

Building relationships with partners and potential clients will be another key activity. We will rely on seamless cooperation to move our services through our partner company to the clients. They will need to understand what exactly we can provide and we will need to understand how they approach training and project support.

\section{Key Resources}

Caprock Carbon Services' primary resource is its human capital. Our geoscience and modeling expertise is our core strength. The talent we hire to provide expertise in other areas of CCUS will be a key resource once they are a part of the team. In order to deliver on our mission of providing high-end training and tailored project support to CCUS undertakings, we will require a highly capable team.

- Both hiring this team and connecting with clients will require a strong professional network to bring together new partners, find project applications and identify potential stakeholders.

- Another key resource will be credibility and brand recognition. Our partnership with Schlumberger will be a tremendous asset in that respect.

- Our primary financial obligation will be to provide resources needed to create our training programs, cover travel expenses and compensation.

Key Partners

Our key partners include:

- CCUS research team

- NExT

- University of Utah

- Southwest Partnership Universities

Our primary key partner is our CCUS research team. Their expertise is the real source of value for Caprock Carbon Services. Their technical knowledge and modeling capabilities will likely be the most valuable asset from the clients' perspective. They will be supplying a substantial portion of our ability to add value. 
Another key partner is Schlumberger's NExT training program. Our relationship with them will be vital for identifying potential clients and potential projects, establishing name recognition with customers and providing further expertise in CCUS. Schlumberger will also be able to provide us with a framework for creating a training program that caters to clients' needs. Their extensive experience in providing training for the oil and gas industry would become a valuable resource for Caprock Carbon.

The University of Utah, New Mexico Tech, or another university in the Southwest Partnership may be a source of our human capital. As identified earlier, our value to clients depends on our ability to provide expertise. By drawing on the talent of these and other universities, we may be able to add some complementary personnel.

\section{Organizational Framework}

\section{Cost Structure}

Human capital is our most important resource; our salary costs will be our most important expenditures. Salary costs will remain fixed once hiring is complete.

- Elements like credibility, brand recognition, etc. will not be major costs given our plan to partner with an existing firm. The primary cost associated with these resources will be whatever revenue-sharing model we decide on with our partner organization. Depending on how we choose to structure our training, we will have costs associated with training material production (i.e. recording, encoding, web-hosting, etc.) and with project support (travel, IT resources for video conferencing, etc.)

Our team's current position at the University of Utah may allow for sharing of resources like office space, computing, etc. This will need to be refined further, but it may allow us to avoid significant investment in computer modeling capabilities, new office space and similar expenses.

\section{Revenue Streams}

Potential customers will be most willing to pay for services and training tailored to specific projects. There appears to be little interest in general education-style training.

- Currently, technical training courses for oil and gas engineers are offered in 2-5 day formats, typically offered at $\$ 2,500-\$ 5,000$ for the course. 
- These courses focus in high-end, technical training and target high-value professionals. In order to be competitive with existing training material, Caprock Carbon Services will need to offer a similarly high-end product.

In order to maximize value creation, our services will need to be tailored to individual clients' needs. In addition to offering short courses on CCUS:

- We will need to explore long-term project support that caters to individual teams' needs and addresses the challenges of unique projects. This training approach, which discussed during an informal conversation with Schlumberger, would require further clarification on the revenue structure.

\section{Conclusions - Challenges and Opportunities}

The overarching direction of Caprock Carbon Services is a partnership with NExT. Given the narrow focus of a CCUS training center, partnering with a larger training and service provider appears to offer the best chance of commercial viability. Both NExT and the Caprock Carbon Services team remain optimistic about the opportunity to establish a mutually beneficial working relationship that furthers CCUS training, knowledge and expertise.

Currently, challenges remain that will need to be addressed before a partnership is established. The primary reason for this is because this is a completely new project for the University of Utah. There are many remaining questions on how to handle ownership, licensing, intellectual property and conflict of interest. Without an existing framework, resolving many of these issues will be difficult for the University of Utah. However, we remain engaged in discussions with the Technology Commercialization Office, the University Conflict of Interest Committee, leadership at the College of Engineering and the University's General Counsel. As we resolve these issues, we will be able to move forward with delivering high-quality technical training based on the work done by the Southwest Partnership. 


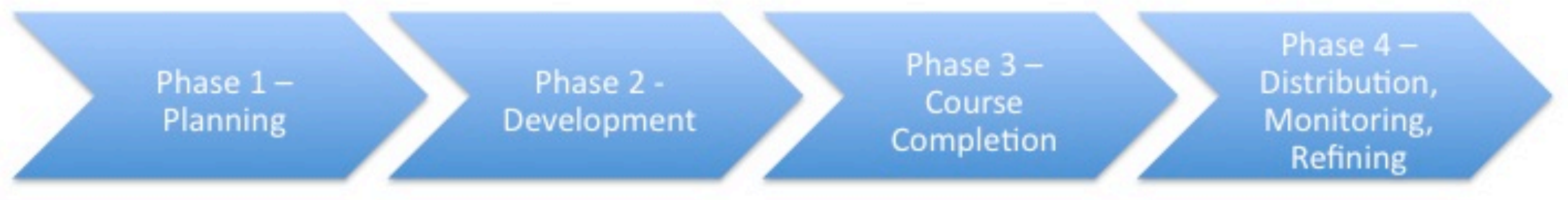

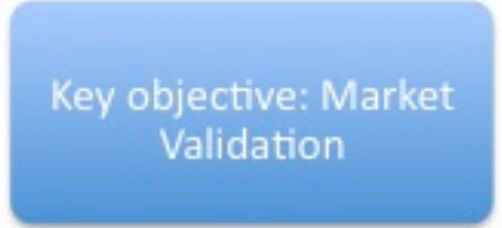

0

Determine focus area of course based on client feedback

Identify key activities for
research team

Focus on value creation for clients

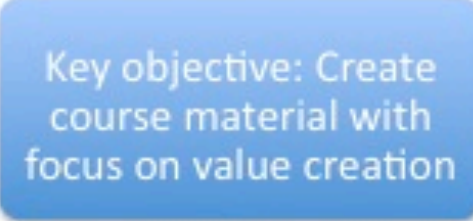

(8)

Research team executes on key activities

\section{Develop course material \\ aligned with customer need}

$$
0
$$

Leverage partner support for course feedback, distribution strategy

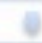

Beta-testing of course material, if market approves, proceed to phase 3 , otherwise refine development process

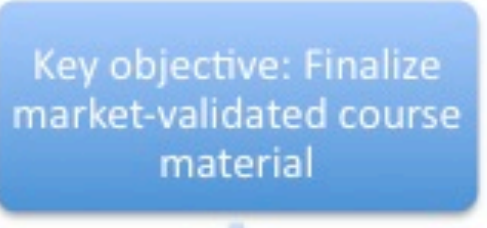

(1)

Course material will be in suitable formats

ac

Course material focused in topics that add value for clients (6)

With partner support, identify key distribution channels, go-
to market strategy (c)

Determine pricing and revenue model for training course
Key objective: Apply

lessons from first course

to expansion and growth

(2)

Track course performance

(both sales and reception by clients), identify strengths, weaknesses a

Identify new areas for potential training material 0

Refine existing course based on performance metrics $\sqrt{6}$

Assess research team capacity - if necessary, identify hiring needs 


\section{Profit and Loss Projection (3 Years)}

cCus Training Partnership

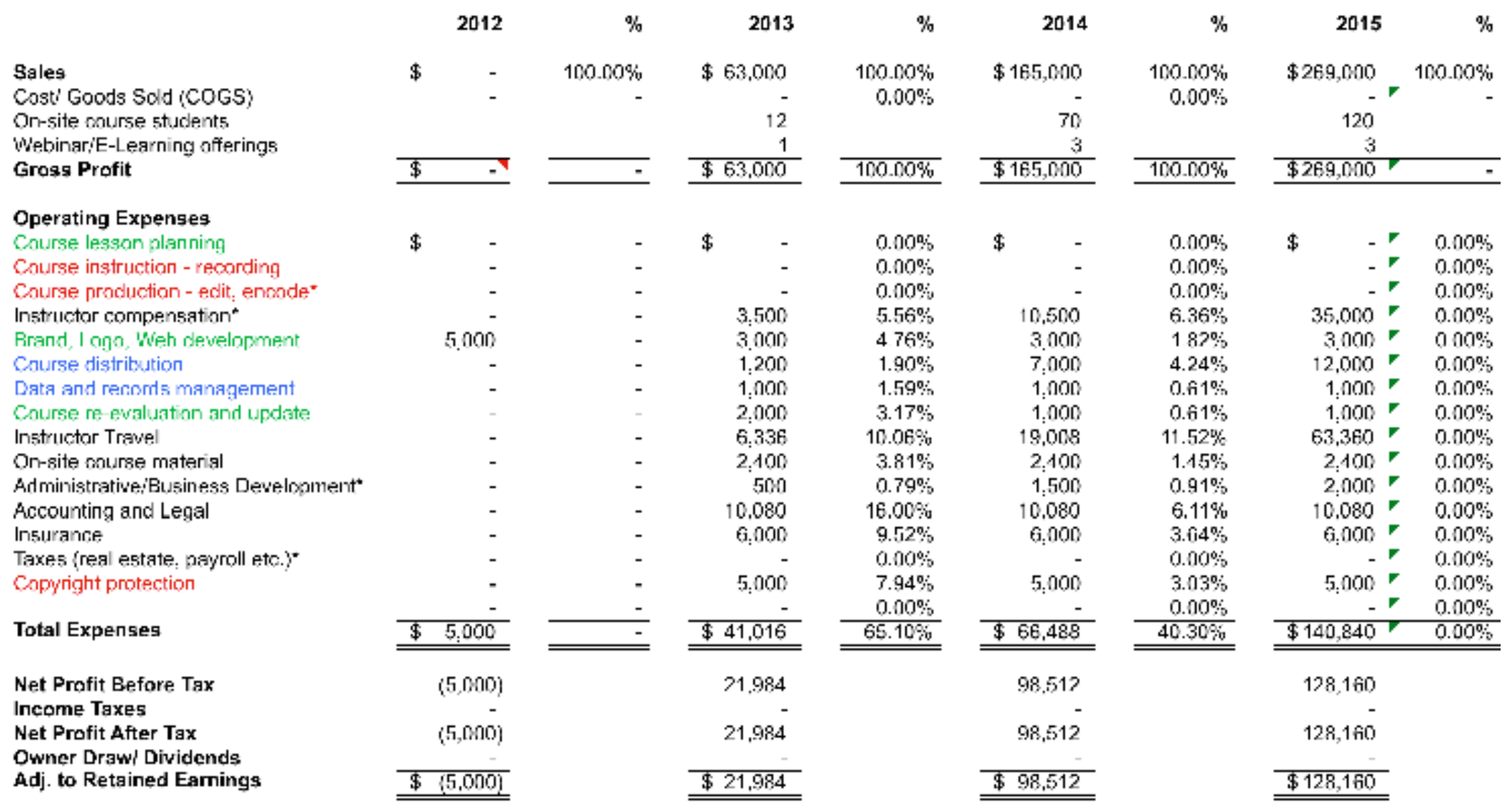

Red indisates items that are the primary responsibility of the SWIP,USTAR

Blue indinates items that will primarily narried hy Snhlumherger

Green indicates shared responsibility or efforts

Blark is TBD 


\section{Training Center Projections - Attachment}

\section{Course Lesson planning}

This item marks the development of course training materials based on industry demands. Labor is the primary cost associated here, with limited direct expenses. SWP can develop course materials with Schlumberger input on areas of interest, etc.

\section{Course Instruction - Recording}

This item marks the presentation and recording of course material. Aside from basic audio and video recording equipment, which is already available, the main cost here is the required labor.

\section{Course production - edit, encode}

Once the course material has been planned and recorded, it will need to be compiled, edited and encoded for distribution. University of Utah Technology Commercialization Office (TCO) may be able to provide support with this for a fee. This may require the purchase of editing software. (Final Cut Pro is available for $\$ 300$ with university license, or this may be available in University computer labs.) Again, labor is the primary cost here. This will likely be a time-consuming step.

\section{Instructor Compensation}

Based on discussion with NExT/Schlumberger, this is estimated at $\$ 2500-\$ 3500$ per course offering

\section{Brand, Logo, Web development}

This cell marks the initial web development costs, along with other branding and marketing devices. Estimate is based off TCO guidelines, using higher-end estimates for cost of web development. Recurring costs for later years recognizes that once the initial development is done, there will be ongoing costs associated with domain registry, maintenance, expansion, etc. This item also includes the cost for domain registry, data storage, etc. A typical subscription for unlimited data storage runs \$8$12 /$ month.

\section{Data and Records Management}

This item marks the need to track who has taken the course, handle payment and maintain the database of lectures, modeling information, etc. Given Schlumberger's extensive experience in commercial training, this is one area where the training center 
will likely rely on their expertise. Expenses will include secure data and records storage and IT support. Assume $1 \mathrm{hr}$ per week of FT employee $(\$ 20 / \mathrm{hr})$

\section{Course re-evaluation and update}

This item marks the ongoing need for evaluation of course material to ensure that training products are kept to the high standard the SWP Universities and Schlumberger expect. There will be costs associated with refining training materials and data collection from course participants, but again primarily labor here. Estimated $\$ 2000$ after first year, decreasing to $\$ 1000$ per year as course matures

\section{Instructor Travel}

This becomes relevant if courses are offered on-location. For the purpose of my estimates, I'm assuming 2 instructors flight ( $\$ 500$ ea), lodging ( $\$ 200 /$ night - based on federal rate for 2013) and per diem ( $\$ 71$ - based on federal rate) for a 4 -day course twice annually.

\section{Administrative/Business Development}

Based on NExT/Schlumberger discussions, they estimate this number at approximately $\$ 500$ per course offering.

\section{On-site course material}

Allowance for training materials to be distributed at on-location training courses ( 2 annually). Estimated 12 students per class, $\$ 100$ per day of training materials (4 days).

\section{Payroll (taxes)}

\section{Accounting and Legal}

Estimated 4 hours/month of legal counsel, $\$ 150 / \mathrm{hr}$

Estimated 4 hours/month - $\$ 60 / \mathrm{hr}$ for CPA bookkeeping

What remains to be determined is whether we will pursue outside legal counsel and bookkeeping services or whether a portion of this will be carried out by university/Schlumberger personnel

\section{Insurance}


Dependent on materials offered. Any field course will require $\$ 1 \mathrm{~m}-\$ 5 \mathrm{~m}$ (my estimate) of professional liability coverage. A premium this size is around $\$ 6000 / \mathrm{yr}$

\section{Taxes}

This item will be determined at a later date

\section{Copyright Protection}

At this stage, it doesn't appear that IP protection will be a primary concern for the course material. Instead, copyright protection of written, audio and visual materials will be the main focus. University of Utah/TCO resources can be relied on for handling this aspect.

\section{Income from on-site course instruction}

Net sales from the on-location courses assume at $\$ 2000$ fee per student, based on current market rates. Offered to 12 students, twice annually for year one. (\$48000 revenue)

Offered to 70 students (five classes) in second year

Offered to 120 students (ten classes) in third year

\section{Income from web-learning course instruction}

Webinar offered once annually - 1 day, est. $\$ 150$ entry. Assume 20 participants ( $\$ 3000$ revenue)

Offered 3 times year $3-(\$ 9000)$

Online course offered year-round - Est. 8 instruction hours, $\$ 400$ to take. Assume 30 participants. ( $\$ 12000$ revenue)

Assume 40 participants year 2

Assume 50 participants year 3 


\section{APPENDIX B}

\section{Carbon Bond Analyses \\ Michael J. Liles and Markus J. Peterson \\ 16 March 2012}

Students from grades 6-8 took a pre-test, played the Carbon Bond game, and then took a posttest. Data on students' test scores were exported to JMP 9.0 for statistical analysis. We ran a series of statistical tests on data for students from grades $6-8$. The results of the tests for grades 6-8 are described below.

Our overall interest was to learn whether middle-school /junior high students (grades 5-8) who play this game learn basic information about the carbon cycle and CCS? To address the overall question, we ran a paired t-test to compare the means of pre- and post-game scores for each student $(\mathrm{n}=116)$ in grades $6-8$. There was a significant difference between pre-game scores $(\mathrm{M}$ $=6.862, \mathrm{SD}=1.7688)$ and post-game scores $(\mathrm{M}=8.448, \mathrm{SD}=1.7212) ; t=9.5226, \mathrm{DF}=115, P$ $<0.0001$ ). These results demonstrate that middle-school /junior high students (grades 6-8) who played this game learned basic information about the carbon cycle and CCS. In addition to a significant increase in post-game scores, note the difference in the distribution of pre- and postgame scores (see figures 1 and 2).

We also asked whether gender made a difference in learning outcomes. To address this question, we ran the same paired t-test described above, but in a manner that would detect differences between the means of pre- and post-game scores for boys $(n=60)$ and girls $(n=56)$. Girls' pregame mean scores $(\mathrm{M}=6.786, \mathrm{SD}=1.8262)$ were lower than those of boys' $(\mathrm{M}=6.933, \mathrm{SD}=$ $1.7258)$, but their post-game mean scores $(\mathrm{M}=8.625, \mathrm{SD}=1.5083)$ were higher than the boys' post-game scores $(\mathrm{M}=8.283, \mathrm{SD}=1.8964)$. Thus, girls learned more than boys from playing the game. However, these differences were not statistically significant $(P=0.1429$; $\mathrm{MD}=1.840)$ between pre- and post-game mean scores for girls and $\mathrm{MD}=1.350$ between pre- and post-game mean scores for boys. We found no overall difference $(P=0.7289)$ between how boys and girls answered the questions when pre- and post-game scores were not evaluated. Again, note the changes in the distributions of pre- and post-game scores by gender (see figures 3 and 4). 
Figure 1:

Matched Pairs for players in Grades 6-8

Difference: Post_score-Pre_score

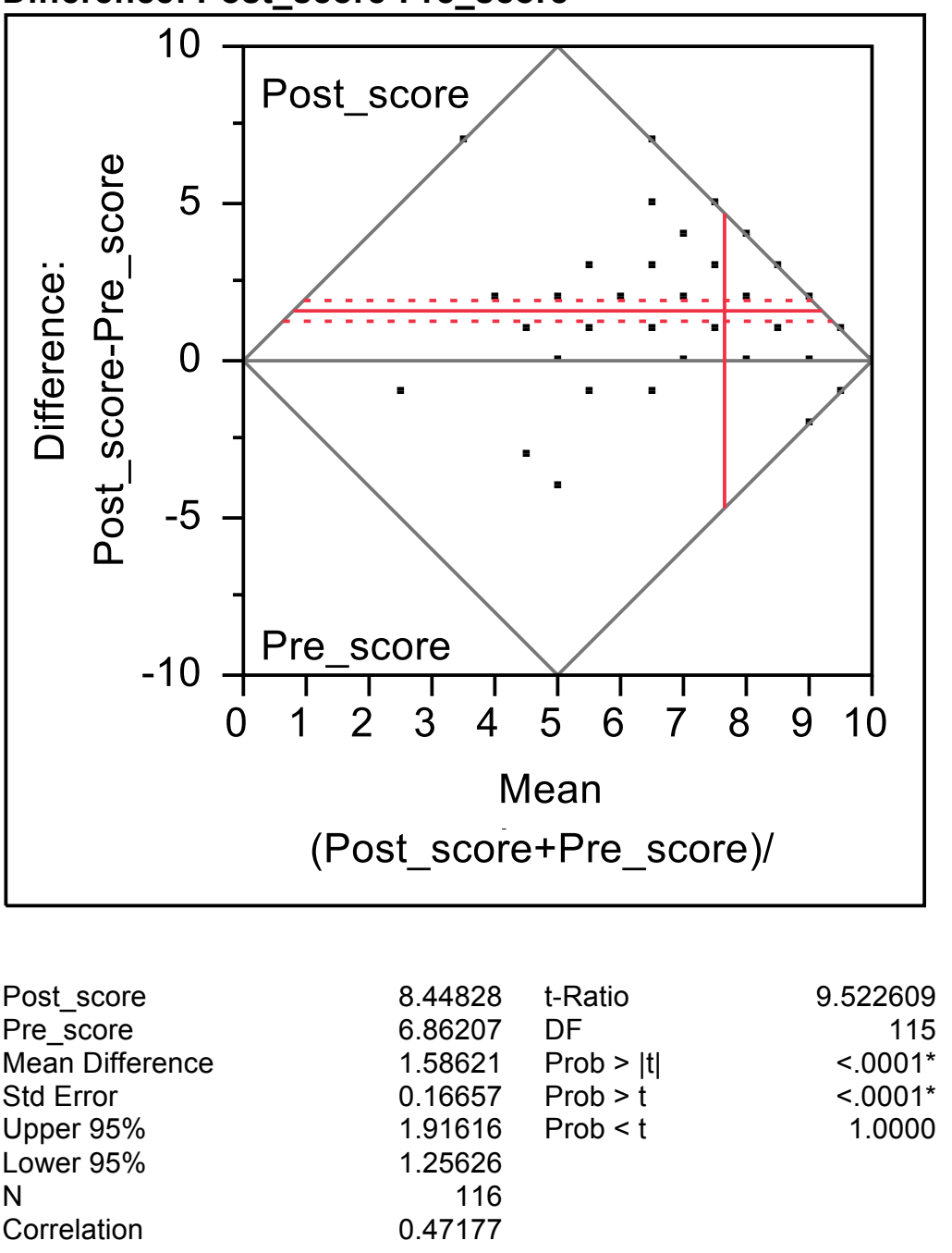


Figure 2:

Matched Pairs for players in Grades 6-8

Differences in pre and post distributions

\section{Distributions}

Pre_score

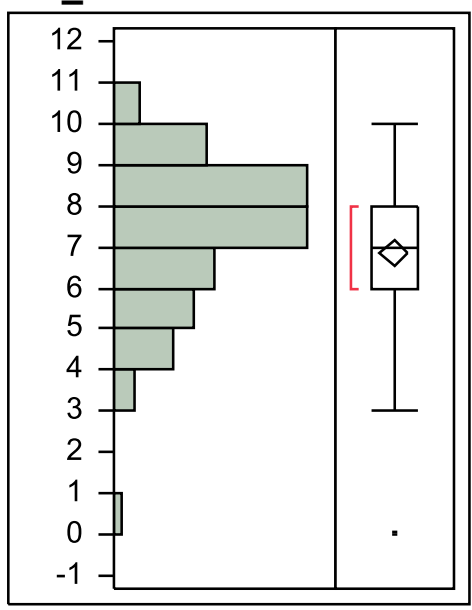

\section{Quantiles}

$\begin{array}{llr}100.0 \% & \text { maximum } & 10 \\ 99.5 \% & & 10 \\ 97.5 \% & & 10 \\ 90.0 \% & & 9 \\ 75.0 \% & \text { quartile } & 8 \\ 50.0 \% & \text { median } & 7 \\ 25.0 \% & \text { quartile } & 6 \\ 10.0 \% & & 4 \\ 2.5 \% & & 3 \\ 0.5 \% & & 0 \\ 0.0 \% & \text { minimum } & 0\end{array}$

\section{Moments}

Mean

Std Dev

Std Err Mean

1.768795

Upper 95\% Mean

0.1642285

Lower 95\% Mean

$\mathrm{N}$

7.187374

6.5367639

116

\section{Post_score}

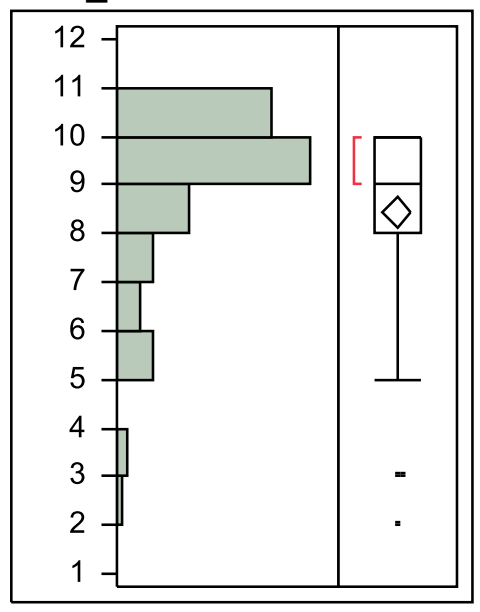

\section{Quantiles}

$\begin{array}{llr}100.0 \% & \text { maximum } & 10 \\ 99.5 \% & & 10 \\ 97.5 \% & & 10 \\ 90.0 \% & & 10 \\ 75.0 \% & \text { quartile } & 10 \\ 50.0 \% & \text { median } & 9 \\ 25.0 \% & \text { quartile } & 8 \\ 10.0 \% & & 5.7 \\ 2.5 \% & & 3 \\ 0.5 \% & & 2 \\ 0.0 \% & \text { minimum } & 2\end{array}$

\section{Moments}

$\begin{array}{lr}\text { Mean } & 8.4482759 \\ \text { Std Dev } & 1.7211969 \\ \text { Std Err Mean } & 0.1598091 \\ \text { Upper 95\% Mean } & 8.764827 \\ \text { Lower 95\% Mean } & 8.1317248 \\ \text { N } & 116\end{array}$


Figure 3

Matched Pairs for boys and girls

Difference: Post_score-Pre_score

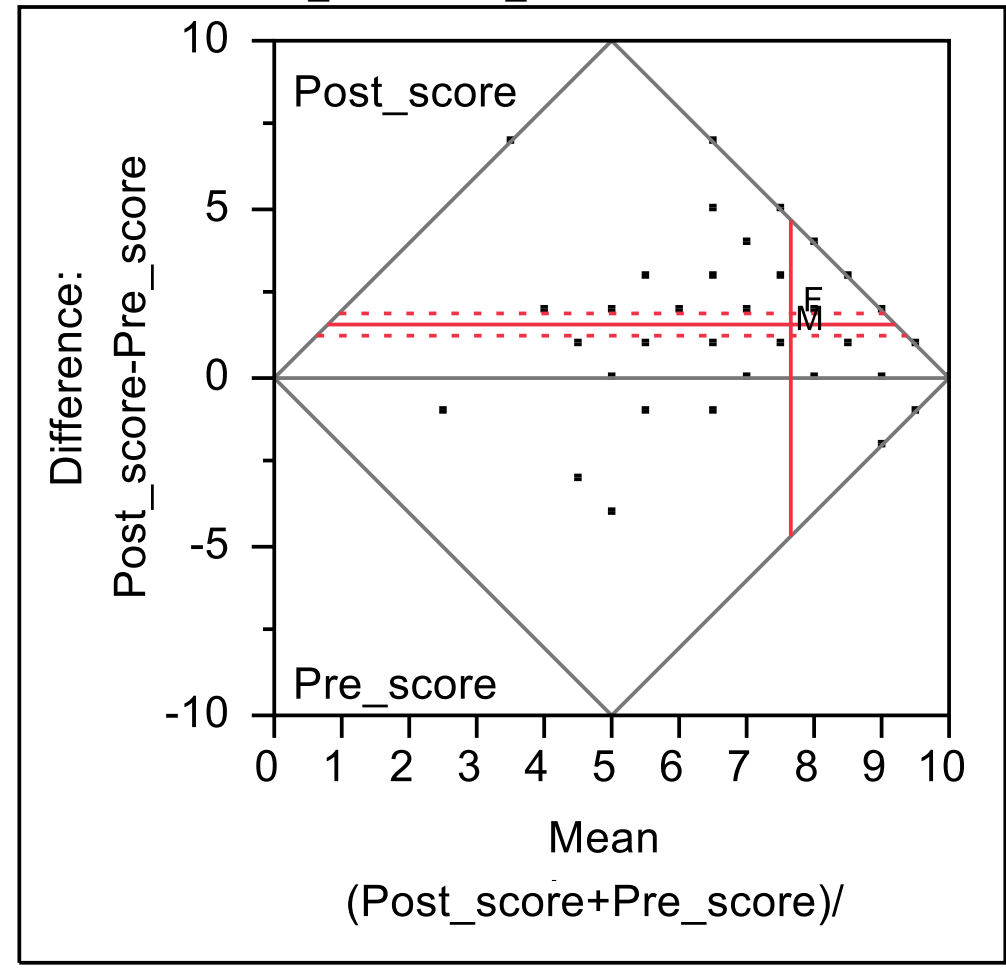

$\begin{array}{lrlr}\text { Post_score } & 8.44828 & \text { t-Ratio } & 9.522609 \\ \text { Pre_score } & 6.86207 & \text { DF } & 115 \\ \text { Mean Difference } & 1.58621 & \text { Prob }>|t| & <.0001^{*} \\ \text { Std Error } & 0.16657 & \text { Prob }>\mathrm{t} & <.0001^{*} \\ \text { Upper 95\% } & 1.91616 & \text { Prob }<\mathrm{t} & 1.0000 \\ \text { Lower 95\% } & 1.25626 & & \\ \text { N } & 116 & & \\ \text { Correlation } & 0.47177 & & \end{array}$

\section{Across Groups}

Sex Count Mean Difference

$\begin{array}{lrr}\mathrm{F} & 56 & 1.8393\end{array}$

$\begin{array}{lll}M & 60 & 1.35\end{array}$

Mean Mean
7.7054
7.6083

Test Across Groups

F Ratio

Mean Difference

2.1765

Prob $>$ F

Mean Mean

0.1207

0.1429 Within Pairs

Y Axis

0.7289 Among Pairs $X$ Axis 
Figure 4a:

Matched Pairs for boys and girls.

Differences in pre and post distributions

Distributions for Females
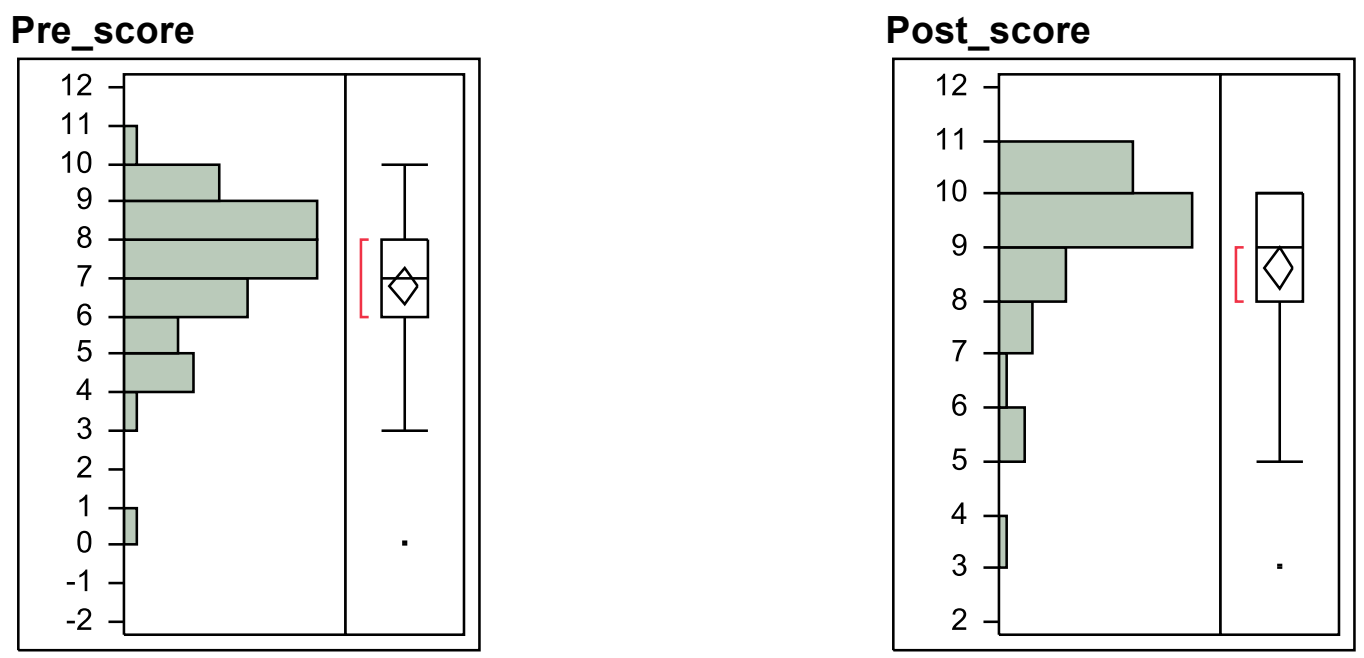

\section{Quantiles}

$\begin{array}{llr}100.0 \% & \text { maximum } & 10 \\ 99.5 \% & & 10 \\ 97.5 \% & & 9.575 \\ 90.0 \% & & 9 \\ 75.0 \% & \text { quartile } & 8 \\ 50.0 \% & \text { median } & 7 \\ 25.0 \% & \text { quartile } & 6 \\ 10.0 \% & & 4 \\ 2.5 \% & & 1.275 \\ 0.5 \% & & 0 \\ 0.0 \% & \text { minimum } & 0\end{array}$

\section{Moments}

Mean

Std Dev

Std Err Mean

Upper 95\% Mean

Lower 95\% Mean

N

6.7857143

1.826216

0.2440384

7.2747781

6.2966504

56

\section{Quantiles}

$\begin{array}{llr}100.0 \% & \text { maximum } & 10 \\ 99.5 \% & & 10 \\ 97.5 \% & & 10 \\ 90.0 \% & & 10 \\ 75.0 \% & \text { quartile } & 10 \\ 50.0 \% & \text { median } & 9 \\ 25.0 \% & \text { quartile } & 8 \\ 10.0 \% & & 6.7 \\ 2.5 \% & & 3.85 \\ 0.5 \% & & 3 \\ 0.0 \% & \text { minimum } & 3\end{array}$

\section{Moments}

$\begin{array}{lr}\text { Mean } & 8.625 \\ \text { Std Dev } & 1.5083103 \\ \text { Std Err Mean } & 0.2015564 \\ \text { Upper 95\% Mean } & 9.0289281 \\ \text { Lower 95\% Mean } & 8.2210719 \\ \text { N } & 56\end{array}$


Figure 4b:

Matched Pairs for boys and girls.

Differences in pre and post distributions

Distributions for Males

\section{Pre_score}

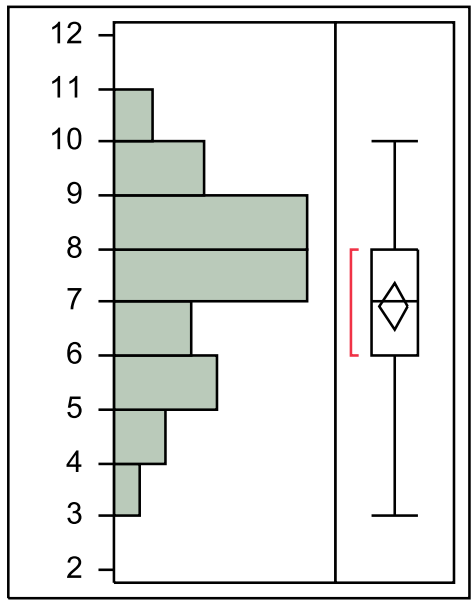

\section{Quantiles}

$\begin{array}{llr}100.0 \% & \text { maximum } & 10 \\ 99.5 \% & & 10 \\ 97.5 \% & & 10 \\ 90.0 \% & & 9 \\ 75.0 \% & \text { quartile } & 8 \\ 50.0 \% & \text { median } & 7 \\ 25.0 \% & \text { quartile } & 6 \\ 10.0 \% & & 4.1 \\ 2.5 \% & & 3 \\ 0.5 \% & & 3 \\ 0.0 \% & \text { minimum } & 3\end{array}$

\section{Moments}

Mean

6.9333333

Std Dev

Std Err Mean

Upper 95\% Mean

Lower 95\% Mean

$\mathrm{N}$

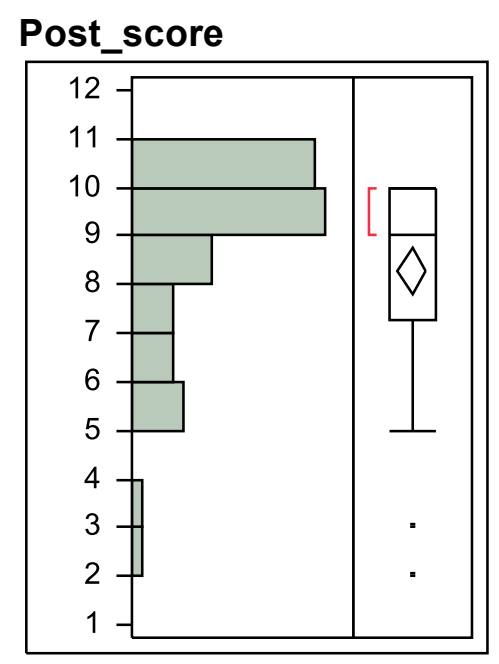

\section{Quantiles}

$\begin{array}{llr}100.0 \% & \text { maximum } & 10 \\ 99.5 \% & & 10 \\ 97.5 \% & & 10 \\ 90.0 \% & & 10 \\ 75.0 \% & \text { quartile } & 10 \\ 50.0 \% & \text { median } & 9 \\ 25.0 \% & \text { quartile } & 7.25 \\ 10.0 \% & & 5 \\ 2.5 \% & & 2.525 \\ 0.5 \% & & 2 \\ 0.0 \% & \text { minimum } & 2\end{array}$

\section{Moments}

$\begin{array}{lr}\text { Mean } & 8.2833333 \\ \text { Std Dev } & 1.8963986 \\ \text { Std Err Mean } & 0.244824 \\ \text { Upper 95\% Mean } & 8.773225 \\ \text { Lower 95\% Mean } & 7.7934416 \\ \text { N } & 60\end{array}$




\section{APPENDIX C}

\section{Rise of the Hero: How the Creation of a Fictitious Hero could overcome the Melodrama that is Climate Change and Carbon Sequestration}

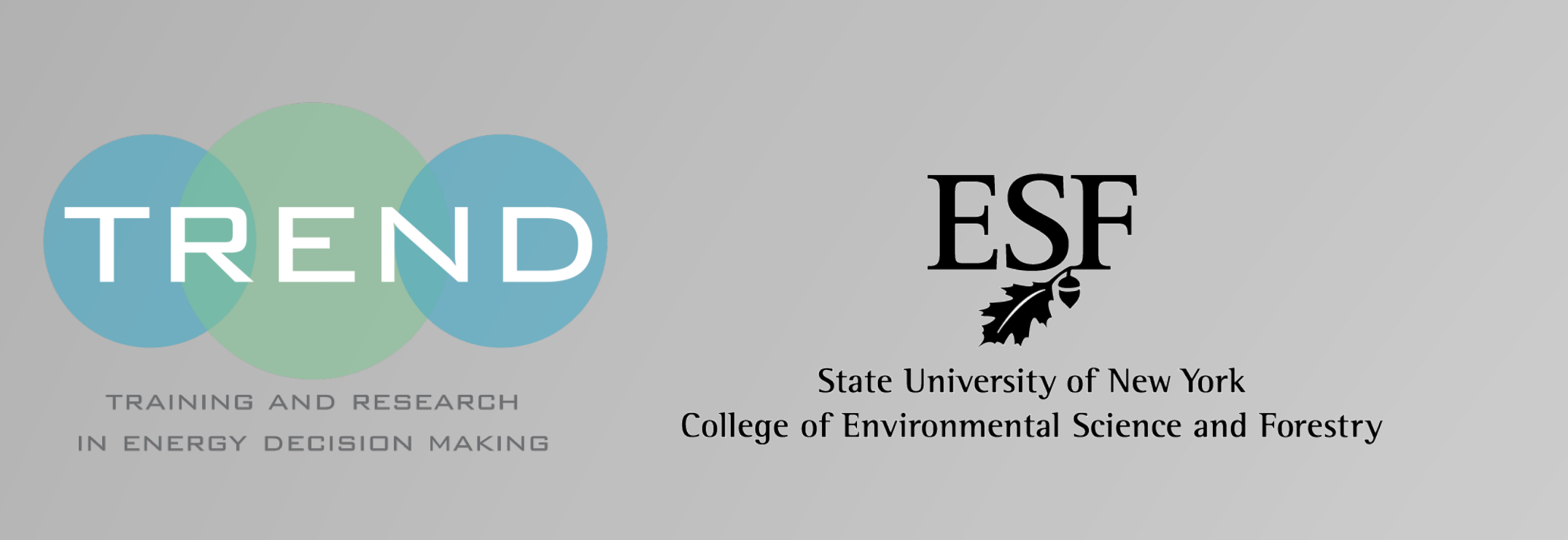

Andrea Feldpausch-Parker ${ }^{1}$, Megan O'Byrne ${ }^{2}$, Nicole Schero ${ }^{3}$, Adrienne Strubb ${ }^{3}$, Danielle Endres ${ }^{2}$, and Tarla Rai Peterson ${ }^{3}$ 'Department of Environmental Studies, SUNY College of Environmental Science and Forestry, Syracuse, NY 2Department of Communication, University of Utah, Salt Lake City, UT ${ }^{3}$ Department of Wildlife and Fisheries Sciences, Texas A\&M University, College Station, TX

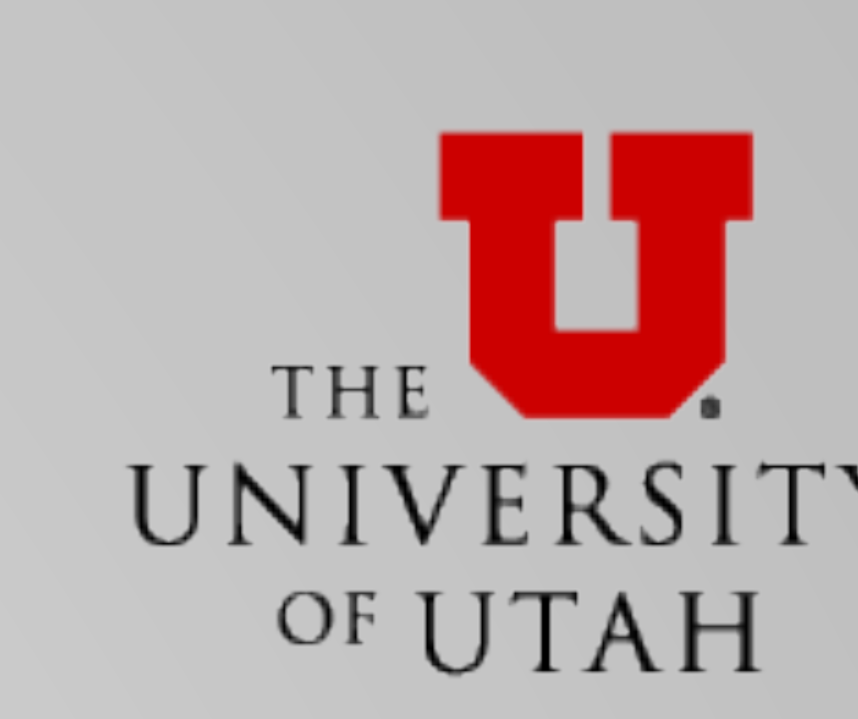

Research Questions
Opponents of climate change mitigation policy
climate change outside the realm of facticity

- Proponents of CCMP tend to dismiss the melodramatic fram

- We argue that melodrama can be co-opted to support CCMP by focusing on a hero that is aided by science and technology to fight the villain of green house gases (GHGs)

- The Adventures of Carbon Bond is an educational video game that uses this recast melodramatic frame to teach students about climate change science and CCS as a mitigation
strategy

What is Melodrama?

- A rhetorical frame that emphasizes a polarization between heroes and villains that entails "a focus on socio-political conflict, polarization of characters and positions, a moral framing of

- Melodrama can cause transformative shifts in thinking about an issue

Video Games as Rhetorical Devices

Video games have immense potential to transform their player's perceptions of the world
(Bogost, 2006, 2007a, 2007b; Gee, 2011; Konzack, 2007; Pötzsch, 2011)

- Both the narrative and rules of video games are persuasive

- Video games can use storytelling to reframe the climate change melodrama
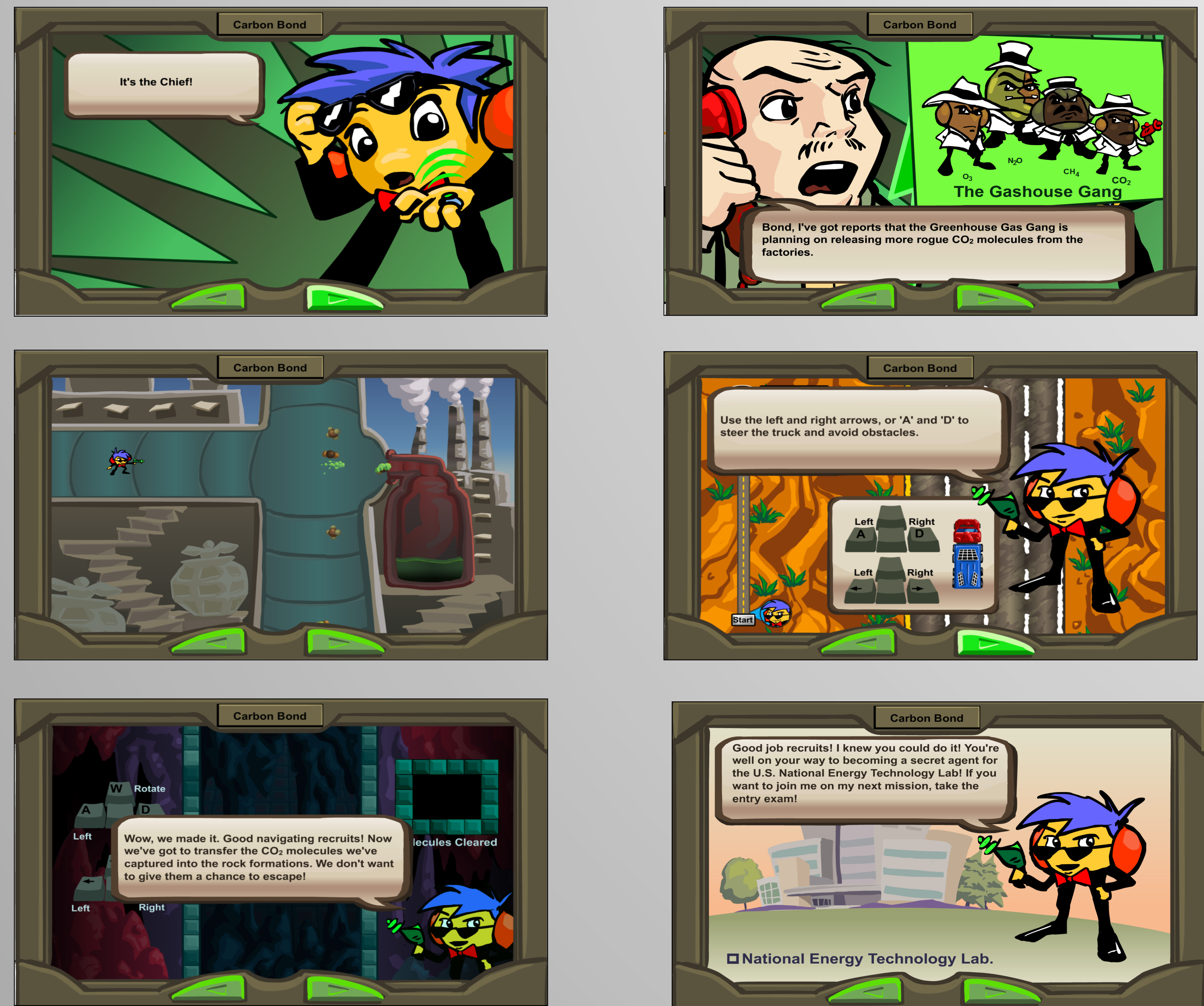

Figure 1. Differences in pre and post distributions for players
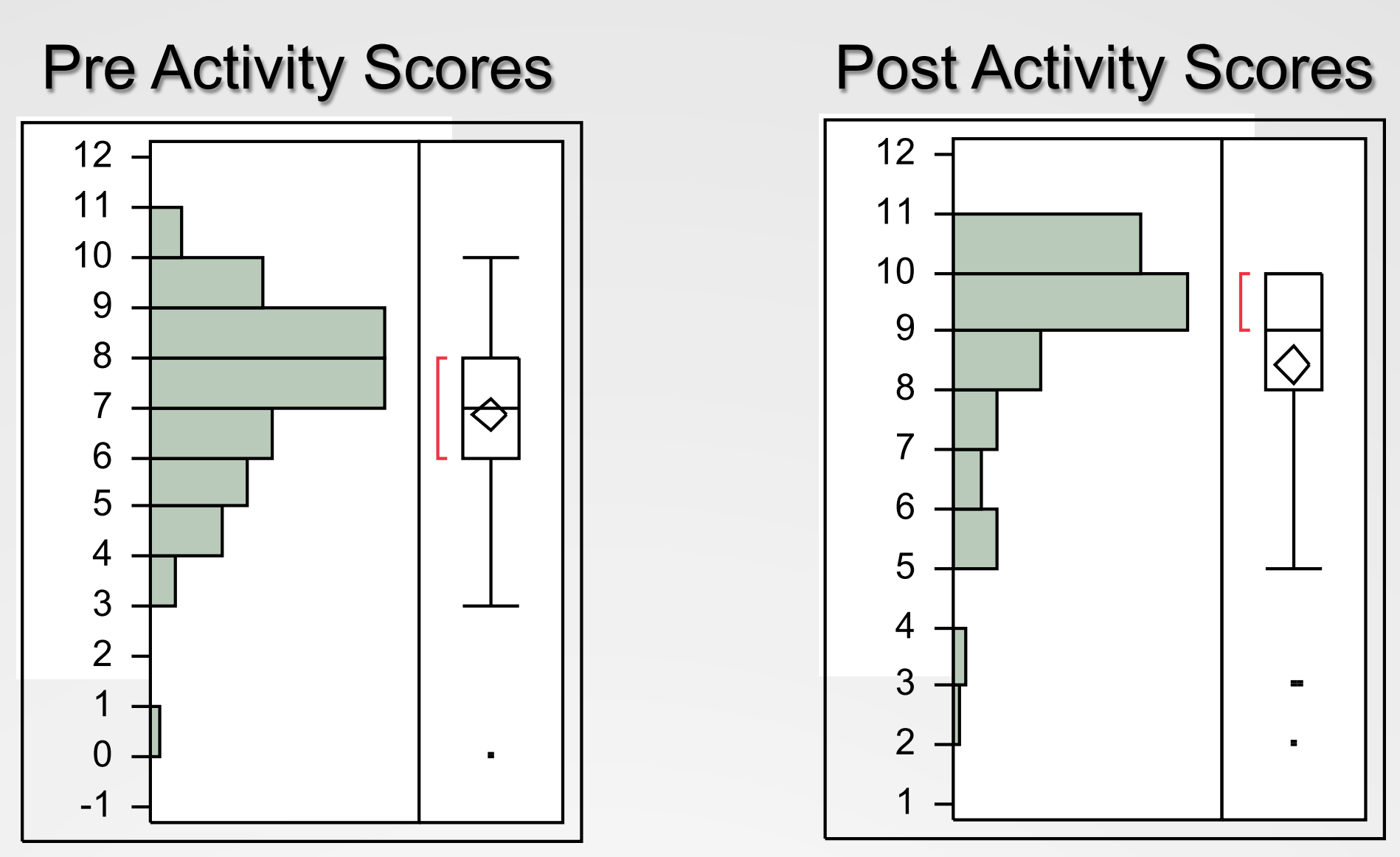

Figure 2. Differences in pre and post distributions for girls
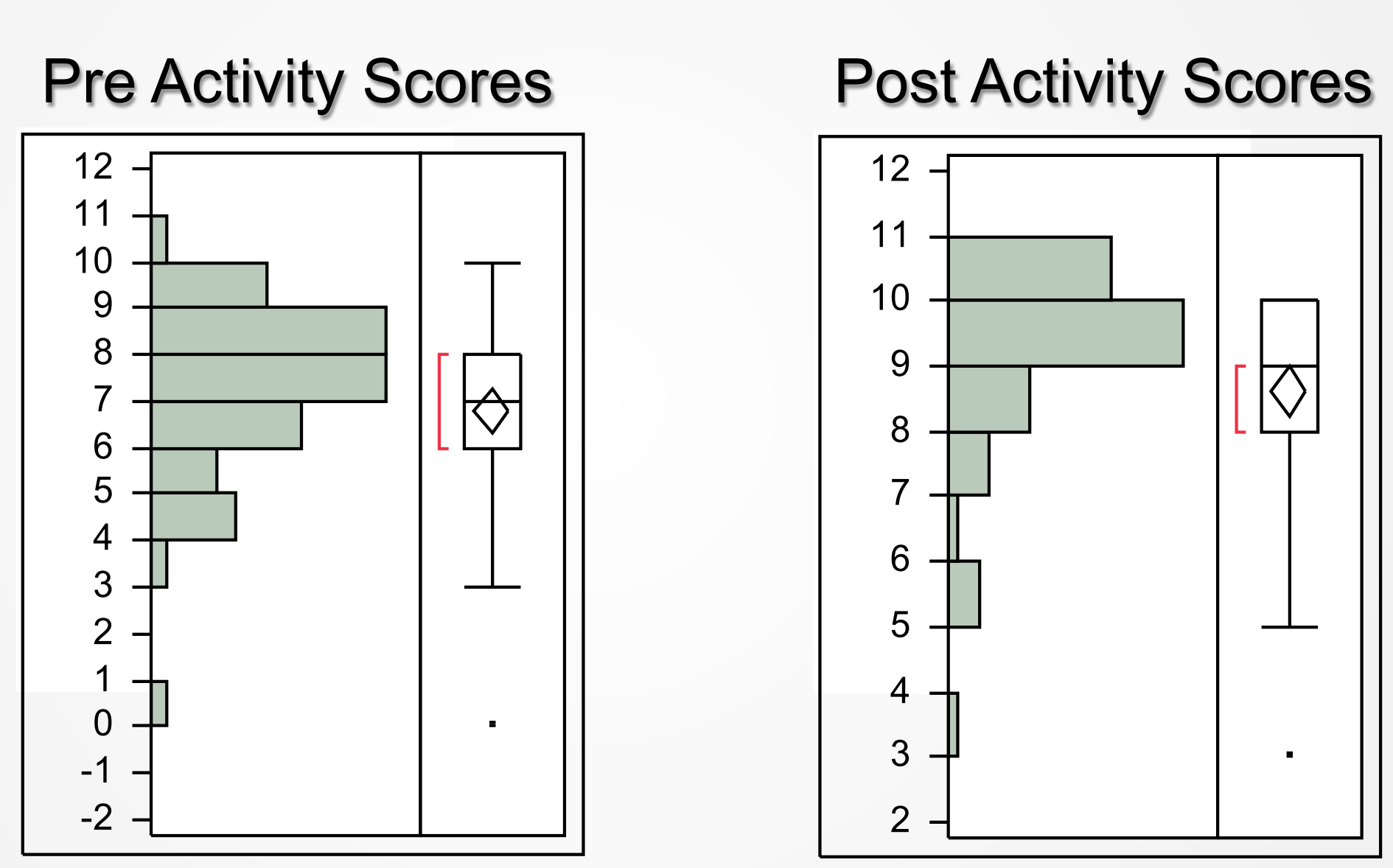

Figure 3. Differences in pre and post distributions for boys
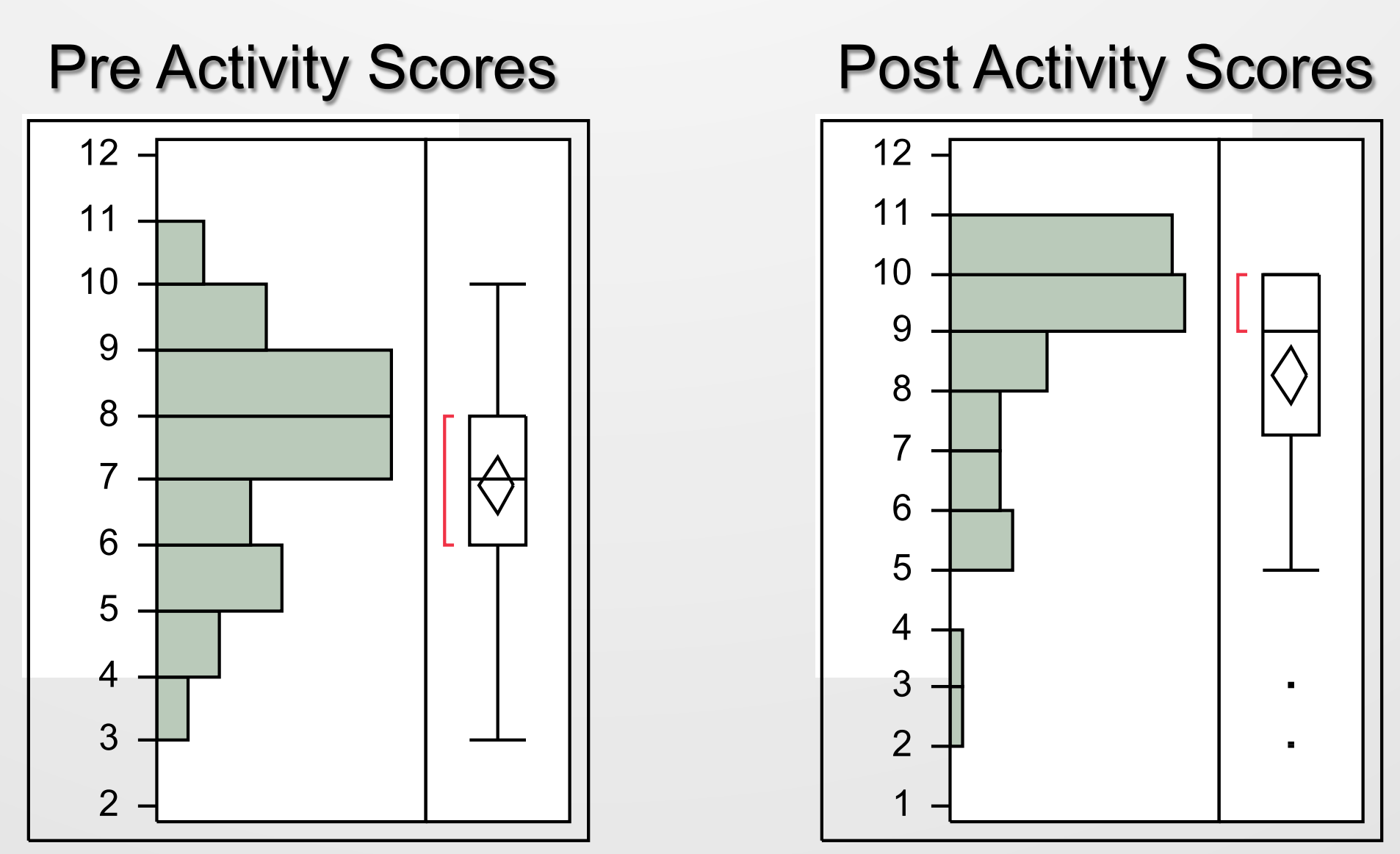

The Adventures of Carbon Bond change; and 2) science and technology of geologic CCS many rogue $\mathrm{CO} 2$ molecules as possible and putting them safely behind bars (or down an injection well into an underground formation). Game play includes: Gang at a local power plan to prison

- a storage activity to imprison the gang in an underground formation
RQ 1: Do students learn basic science information related to climate change through playing
The Adventures of Carbon Bond? $\mathrm{RQ}$ 2: Do students learn how CCS contributes to climate change mitigation through playing The Adventures of Carbon Bond?

RQ 3: Do students enjoy the learning process through playing The Adventures of Carbon Bond?

RQ 4: Do boys and girls learn differently from the game play experience of The Adventures of Carbon Bond?

\section{Results}

- RQ1 \& RQ2 showed an in basic knowledge of climate change science and

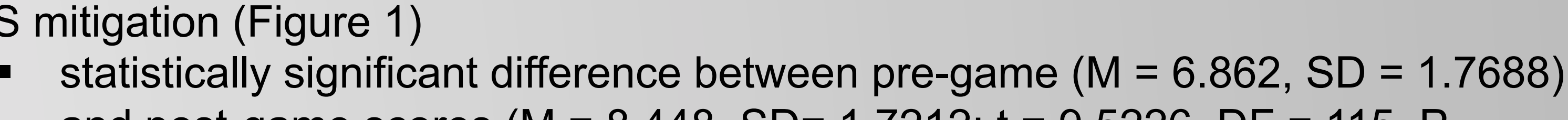
and post-game scores $(M=8.448, S D=1.7212 ; t=9.5226, D F=115, P$

RQ3 showed that students enjoyed playing the game in the classroom - $55 \%$ of students would play it again on their own
$66 \%$ thought other students would enjoy the activity.

- RQ 4 suggested that girls might learn more than boys (Figures 2 \& 3) girls' pre-game mean scores $(n=56 ; M=6.786, S D=1.8262)$ were lower than those of boys' $(n=60 ; M=6.933, S D=1.7258)$, but their post-game mean scores $(M=8.625, \mathrm{SD}=1.5083)$ were higher than the boys' post-game scores
$(\mathrm{M}=8.283$, $\mathrm{SD}=1.8964)$.
these differences were not statistically significant $(\mathrm{P}=0.1429)$ between pre- and

these differences were not statistically significant $(P=0.1429)$ between pre- and
post-game mean scores for girls $(M D=1.840)$ and for boys $(M D=1.350)$

\section{Discussion and Conclusion}

- We found that The Adventures of Carbon Bond did serve as a useful educational tool to educate youth about climate change and CCS, in addition to being enjoyable

- The findings did not fully address the effectiveness of the representation of the melodramatic frame

- Future research will include more extensive methodologies such as: - interviews and focus groups with students and teachers to explore changes perspective toward climate change action attributed to game play the addition of more study participants to the current dataset to further explore the significance of gender differences noted above.

An educational video game for students in grades 6-8 that teaches: 1) basic science of climate

- The game focuses on Carbon Bond who is on a mission to save the planet by capturing as

a shooting activity, using a "Goo Gun," to capture members of the Greenhouse Gas

a driving activity with the goal to avoid collision with storm debris while hauling the gang an entrance exam into the National Energy Technology Laboratory as a secret agent
- Future research to expand the game to include more gaming activities that would address other mitigation and adaptation strategies and give a more holistic picture of
the tools, technologies and choices at our disposal for combating climate change.

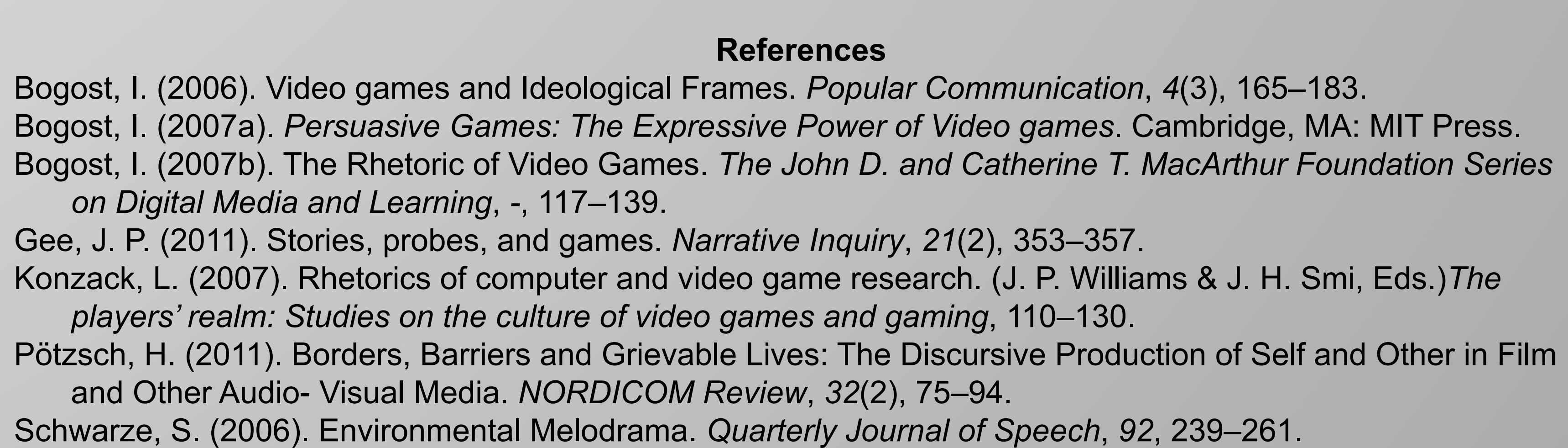




\section{The Adventures of Carbon Bond: Using a melodramatic game to explain CCS as a mitigation strategy for climate change}

Andrea M. Feldpausch-Parker, State University of New York College of Environmental Science and Forestry, Syracuse, NY, USA

Megan O'Byrne and Danielle Endres, University of Utah, Salt Lake City, UT, USA Tarla R. Peterson, Texas A\&M University, College Station, TX, USA

Abstract: Policy options for mitigating climate change have been severely limited in the USA by the clash of competing ideologies. People who oppose policies to mitigate climate change have successfully framed climate change as existing outside the realm of fact and empirical reality. Instead, opponents frame the issue as a melodramatic struggle between good and evil. While scientists and engineers tend to be uncomfortable with melodramatic framing, we argue that melodrama resonates with people. Constructing a different melodramatic frame can tap into people's tendency to conceptualize issues in terms of heroes and villains and assist in creating a shift in the political controversy from debating the factuality of climate change to a focus on mitigation. We developed an educational video game that uses this frame to teach students about climate change and carbon capture, and sequestration, to create an understanding of $\mathrm{CO}_{2}$ as the villain and humans as heroes through participation in mitigation strategies. The hero of this melodrama is aided by science and technology to mitigate anthropogenic climate change. We analyze The Adventures of Carbon Bond ${ }^{\odot}$ as a medium for educating students about climate change and shifting framing. We begin with a discussion of melodrama and the rhetorical nature of video games. Then, through statistical analysis of surveys completed by students who played the game, we demonstrate that students experienced a knowledge increase as a result of game play. We conclude by discussing the implications of our findings for productively reframing climate change towards an emphasis on technological mitigation.

(C) 2012 Society of Chemical Industry and John Wiley \& Sons, Ltd

Keywords: carbon bond; CCS; climate change; gaming; melodrama; rhetoric

Footnote: An earlier version of this paper was presented at and included in the proceedings from the 11th Annual Conference on Carbon Capture Utilization \& Sequestration in Pittsburgh, Pennsylvania, April 30-May 3, 2012 and was nominated by delegates as one of the best oral or poster presentations from this event to publish in a special issue of Greenhouse Gases: Science and Technology Correspondence to: Andrea M. Feldpausch-Parker, Department of Environmental Studies, State University of New York College of Environmental Science and Forestry, Syracuse, NY, USA. E-mail: amparker@esf.edu 


\section{Introduction}

Policy options for mitigating anthropogenic climate change have been severely limited in the United States by ideological conflict. One focal point in this controversy is the manufactured debate over whether climate change is factually based. Contingents of people who oppose policy to mitigate climate change have successfully framed it as existing outside the realm of fact and empirical reality. Instead, these opponents of climate mitigation policy frame climate change as a melodrama, which Burke defines as a polarized struggle between good and evil. ${ }^{1}$ Scientists, engineers, and others who accept the factuality of anthropogenic climate change tend to be put off by melodramatic framing, and indict it for being irrational. From a political perspective, however, it is more practical to work within the dominant cognitive frame than to denigrate it.

We contend that co-opting the melodramatic frame for climate change can contribute to shifting public discussion in the USA toward mitigation strategies, rather than continuing to argue over whether the climate is changing. Despite the criticism of melodrama as irrational, it represents how people understand and come to terms with complex and daunting issues such as climate change. ${ }^{2}$ In other words, people tend to make sense of complex issues by categorizing the good and the evil and identifying heroes and villains. Instead of ignoring or repudiating melodrama, proponents of climate change mitigation technology and policy have much to gain by adapting a melodramatic frame for their purposes. While the melodramatic frame may be perceived to eschew reason in favor of emotion, we show that a melodramatic frame is compatible with promoting the use of science and reason to solve complex problems. Offering a melodramatic frame that is supported by climate change science enables people to shift their focus from debating the reality of climate change to solving the climate change problem with mitigation technologies. We tested this idea by developing an educational video game that uses the melodramatic frame to teach students: (i) basic carbon cycle information; (ii) how carbon dioxide $\left(\mathrm{CO}_{2}\right)$ and other greenhouse gases (GHGs) contribute to climate change; and (iii) how carbon capture and storage (CCS) can be used as a mitigation strategy. In line with the game's effort to avoid presenting an inaccurately negative perspective toward $\mathrm{CO}_{2}$, the hero of this melodrama is a $\mathrm{CO}_{2}$ molecule who uses science and technology to solve a problem, or mitigate anthropogenic climate change. The villains are a gang of unruly GHGs, rather than people with different ideologies. By drawing attention to the technologies (CCS in this case) that people can use to address a problem, melodrama moves beyond the unproductive debate over who causes climate change to an exploration of options for mitigating it.

In this paper, we analyze The Adventures of Carbon $B o n d^{\odot}$ as a medium through which to educate students about climate change and CCS, and shift the framing of climate change toward mitigation strategies. We begin with a discussion of melodrama and the rhetorical nature of video games. Then, through statistical analysis of surveys completed by students, we demonstrate that students experienced a knowledge increase as a result of playing the game. We conclude by discussing the implications of our findings for productively reframing CCS and other strategies for climate change mitigation.

\section{Melodrama}

The political controversy over climate change in the USA falls within what Burke has termed the melodramatic frame of rhetoric. ${ }^{1}$ While melodrama is often referred to as a dramatic form, Burke expanded the concept of melodrama (as well as other dramatic forms) as a way to conceptualize and theorize how people understand the world around them. Melodrama is an overarching frame, or system of interpretation, that emphasizes a polarization between heroes and villains. We follow Schwarze in defining melodrama as 'a recurrent rhetorical form in environmental controversies' (p. 239) that entails 'a focus on socio-political conflict, polarization of characters and positions, a moral framing of public issues, and development of monopathy' (p. 245). ${ }^{3}$ This definition, while perhaps more operationally oriented, is consistent with the ordinary language definition of melodrama as, 'a work (as a movie or play) characterized by extravagant theatricality and by the predominance of plot and physical action over characterization' (http://www.merriam-webster.com/dictionary/ melodrama). While some scholars have criticized melodrama for its polarizing perspective,${ }^{4-6}$ it remains a dominant way for people to understand and come to terms with complex and daunting issues. ${ }^{2}$ During the 1980s, many scientists and policymakers subscribed to a view of science communication that assumed 
members of the lay public suffered from a deficit of information, as well as a deficit in the way that they viewed the world. According to the deficit model, good science communication simply needed to fill the void with correct information, and with training in how to view the world more rationally. It has become increasingly clear, however, that this approach is not effective. ${ }^{7-9}$ Meaningful engagement requires thoughtful recognition of the validity of people's implicit values, emotions and attitudes, especially with a topic as dynamically complex as climate change. ${ }^{10}$

Schwarze argues that in certain situations melodrama can be transformative and 'shift the parameters of ongoing controversies' (p. 253). ${ }^{3}$ The polarization between heroes and villains is important to the transformative potential of melodrama. Schwarze continues: 'as melodrama polarizes, it can encourage reconsideration of the allegiances and shared substance that might normally lead audiences to accept a certain set of social and political arrangements' (p. 248). ${ }^{3}$ For climate change, a melodramatic frame can facilitate a shift in thinking from considering one's political opponents as villains to considering $\mathrm{CO}_{2}$ and other greenhouse gases as villains. A melodramatic frame that places audiences (or players) in the position to act as heroes by taking action to fight $\mathrm{CO}_{2}$ emissions can challenge here to fore successful efforts to evade the issue of climate change by offering concrete techniques for mitigating it. In this paper, we demonstrate that educational video games hold unique potential to not only incorporate the melodramatic frame into the story of a game but also to reach audiences that may otherwise close themselves off from climate science.

\section{Video games}

Video games have often been trivialized as a medium that does not warrant further critical attention. Yet video games, as rhetorical constructs with the power to persuade, ${ }^{11-16}$ have immense potential to transform their players' perceptions of the world. The rhetorical force of video games can come from both the explicit story of the game and the implicit procedural aspects of a game. Regarding the former, Gee explains that the use of storytelling and narrative forms in video games impact players in the course of gameplay and in their lived experiences outside of the game. ${ }^{14}$ In the case of climate change, a video game can use storytelling to reconfigure the main characters in climate change. For example, in The Adventures of Carbon Bond $^{\odot}$, the story involves the player acting as a hero who protects the world by capturing and sequestering $\mathrm{CO}_{2}$ before it enters the atmosphere. Regarding the latter, Bogost coined the term 'procedural rhetoric' to describe 'the art of persuasion through rule-based representations and interactions rather than the spoken word, writing, images, or moving pictures' (p. ix). ${ }^{12}$ That is, procedural rhetoric entails the arguments put forth through the rules of the game. The implicit structure, as well as the explicit narrative, of the game is rhetorical. Procedural rhetoric has the potential to 'disrupt and change fundamental attitudes and beliefs about the world, leading to potentially significant long-term social change' (p. ix). ${ }^{12}$ In The Adventures of Carbon Bond ${ }^{\odot}$, procedural aspects of the game encourage players to recognize climate change as an anthropogenic problem that is amenable to anthropogenic remedies. Players advance by sequestering GHG emissions and in so doing focus attention on how to mitigate climate change, rather than whether it is occurring or what is causing it. In other words, the procedural rules of the game already assume that it is desirable to prevent more $\mathrm{CO}_{2}$ from entering the atmosphere. This procedural aspect of the game then provides a learning experience as it nudges US players outside of the debate over whether anthropogenic climate change is happening to experience climate change and climate mitigation strategies in an educational context.

Video games, therefore, are not only persuasive, but also hold the potential to transform the way we think about the world. Indeed, according to Chang 'games could affect our understanding of real-world environmental issues, either by implicitly or explicitly modeling different forms of our individual and collective environmental agency' (p. 60). ${ }^{17}$ Therefore, constructing a game that uses the melodramatic frame to represent mitigation strategies for climate change has the potential to move beyond the ideological gridlock in contemporary US political discussions of climate change.

\section{The Adventures of Carbon Bond}

The Adventures of Carbon Bond ${ }^{\odot}$ is an Internet-based videogame geared toward teaching students about climate change and geologic CCS as a mitigation strategy. ${ }^{18}$ The game was created for the Southwest Regional Partnership on Carbon Sequestration and the Southwestern United States Carbon Sequestration 
Training Center as a means of engaging youth in discussions of climate change mitigation through CCS while also providing imagery for geologic CCS, which is difficult for many people to visualize. Based on a review of public school curricula to see where material on climate change and CCS might best fit, we chose to design the game for students in grades six through eight, from middle and junior high schools (age 11-14). Players have the opportunity to learn: (i) the basic science of climate change; and (ii) the science and technology behind geologic CCS, which is an important option for mitigating climate change but is still not well understood within the public realm. ${ }^{18-20}$

Beyond these informational goals, the narrative of the game creates a melodramatic frame that focuses on climate change mitigation by positioning players as heroes through capturing and sequestering villainous $\mathrm{CO}_{2}$ molecules. The storyline of the game focuses on a main character, Carbon Bond, who is on a mission to save the planet by capturing as many rogue $\mathrm{CO}_{2}$ molecules as possible and sequestering them in an underground formation. Being a $\mathrm{CO}_{2}$ molecule himself, Bond separates himself from anthropogenic $\mathrm{CO}_{2}$ at the beginning of the story by claiming to be 'naturally formed' through the carbon cycle, thus distinguishing for players the difference between natural $\mathrm{CO}_{2}$ and $\mathrm{CO}_{2}$ from industrial operations. Bond's adventures take him from the smokestacks of an integrated gasification combined cycles power plant, to the stormy coasts of the Gulf of Mexico (impacted by increased storm intensity related to climate change), and finally to a $\mathrm{CO}_{2}$ storage facility in the Southern Rockies where the Greenhouse Gas Gang (anthropogenic GHGs) is locked away. The narrative begins with the assumption that climate change is a factual problem that needs to be solved, offers CCS as a technological solution to mitigating climate change, and positions players to be a part of the solution by capturing and sequestering $\mathrm{CO}_{2}$ molecules. Following a melodramatic frame, the game presents anthropogenic $\mathrm{CO}_{2}$ as the villain and players (through the game persona of Carbon Bond) as the heroes.

The game is made up of four progressive gaming activities interspersed throughout the melodramatic narrative: (i) a shooting activity, using a 'Goo Gun', to capture members of the Greenhouse Gas Gang at a local power plant; (ii) a driving activity with the goal of avoiding collision with storm debris while hauling the gang to prison; (iii) a storage activity to imprison the gang in an underground formation; and (iv) an entrance exam into the National Energy Technology Laboratory as a secret agent like Carbon Bond (Fig. 1). This final activity tests players on their knowledge of the carbon cycle, GHGs, energy production, rock formations, and climate change. If enough points are earned, players can print their own badges. The video game provides opportunities for students to: (i) learn through activities presented within a social/environmental context; (ii) define a problem and create solutions; and (iii) transition from being a fictitious hero to a real-life hero.

\section{Research questions}

Through the creation of The Adventures of Carbon Bond $^{\complement}$, we attempted to recast the narrative about climate change from one of dueling political ideologies to a drama focused on technological solutions. We hypothesized that an educational video game could provide an appropriate vehicle to present a controversial topic such as climate change mitigation within a melodramatic structure that placed players (and by extension, all humans) in the role of hero. We developed The Adventures of Carbon Bond ${ }^{\odot}$ to enable students to learn about the science and technology related to climate change in an atmosphere relatively free from ideological conflict. To examine the effectiveness of the game we posed the following research questions:

RQ1: Do students learn basic science information related to climate change through playing The Adventures of Carbon Bond ${ }^{\oplus}$ ?

RQ2: Do students learn how CCS contributes to climate change mitigation through playing The Adventures of Carbon Bond ${ }^{\circ}$ ?

RQ3: Do students enjoy the learning process through playing The Adventures of Carbon Bond ${ }^{\circ}$ ?

In addition to these questions, widespread USA interest in attracting more females into Science, Technology, Engineering, and Math (STEM) fields, such as climate science, led us to ask:

RQ4: Do boys and girls learn differently through playing The Adventures of Carbon Bond@?

\section{Methods}

Students in grades six through eight, from middle and junior high schools (age 11-14) in the states of Michigan, North Carolina, and Texas $(\mathrm{n}=116)$ played the 


\section{APPENDIX D}
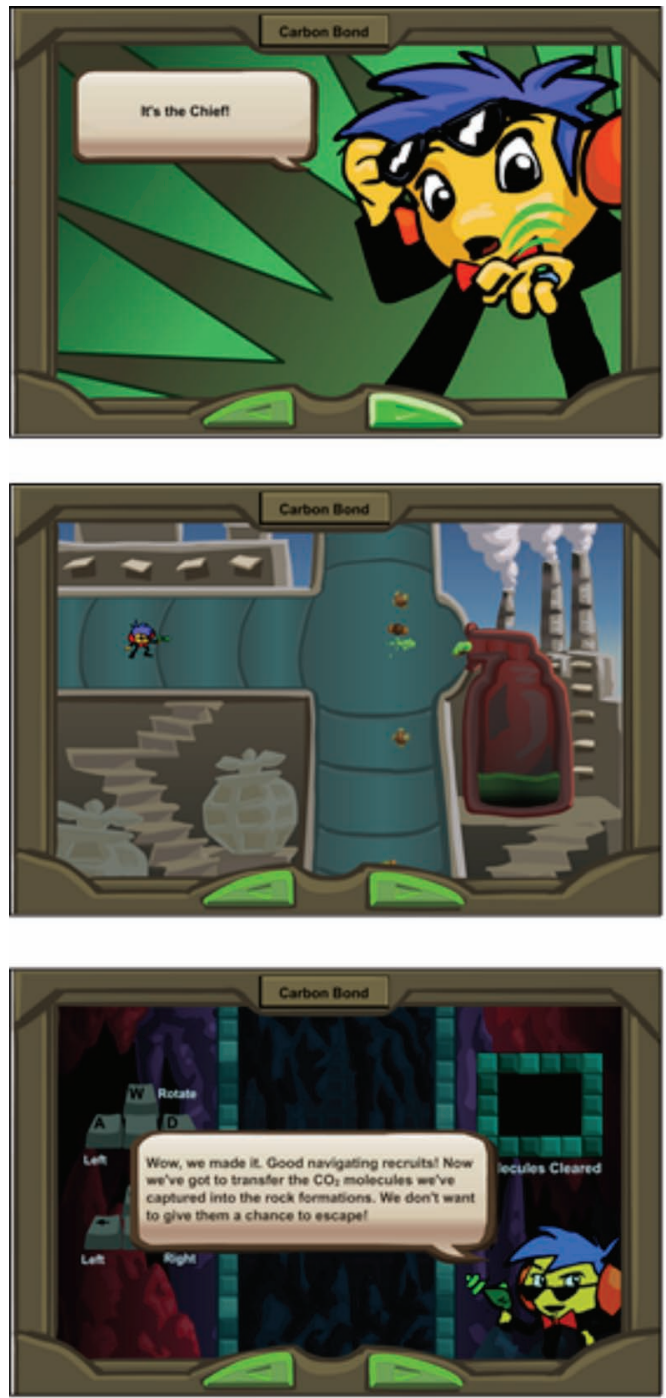
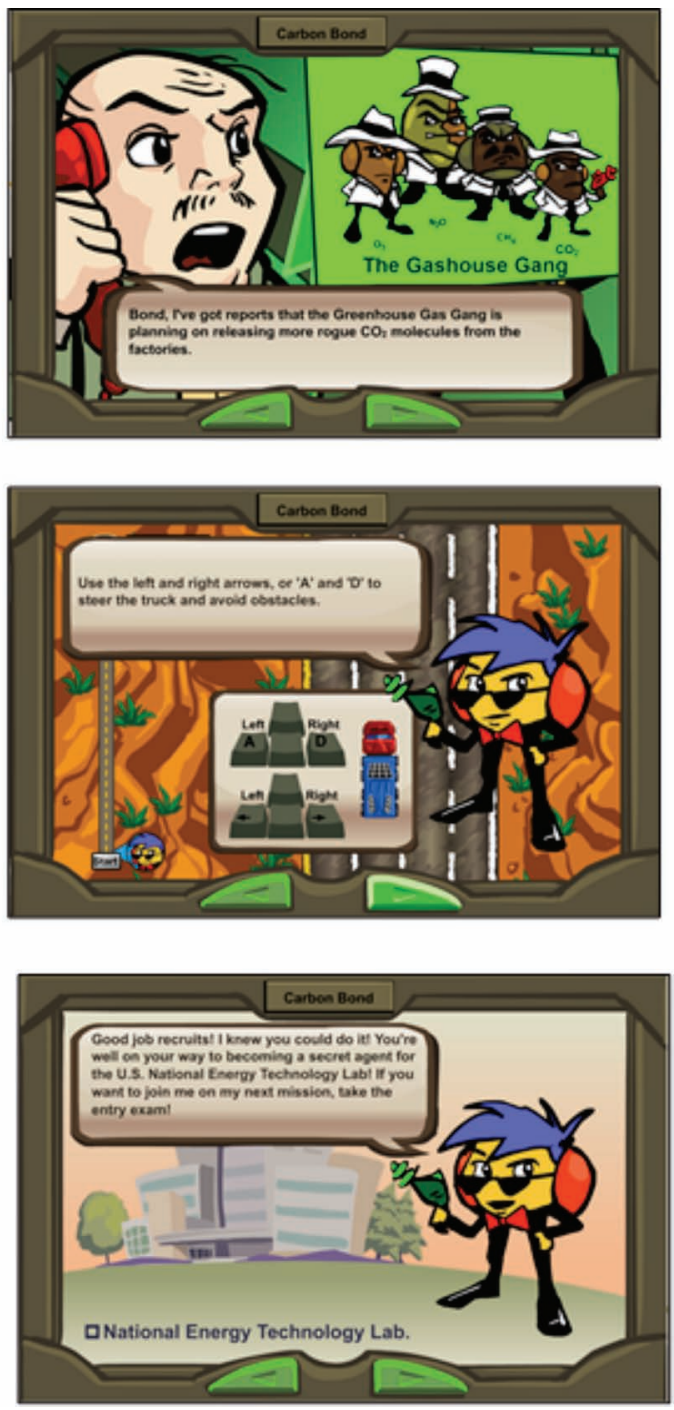

Figure 1. Images from The Adventures of Carbon Bond.

game. We conducted pre- and post-game surveys to determine knowledge gained and enjoyment accrued from students' gaming experience. The study period was from May to December 2011. Video game play and surveys were administered online. We used Survey Monkey to administer the pre- and post-game surveys. Survey material included: (i) a knowledge test covering information from the storyline and activities; (ii) questions pertaining to activity enjoyment; and (iii) questions addressing demographics. The entire process (game play and two surveys) took a total of 30 to 45 minutes, or one class period, to complete. Differences in delivery time depended on class size and teacher preparation.
For data analysis, we used JMP 9.0 to conduct paired $\mathrm{t}$-tests on the pre- and post-game knowledge data and descriptive statistics for questions addressing gaming enjoyment. This study was conducted in accordance with the Texas A\&M University Institutional Review Board.

\section{Results}

From our analysis of the students' knowledge tests (RQ1 and RQ2), we found a statistically significant difference between pre-game $(\mathrm{M}=6.862, \mathrm{SD}=1.7688)$ and post-game scores $(\mathrm{M}=8.448, \mathrm{SD}=1.7212, t=9.5226$, $\mathrm{DF}=115, P<0.0001)$ as well as a change in score 
Pre Activity Scores

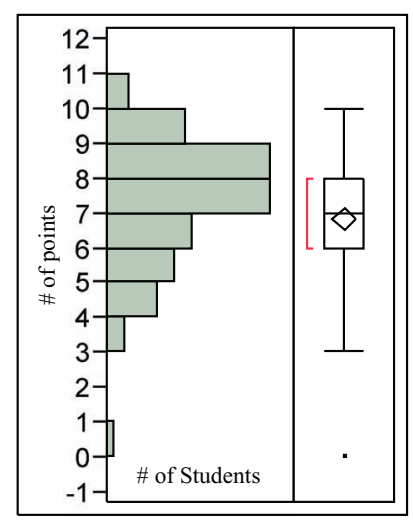

$\mathrm{M}=69 \%$
Post Activity Scores

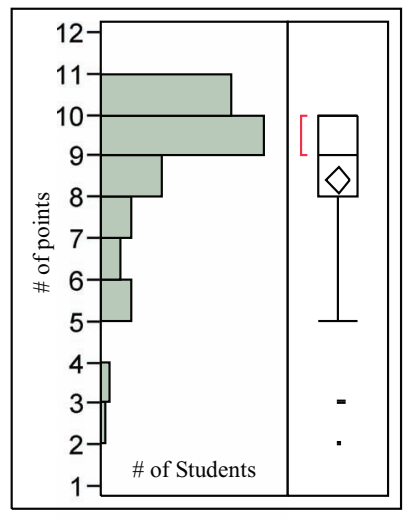

$\mathrm{M}=84 \%$

Figure 2. Differences in pre and post distributions for players in grades 6 through 8 . Highest score possible is 10 out of 10 points. Diamond indicates student mean $(n=116)$. After playing the game, students scored significantly higher on the knowledge test, with the mean score increasing from $69 \%$ to $84 \%$.

distribution from pre- and post-gaming (Fig. 2). Table 1 depicts an overall increase in average scores by question. These results demonstrate an increase in basic knowledge of the carbon cycle and other information relevant to student learning about CCS and anthropogenic climate change. These increases are in light of students reporting that $73 \%$ had learned about $\mathrm{CO}_{2}$ prior to playing the game, and $86 \%$ about climate change.

In response to RQ3, we found that students enjoyed playing The Adventures of Carbon Bond ${ }^{\odot}$ in the classroom, with $55 \%$ of students saying that they would play it again on their own, and $66 \%$ saying that they thought other students would enjoy the activity. Of the four separate activities that make up the game, the shooting activity involving the Goo Gun was the favorite, with the Entrance Exam being the least favorite but admittedly most educational (Fig. 3).

When examining differences in scores due to sex (RQ4), we found that girls' pre-game mean scores ( $\mathrm{n}=$ $56 ; \mathrm{M}=6.786, \mathrm{SD}=1.8262$ ) were lower than those of boys ( $\mathrm{n}=60 ; \mathrm{M}=6.933, \mathrm{SD}=1.7258)$, but their post-game mean scores $(\mathrm{M}=8.625, \mathrm{SD}=1.5083)$ were higher than the boys' post-game scores $(\mathrm{M}=8.283$, $\mathrm{SD}=1.8964)$. Thus, girls learned more than boys from playing the game. However, the differences between pre- and post-game mean scores for girls $(\mathrm{MD}=1.840)$ and pre- and post-game mean scores for boys $(\mathrm{MD}=$ 1.350) were not statistically significant $(P=0.1429)$. Changes in the distributions of pre- and post-game scores by sex can be seen in Figs. 4 and 5. Similar to sex, no statistically significant differences were found when we attempted to differentiate between the different grade levels (grades 6-8; $P=0.9229$ ).

To summarize, playing the game enabled students to learn about the carbon cycle, climate change, and geological CCS. Girls' knowledge of these topics increased more than boys' knowledge. Both boys and girls reported that they enjoyed playing the game.

Table 1. Difference in means by question between pre and post responses for players in grades 6 through 8.

\section{Question}

Carbon dioxide $\left(\mathrm{CO}_{2}\right)$ is...

Carbon is the building block for all living things.

How does your home and school get electricity?

Rock formations have spaces underground that hold resources such as oil and natural gas.

Planting a tree or other plants could help lower carbon dioxide $\left(\mathrm{CO}_{2}\right)$ in the atmosphere.

The temperature on Earth is...

How can you help cut carbon dioxide $\left(\mathrm{CO}_{2}\right)$ emissions?

Reducing carbon dioxide $\left(\mathrm{CO}_{2}\right)$ emissions helps control climate change.

Carbon dioxide $\left(\mathrm{CO}_{2}\right)$ can be captured from a factory...

Carbon dioxide $\left(\mathrm{CO}_{2}\right)$ can be stored in underground rock formations.

$\begin{array}{ccc}\begin{array}{c}\text { Pre-activity } \\ \text { Mean }\end{array} & \begin{array}{r}\text { Post-activity } \\ \text { Mean }\end{array} & \text { Difference } \\ 74 \% & 73 \% & -1 \% \\ 35 \% & 86 \% & 51 \% \\ 91 \% & 91 \% & 0 \% \\ 82 \% & 92 \% & 10 \% \\ 76 \% & & \\ 82 \% & 93 \% & 17 \% \\ 80 \% & 91 \% & 9 \% \\ 84 \% & 89 \% & 9 \% \\ 38 \% & 93 \% & 9 \% \\ 47 \% & 55 \% & 17 \% \\ & 84 \% & 37 \%\end{array}$




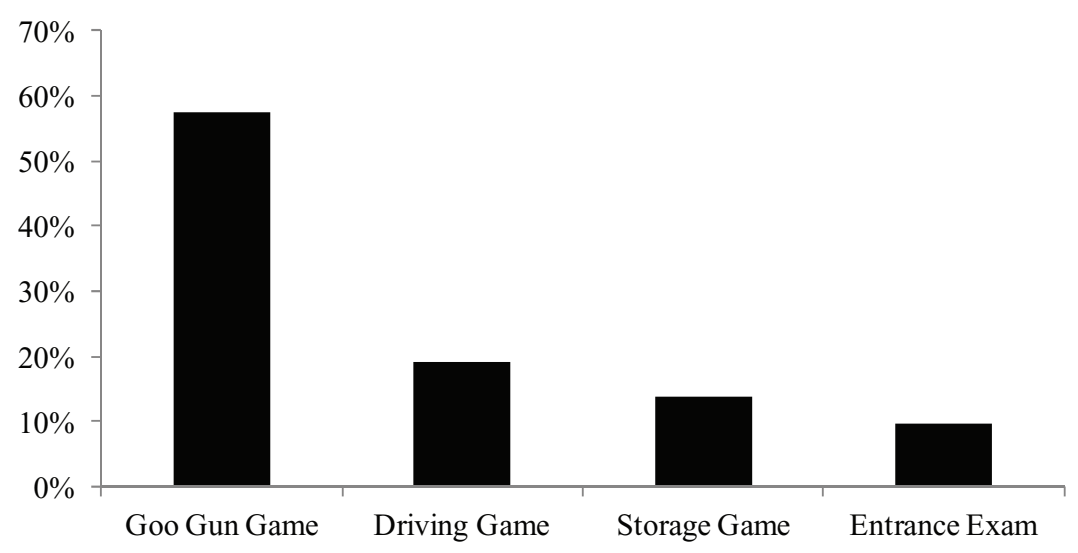

Figure 3. Distribution of students' favorite activity within The Adventures of Carbon Bond

\section{Discussion and conclusions}

When it comes to the mitigation of climate change, controversy and ideological hostility have constructed a significant hurdle to policy action. This hurdle stems from multiple causes, including the complexities of modern society with its pluralistic value systems (i.e. cultural, economic, political, scientific). When faced with phenomena of such scale and complexity as climate change, humans often resort to melodrama as a way to make sense of the complexity through

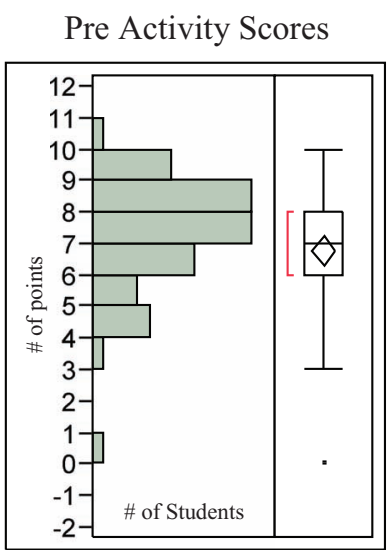

$\mathrm{M}=68 \%$
Post Activity Scores

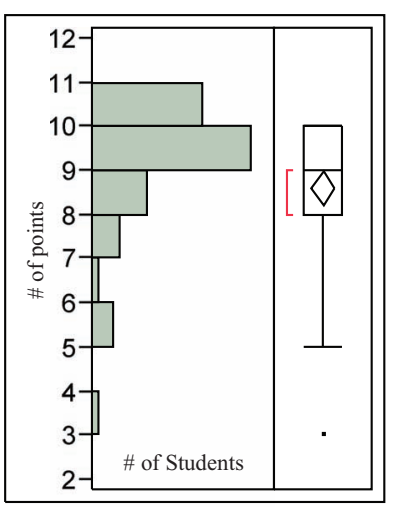

$\mathrm{M}=86 \%$
Figure 4. Differences in pre and post distributions for girls grades 6 through 8 . Highest score possible is 10 out of 10 points. Diamond indicates student mean $(n=116)$. After playing the game, girls scored significantly higher on the knowledge test, with the mean score increasing from $68 \%$ to $86 \%$. narratives with heroes and villains. In this study, we demonstrated one way that the strategic use of this commonly used frame can enable science educators to work within melodrama by recasting what is constituted as good and evil or villainous and heroic. The enjoyment and significant knowledge gains of student players suggest that The Adventures of Carbon Bond ${ }^{\odot}$ has the potential to reframe the issue of climate change to villianize GHGs and make heroes out of people (the students in this case) who combat these emissions.

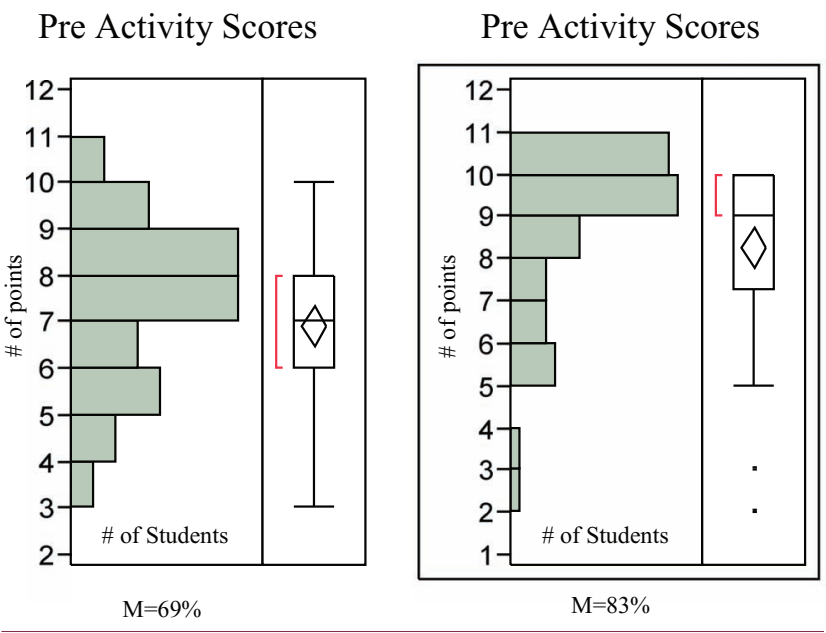

Figure 5. Differences in pre and post distributions of boys grades 6 through 8 . Highest score possible is 10 out of 10 points. Diamond indicates student mean $(n=116)$. After playing the game, boys scored significantly higher on the knowledge test, with the mean score increasing from $69 \%$ to $83 \%$. 
Though the knowledge gain and enjoyment of game players is a strong demonstration of the value of reframing the melodrama of climate change through game play, it did not fully address the potential value of recasting the melodramatic frame through video gaming. We recommend more extensive research, including: (i) interviews and focus groups with students and teachers to explore changes in perspective toward climate change action attributed to game play; and (ii) the addition of more study participants to the current dataset to further explore the significance of sex differences noted above.

In conclusion, we found that game play freed players from the ideological tensions that surround climate change in US society, and that prevent engagement with climate change mitigation. Youth are both aware of and deeply embedded in the conflicting claims made by the adults in their lives; they also can be powerful ambassadors for science and technology. ${ }^{21}$ Because The Adventures of Carbon Bond ${ }^{\odot}$ is clearly a game, it invited students to play with an issue that is fraught with conflict. Once they began playing, they learned how climate change connects to basic science, and were able to explore CCS as a potential technology for working through the contemporary challenge of anthropogenic climate change. Although we recognize that important differences in preferences for individual climate change mitigation technologies remain, reframing all humans (i.e. energy producers and consumers, environmentalists, consumer advocates) as the 'good guys' is an important step toward involving non-scientists in a positive exploration of policy options designed to mitigate climate change.

\section{Acknowledgements}

We would like to thank Susan DePerno, Nicole Schero and Larry Feldpausch for their efforts in recruiting students and organizing classroom testing, and Adrienne Strubb and Michael Liles for their assistance with data preparation and analysis. Research Sponsor: Southwestern United States Carbon Sequestration Training Center. Finally, we would like to thank the participating schools for their time, effort and generosity in testing the game.

\section{References}

1. Burke K, Attitudes toward History, 3rd edn. University of California Press, Berkeley (1937).
2. Kinsella WJ, Bsumek PK, Walker GB, Check T, Peterson TR, and Schwarze S, Narratives, rhetorical genres, and environmental conflict: responses to Schwarze's 'Environmental Melodrama'. Environ Commun 2(1):78-109 (2008).

3. Schwarze S, Environmental melodrama. Quart J Speech 92:239-261 (2006).

4. Anker E, Villains, victims, and heroes: Melodrama, media, and September 11. J Commun 55(1):22-37 (2005).

5. Desilet G, Nietzsche contra Burke: The melodrama in dramatism. Quart J Speech. 75:65-83 (1989).

6. Osborn $\mathrm{M}$ and Bakke J, The melodramas of Memphis: Contending narratives during the Sanitation Strike of 1968. Southern Commun J 63:220-234 (1998).

7. Wynne B, Public uptake of science: A case for institutional reflexivity. Public Underst Sci 2:321-337 (1993).

8. Hornig Priest S, Misplaced faith: Communication variables as predictors of encouragement for biotechnology development. Sci Commun 23(2):97-110 (2001).

9. Kahlor $L$ and Rosenthal S, If we seek, do we learn? Sci Commun 30(3):380-414 (2009).

10. Ockwell D, Whitmarsh L and O'Neill S, Reorienting climate change communication for effective mitigation forcing people to be green or fostering grass-roots engagement? Sci Commun 30(3):305-327 (2009).

11. Bogost I, Video games and ideological frames. Pop Commun 4(3):165-183 (2006).

12. Bogost I, Persuasive Games: The Expressive Power of Video Games. MIT Press, Cambridge (2007a).

13. Bogost I, The rhetoric of video games, in The Ecology of Games: Connecting Youth, Games, and Learning, ed by Salen K. The John D and Catherine T MacArthur Foundation Series on Digital Media and Learning, MIT Press, Cambridge, pp. 117-140 (2008).

14. Gee JP, Stories, probes, and games. Narrat Inq 21(2):353357 (2011).

15. Konzack L, Rhetorics of computer and video game research, in The Players' Realm: Studies on the Culture of Video Games and Gaming, ed by Williams JP and Smith JH. McFarland \& Company Inc, Jefferson, pp. 110-130 (2007).

16. Pötzsch H, Borders, barriers and grievable lives: The discursive production of self and other in film and other audio-visual media. NORDICOM Rev 32(2):75-94 (2011).

17. Chang AY, Games as environmental texts. Qui Parle 19(2):5784 (2011).

18. Feldpausch-Parker AM, Communicating Carbon Capture and Storage Technologies: Opportunities and Constraints Across Media. Doctoral dissertation, Texas A\&M University, College Station, TX (2010).

19. Johnsson $\mathrm{F}$, Perspectives on $\mathrm{CO}_{2}$ capture and storage. Greenhouse Gas Sci Technol 1(2):119-133 (2011).

20. Moutenet JP, Bedard $\mathrm{K}$ and Malo M, Public awareness and opinion on CCS in the province of Québec, Canada. Greenhouse Gas Sci Technol 2(2):126-135 (2012).

21. Van Der Zee B, Pester power: More and more schoolchildren are promoting the green message - including badgering parents about turning off lights and shunning cheap holiday flights.[Online] (2007). Guardian Online. Available at: http:// www.guardian.co.uk/environment/2007/feb/01/schools. ethicalliving [July 3, 2012]. 


\section{APPENDIX D}

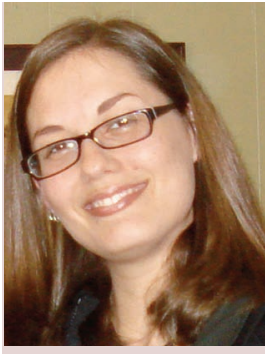

Andrea M. Feldpausch-Parker

Andrea Feldpausch-Parker, $\mathrm{PhD}$, is an Assistant Professor in the Department of Environmental Studies at the SUNY College of Environmental Science and Forestry. Her research focus is on environmental communication and public participation in environmental decision-making. She has six years of experience working on public outreach and social science research on carbon capture and storage technologies. She received two BSc degrees in Zoology and Fisheries and Wildlife from Michigan State University, and holds an MS and PhD in Wildlife and Fisheries Sciences from Texas A\&M University with a focus on environmental education and communication.

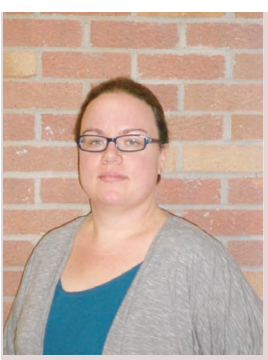

\section{Megan O'Byrne}

Megan O'Byrne, MA, is a Graduate Teaching Fellow and Doctoral Candidate at the University of Utah. Her dissertation research focuses on the rhetoric of an environmental social movement related to anti-oil drilling activism. She has two years of experience working on public outreach and social science research on carbon capture and storage technologies. She received BSc degrees in Organization Communication, Speech Communication, and History from the University of Nebraska at Kearney, and an MA in Communication from Bowling Green State University.

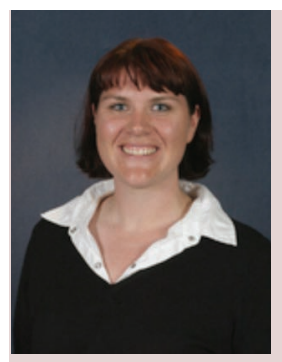

\section{Danielle Endres}

Danielle Endres, $\mathrm{PhD}$, is an Associate Professor of Communication, and an Environmental Humanities faculty member at the University of Utah. Her research focuses on the rhetoric of environmental controversies and social movements including nuclear waste siting decisions, climate change activism, and energy policy. She has three years of experience working on public outreach and social science research on carbon capture and storage technologies. She received a BA in History from the University of Oregon, an MA in Communication from San Diego State University, and a PhD in Communication from the University of Washington.

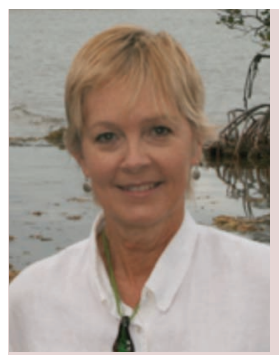

\section{Tarla Rai Peterson}

Tarla Rai Peterson, $\mathrm{PhD}$, is the Boone and Crocket Endowed Professor of Wildlife and Conservation Policy at Texas A\&M University, Guest Professor of Environmental Communication at Swedish University of Agricultural Sciences, and Adjunct Professor of Communication at the University of Utah. She studies intersections between communication, public policy, and democracy, with the goal of contributing to sustainable development. She has eight years of experience working on public outreach and social science research on carbon capture and storage technologies. She received a BA in History from the University of Idaho, and a MA in Speech Communication and PhD in Environmental Communication from Washington State University. 
APPENDIX E: REVIEW OF STATE CURRICULA

\title{
U.S. Southwest Carbon Sequestration Training Center State Specific Curriculum (Task 3.2)
}

\section{Western States' Science Standards Summary: \\ Where does CCS Education Fit?}

May 2010

\author{
Samantha Senda-Cook \\ In collaboration with \\ Danielle Endres \\ Andrea Feldpausch-Parker \\ Tarla Rai Peterson
}


After reviewing the science standards for eight Western U.S. states, it is clear that states prescribe similar core standards, want students to build knowledge in these core areas year after year, and provide contexts in which education about carbon sequestration or carbon capture and storage (CCS) would make sense.

These states have similar core areas that revolve around six specific areas of knowledge they want students to gain by learning about science. I have used Arizona's six standards here because they are illustrative of the general trend. They are: (1) inquiry process, (2) history and nature of science, (3) science in personal and social perspectives, (4) life science, (5) physical science, and (6) Earth and space science. The inquiry process standard encourages students to learn how to observe, ask questions, record data, communicate findings, and judge scientific knowledge. In learning about the history and nature of science, students are asked to see science as a human endeavor and understand how scientific knowledge is built upon itself to form increasingly complicated theories about our world. Science in personal and social perspectives teaches students that science impacts and is impacted by humans and asks students to evaluate technologies that have come into common use or decide what technologies might be useful in the future. Life science focuses on biological characteristics of, cycles of, and interactions among organisms. In the physical science standard, students must demonstrate understanding of the properties and motion of different materials. Finally, Earth and space science examines cycles and systems that exist on and around Earth.

In learning about these standards, students are supposed to be prepared for life, in general. Most states seek to cultivate a sense of curiosity among students and give them the tools with which they can asses scientific claims in the future. According to Utah's standards, "the ultimate goal" is to make "science instruction as thrilling an experience for a child as seeing a rainbow, growing a flower, or holding a toad" (4). It continues, "Science is not just for those who have traditionally succeeded in the subject, and it is not just for those who will choose science-related careers. In a world of rapidly expanding knowledge and technology, all students must gain the skills they will need to understand and 
function responsibly and successfully in the world" (4). Science education in these states is designed to build knowledge by revisiting these core areas year after year.

CCS information not only fits into the overarching goals of science education in the Western states, it also has a place in specific science units. The most common areas are in units about weather, global climate, energy, technology, and cycles.

\section{Weather}

Students learn about weather to better understand cycles, patterns, processes of recording and communicating data, local natural history, and different physical features (e.g., Sun, moon, bodies of water, mountains). Such lessons would correspond well with education about carbon sequestration. For example, in Arizona, students are required to "Create a weather system model that includes: the Sun, the atmosphere, [and] bodies of water" in sixth grade (99). This would be good place to help students understand the relationships between different factors that affect weather and how introducing some more of a particular element, like carbon dioxide, can shape the kind of weather that happens. By high school, students in Arizona must be able to "Explain the effect of heat transfer on climate and weather" (150).

In Colorado, high school students develop their knowledge of atmospheric processes. They must also comprehend how weather affects people and the different forces that affect weather. The curriculum standard mentions "proximity to oceans, prevailing winds, fossil fuel burning, volcanic eruptions" as examples of factors that should be discussed (emphasis added, 23). This standard opens the door for information about the problem of increasing levels of carbon dioxide.

In many states, students begin to learn about weather patterns as early as first grade. For example, Oklahoma requires students to record weather patterns that change from day-to-day and seasonally in first grade. In Texas, students begin to record weather patterns in kindergarten. From there, students in first and second grades study how weather patterns affect humans (but not the other way around). Utah and Wyoming provide a similar base throughout their elementary education, but extends weather-related concepts among high school students to develop stronger connections between 
solar energy, oceanic currents, and weather systems. Although these places that discuss weather in general terms are not ideal arenas to learn about techniques of CCS, they do offer a good base for understanding environmental problems associated with carbon dioxide. In later grades, most of the states encourage a shift from learning about weather to learning about climate.

\section{Global Climate}

While "weather" refers to local, daily temperatures and levels of precipitation, humidity, and barometric pressure, "climate" describes regional, continental, and global patterns of weather change. It is when students transition from learning about weather to learning about climate that information about CCS becomes especially relevant because carbon dioxide is connected with global climate change. Framing CCS as a solution for this problem makes it relevant not only in the classroom but also in students' lives. Some states such as Arizona, New Mexico, Nevada, and Utah mention climate change or the greenhouse effect as specific units of study. This usually comes under the purview of weather, but I thought it would be useful to identify the states that already have such messages built into their curriculum as opposed to ones that have not incorporated such information. However, some, such as Arizona, categorize climate change as a natural phenomenon. Although this might seem to undermine the possibility of incorporating information about CCS (i.e., if this is natural, we need not "solve" it), schools could still discuss CCS as a means of coping with it regardless of the source. In other words, as long as schools make the connection between carbon dioxide and global climate change or the greenhouse effect and frame climate change or the greenhouse effect as a problem, education about CCS remains a viable subject.

Educators include the units about the greenhouse effect in a few different strands; some focus explicitly on humans' relationships with the natural world and others on physical systems (e.g., weather). Arizona requires students in eight grade to, "Analyze the risk factors associated with natural, human induced, and/or biological hazards, including: waste disposal of industrial chemicals [and] greenhouse gases" (81). In analyzing potential solutions to this problem, students could learn about CCS. Students in Utah must learn to model global warming and the greenhouse effect in eight grade. To 
conclude, not all of the Western states include information about global climate change, global warming, or the greenhouse effect. But in most, education about CCS is a logical fit.

\section{Energy}

Part of what makes learning about weather and global climate important is that these phenomena enable students to see processes that typically go unobserved. One such example is energy transfer. Carbon dioxide is a problem, in part, because it traps air heated by the sun in the Earth's atmosphere. Therefore, when educators introduce concepts of energy transfer and effects, they could make a connection to atmospheric systems. Utah's curriculum standards outline this very connection. It states:

The sun is the major source of Earth's energy. Some of the solar radiation that reaches Earth is reflected, but most is absorbed. Gases in the atmosphere trap some of the heat energy and delay its radiation into space. This greenhouse effect retains energy longer in the Earth system (19). Additionally, in New Mexico, between fifth and eight grade, students must learn how energy use impacts humans and other life systems. This creates a perfect space to discuss global warming, which is explicitly mentioned in the description of this unit. However, this approach would not work similarly in all discussions of energy. For example, in the sixth grade in Arizona, science teachers must teach about energy

transfer but in the context of electrical energy. This would not have the same opportunity to connect to CCS as other lectures about energy would.

\section{Technology}

Lessons about technology ask students to think about how scientific technological advancements have changed humans' lives as well as systems across the Earth. They also require students to learn about technological solutions to scientific problems. Because CCS is a technological solution to a problem exacerbated by technology, this thread creates a great opportunity to introduce CCS concepts. In Colorado, students in grades five through eight must describe how technology helps solve problems. The description of this thread provides catalytic converters in automobiles as an example of technology that assuaged air pollution. CCS could also be introduced as such a technology. Additionally, several states-Utah and Wyoming, in particular-state that having students understand technology in an increasingly technological 
world is a primary goal. In their characterization, public school is a means of preparing students for situations in which technological knowledge is necessary for daily life. Given such a goal, providing information about CCS to students in this context would be helpful for future decision making.

\section{Cycles}

Lastly, even when the curriculum standards of a state make no explicit mention of global warming or related areas that would offer a good home for information about CCS, education about cycles presents possibilities. For example, Texas's delineation of goals for students does not create much space for discussions about CCS. However, it requires students to observe and describe the cycles of different elements. Carbon is one such element whose cycle must be learned. Thinking about the different stages that carbon goes through enhances students' knowledge about relationships among soil, animals, water, and air. Additionally, it could be a good place to introduce ideas about over-saturation and carbon as well as how to capture and store carbon to solve such problems.

In conclusion, the curriculum science standards set forth by U.S. Western States present opportunities to discuss CCS. Although none currently address this technology, all have units and threads that would be appropriately enhanced by information about this. Students should be given information about this potential solution to climate change as well as the tools with which they may assess its viability.

In other words, material about CCS need not be promotional; rather it should be treated as another means to better understand scientific processes that affect our daily lives. 


\section{Sources}

Arizona Department of Education. "Arizona Academic Standards.” State of Arizona. August 1, 2007.

Colorado Science Educators. "Model Content Standards: Science.” State of Colorado. November 9, 1995.

Nevada Department of Education. "Nevada Science Standards." State of Nevada. March 20, 2004.

New Mexico State Department of Education. "New Mexico Science Content Standards. Benchmarks, and Performance Standards.” State of New Mexico. 2003.

Random House Webster's Unabridged Dictionary, $2^{\text {nd }}$ ed. s.v. "weather" and "climate." “Texas Essential Knowledge and Skills.” State of Texas, n.d.

Utah State Office of Education. "Core Curriculum: Science.” March, 2002.

"Wyoming Science Academic Content Standards." State of Wyoming. n.d. 


\title{
APPENDIX F: REVISED STATE CURRICULA REPORT
}

\author{
U.S. Southwest Carbon Sequestration Training Center \\ State Specific Curriculum (Task 3.2)
}

The Role of The Adventures of Carbon Bond $\odot$ in State Curricula

November 1, 2012

Megan O’Byrne

Danielle Endres

Andrea Feldpausch-Parker

Tarla Rai Peterson 
Two significant findings from tests of the Carbon Bond game impact our recommendations regarding implementation of the game in curriculum across the Intermountain West. First, teachers found that the game was best implemented as a way to introduce, complement, or reinforce curricular goals. Given the design and content of the game, teachers preferred to use it as a way to underpin lessons already underway, rather than as a standalone learning tool. Second, the game was widely reported as being best received among late elementary and middle school students; roughly grades five through eight. That finding was expected as the game was initially designed for these students. When tested among older students the game was found to be too "juvenile". Therefore, we are not recommending that the game be used among high school students even when it seems to be a good curricular fit. We find that deploying the game early on as a reinforcement technique is more productive than attempting to force the game on older students who may find it to be less interesting.

In what follows we make recommendations for the best potential implementations of Carbon Bond in the Intermountain West. We make these recommendations based on the above criteria as well as on a thorough review of the expressed curricula on a state-by-state basis. For purposes of this analysis the curricula were broken into subsections related to weather, global climate, energy, technology, and cycles. These subsections represent the most common types of science units found in the Western states. Specific curricular goals were then fitted into these subsections and used as appropriate for the following recommendations.

\section{Arizona}

We recommend that Carbon Bond be implemented in sixth grade science classrooms in the state of Arizona. The game best complements learning objectives in the categories of global climate, energy, and technology. In the area of global climate it reinforces the ability to assess 
how natural phenomenon affect climate. In the area of energy the game reminds students how energy is transferred and stored as well as how energy is generated in both renewable and nonrenewable resources. Finally, with regard to technology it reinforces the notion that technology can provide a solution to problems.

\section{Colorado}

Based on content, the best curricular fit in Colorado is in high school when issues of the potential impact of burning fossil fuels are mostly likely to be discussed in regard to weather and global climate. Also in this grade range students are most likely to be exposed to the impacts of greenhouse gases while learning about energy and technology and also in regard to understanding the cause and effect relationship in historical cycles. However, given what we have learned in testing Carbon Bond, we know that the game is best utilized in late elementary and middle school classrooms. We recommend that despite the apparent best curricular fit in high school, Carbon Bond should be incorporated into the 5-8 grades in Colorado. In those grades we believe Carbon Bond complements curriculum on: weather patterns, cycles, and changes; advantages and disadvantages of new technologies and how those technologies can be used to solve problems; and in identifying and illustrating natural cycles in global climate.

\section{Nevada}

Carbon Bond best fits curriculum for the state of Nevada in grades 6-8. In those grades the game complements stated curricular goals in the areas of weather, global climate, energy and technology. In weather and global climate Carbon Bond can help to reinforce the relationship between atmosphere, topography, weather, and climate and also illustrate the ways in which the composition of the Earth's atmosphere impacts weather and climate. In regard to energy, Carbon Bond reinforces the concept that heat is a result of chemical, physical, or nuclear energy 
transfers. Finally, and significantly, Carbon Bond reinforces all of the stated curricular goals in regard to technology. It addresses the safe use of technology, the notion that technology can deplete resources and degrade the environment and the counterpoint that technology can increase resources, mitigate damage to the environment, and make new resources economical.

\section{New Mexico}

The best curricular fit for Carbon Bond in the state of New Mexico is in grade eight. In the stated curriculum for eighth graders Carbon Bond complements global climate in addressing how energy flow (e.g., "global climate change") can impact ecosystems. The game also clearly fits the energy curriculum in regard to the impact technological innovations have had on societies and in the impetus to analyze the risks and benefits of technologies associated with energy production. In regard to technology curricula, the game also helps reinforce the goal of analyzing relationships between science and technology. The final area of best fit in the eighth grade curriculum is in describing how matter moves through ecosystems - as in the carbon cycle.

Another potential area of fit is in the seventh grade curriculum. We recommend implementing the game at this earlier point in the students' career as a method of reinforcing two major learning objectives. The first, in regard to energy, is in understanding the effects of humans' use of energy in living systems as in relationship to global warming. The second learning objective is in explaining how matter is transferred from one organism to another or its environment, again as in the carbon cycle.

\section{Oklahoma}

We recommend implementing the game in the seventh grade curriculum in Oklahoma. The game best fits the learning objectives in this grade in the following ways. First, it addresses 
the ways in which global patterns can impact both climate and local weather and second, it reinforces the potential use of technology as a means to gather and analyze data.

\section{Texas}

Carbon Bond best fits the state of Texas curriculum for grade eight. It complements goals in lessons addressing weather, energy, and cycles. It reinforces learning about weather systems, describing matter as consisting of atoms and understanding chemical reactions produce or absorb heat energy. It further aids in analyzing how natural or human events may have contributed to the extinction of some species and also how human activities have modified soil, water, and air quality.

\section{Utah}

In Utah we recommend the use of Carbon Bond in the eighth grade. There are three main areas of curricular overlap including energy, technology, and cycles. In the area of energy, Carbon Bond reinforces the notion that the greenhouse effect causes the atmosphere to retain heat longer than usual and can help students understand concepts related to modeling the flow of energy in ecosystems. Carbon Bond also addresses both of the major curricular goals in relation to technology. First, it can help students understand that technology raises ethical issues. Second, it reinforces the idea that technology and science can be used to solve social, ethical, and ecological problems. In the area of cycles, Carbon Bond can help students describe how matter in the atmosphere cycles through other Earth systems. Related to this content area, the game can also assist students in interpreting evidence suggesting that humans are influencing the carbon cycle as well as comparing the rate at which $\mathrm{CO} 2$ is put into the atmosphere to the rate at which it is removed through the carbon cycle.

\section{Wyoming}


While the best curricular fit for the content of Carbon Bond in the state of Wyoming is in grades 9-12 we recommend implementing it earlier based on the initial criteria we set forth. In the early grades the game best fits with learning goals around energy. It could allow students to investigate the various forms and uses of energy as well as to gather evidence to show that amounts of matter and energy remain constant. If used appropriately at these earlier grade levels to buttress learning in the area of energy we also feel that the game could serve as pre-learning for the energy content of later grades including the role of energy in global climate. 


\section{APPENDIX G \\ TRENDS Training Center Education and Training Survey Data Report}

March 2012

\section{Increase in Knowledge about CCS}

Participants reported that participation in classes and webinars offered by Southwest CCS TREND led to increased knowledge about CCS. During the past two years, the center has offered undergraduate classes, graduate classes, and webinars for industry professionals. Prior to training, students and webinar participants were asked to rate their knowledge of topics related to climate change, CCS technologies, and Best Practices for CCS Project Implementation. Following training, participants again rated their knowledge of these topics. Across all forms of training, participants reported a significant increase in knowledge of these topics.

The average increase in knowledge was greater for students who participated in semester-length classes than for webinar participants. In one of the classes, only natural science topics were covered. After finishing the class, students actually reported that they were less knowledgeable about social topics (including cultural, economic and political issues) related to CCS than prior to taking the class. This may indicate that, although the class did not cover social topics, taking the class increased student awareness that social dimensions are important to deployment of CCS projects.

\section{$\begin{array}{lll} & \text { Graduate } & \text { Teacher } 2011\end{array}$}

\begin{tabular}{|c|c|c|c|c|c|c|c|c|c|}
\hline & Pre & Post & Diff & Pre & Post & Diff & Pre & Post & Diff \\
\hline $\begin{array}{l}\text { How would you rate } \\
\text { your knowledge of } \\
\text { climate change } \\
\text { science? }\end{array}$ & 2.31 & 3.13 & 0.82 & 2.83 & 3.58 & 0.75 & 2 & 3 & 1 \\
\hline $\begin{array}{l}\text { How would you rate } \\
\text { your knowledge of the } \\
\text { social aspects of } \\
\text { climate change (i.e., } \\
\text { economic, political, } \\
\text { cultural)? }\end{array}$ & 2.31 & 3.38 & 1.07 & 3 & 3.75 & 0.75 & 2.67 & 3.5 & 0.83 \\
\hline $\begin{array}{l}\text { How would you rate } \\
\text { your knowledge of } \\
\text { scientific and } \\
\text { technical aspects of } \\
\text { CCS? }\end{array}$ & 2.15 & 3.13 & 0.98 & 2 & 3.75 & 1.75 & 1.33 & 1.5 & 0.17 \\
\hline $\begin{array}{l}\text { How would you rate } \\
\text { your knowledge of } \\
\text { social aspects (i.e., } \\
\text { economic, political, } \\
\text { cultural) of CCS? }\end{array}$ & 2.08 & 2.75 & 0.67 & 2.25 & 3.55 & 1.3 & 2.33 & 2 & -0.33 \\
\hline
\end{tabular}




\begin{tabular}{|c|c|c|c|}
\hline & \multicolumn{3}{|c|}{$\begin{array}{l}\text { Wade } \\
\text { Webinar }\end{array}$} \\
\hline & Pre & Post & Diff \\
\hline $\begin{array}{l}\text { Knowledge of carbon } \\
\text { sequestration } \\
\text { partnership outreach } \\
\text { activities in your } \\
\text { region }\end{array}$ & 3 & 3.2 & 0.2 \\
\hline $\begin{array}{l}\text { Knowledge of overall } \\
\text { carbon sequestration } \\
\text { partnership outreach } \\
\text { activities (all } \\
\text { partnerships) }\end{array}$ & 2.4 & 3.8 & 1.4 \\
\hline $\begin{array}{l}\text { Knowledge of pre- } \\
\text { project outreach } \\
\text { planning including } \\
\text { outreach integration } \\
\text { into project } \\
\text { management and } \\
\text { team development }\end{array}$ & 2.6 & 3.2 & 0.6 \\
\hline $\begin{array}{l}\text { Knowledge of social } \\
\text { characterization }\end{array}$ & 2.4 & 3.8 & 1.4 \\
\hline $\begin{array}{l}\text { Knowledge of } \\
\text { outreach strategy } \\
\text { development } \\
\text { including the } \\
\text { development of } \\
\text { targeted messages }\end{array}$ & 2.6 & 3.4 & 0.8 \\
\hline $\begin{array}{l}\text { Knowledge of the } \\
\text { process of } \\
\text { implementation, } \\
\text { assessment and } \\
\text { refinement to } \\
\text { outreach strategies }\end{array}$ & 2.6 & 3.2 & 0.6 \\
\hline & Almen & dra Web & inar \\
\hline & Pre & Post & Diff \\
\hline $\begin{array}{l}\text { Knowledge of } \\
\text { different stakeholder } \\
\text { groups that require } \\
\text { representation in a } \\
\text { CCS project }\end{array}$ & 4 & 4.5 & 0.5 \\
\hline
\end{tabular}




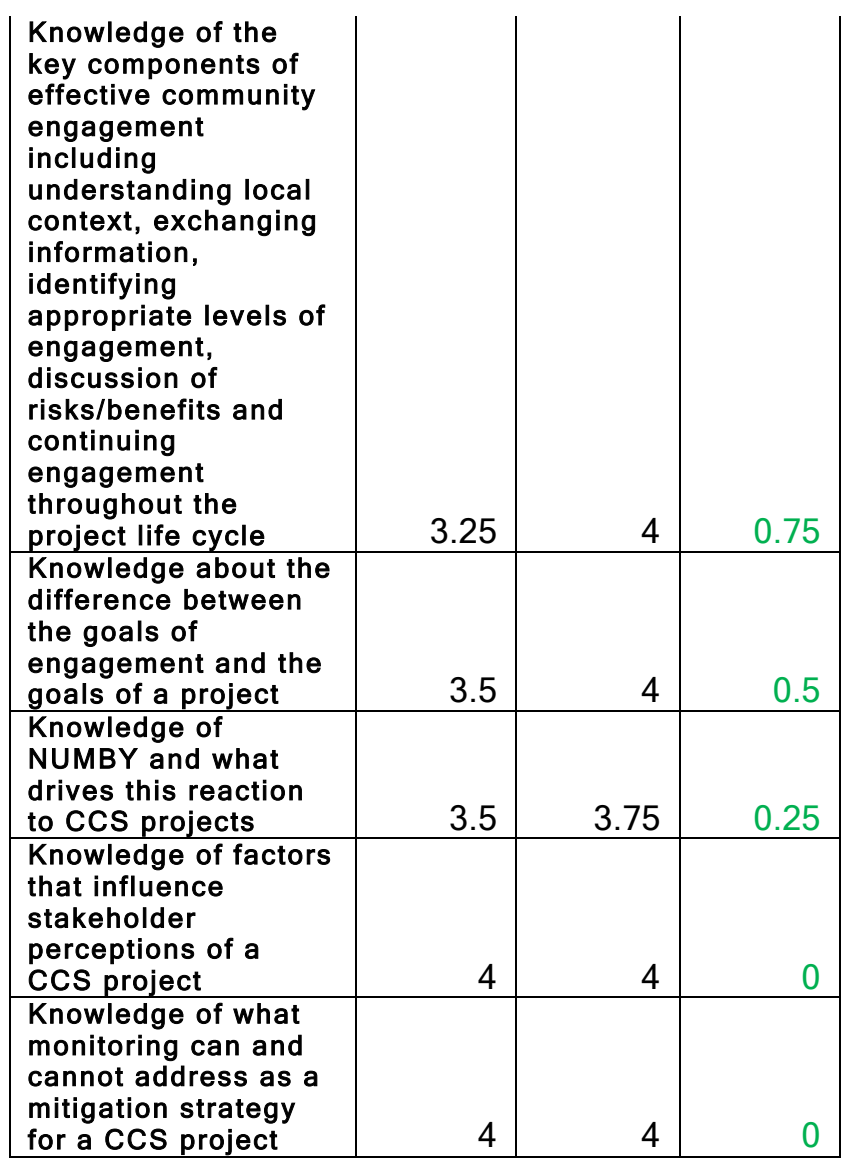

\section{Response to CCS Related Statements}

The charts you'll see below show how the survey respondents agreed, disagreed, or remained uncertain regarding a set of 11 statements per webinar/class.

\section{Statements}

1. We should learn more about geologic and terrestrial CCS - such as how much would it cost, and is it safe and effective - and support more research on this topic.

2. We should encourage landowners to increase the carbon stored in farmlands, forests and open spaces for terrestrial CCS.

3. We should not support geologic and terrestrial CCS because we need to make a major shift away from using emission-causing fuels such as oil, coal and gas. CCS will just delay that shift.

4. Both geologic and terrestrial CCS should be encouraged as part of a larger strategy that includes more renewable energy, higher energy efficiency and other types of energy sources.

5. We should encourage both geologic and terrestrial CCS because there is evidence to suggest that it will be difficult to transition away from our reliance on fossil fuels such as oil, gas and coal, and CCS provides a way we can keep carbon out of the atmosphere as much as possible during a transition. 
6. We should support efforts to test and develop geologic CCS because new technologies need to be tried before they can be adopted nationally.

7. We should support geologic CCS because it is an approach that the U.S. Dept. of Energy and oil /gas /power companies are seriously looking at.

8. We should support geologic and terrestrial CCS because they will aid in climate change mitigation.

9. We should support energy policies that will better enable the deployment of geologic and terrestrial CCS technologies.

10. An understanding of the science and technical aspects of CCS are the most relevant consideration for the deployment of such technologies for commercial use.

11. An understanding of the social aspects (i.e., economic, political, cultural) of CCS are the most relevant consideration for the deployment of such technologies for commercial use.

\section{Figures}

Respondents were asked to rate how well they agree or disagree with the above statements. The range of answers was: agree completely, somewhat agree, uncertain, somewhat disagree, and disagree completely. In order to simplify the figures, agree completely and somewhat agree were combined, as were somewhat disagree and disagree completely, giving three categories: agree, uncertain, and disagree. The numbers on the vertical axis represent the statements above. 


\section{Undergrad PRE}

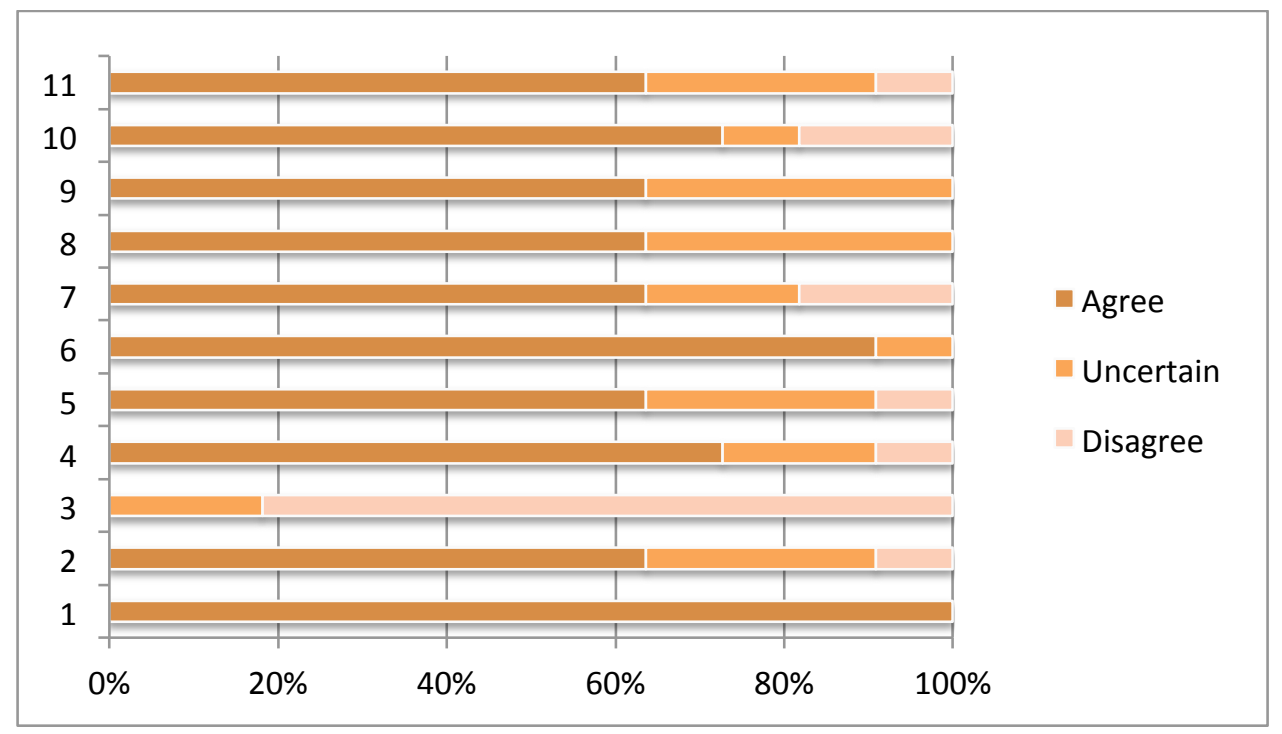

\section{Undergrad POST}

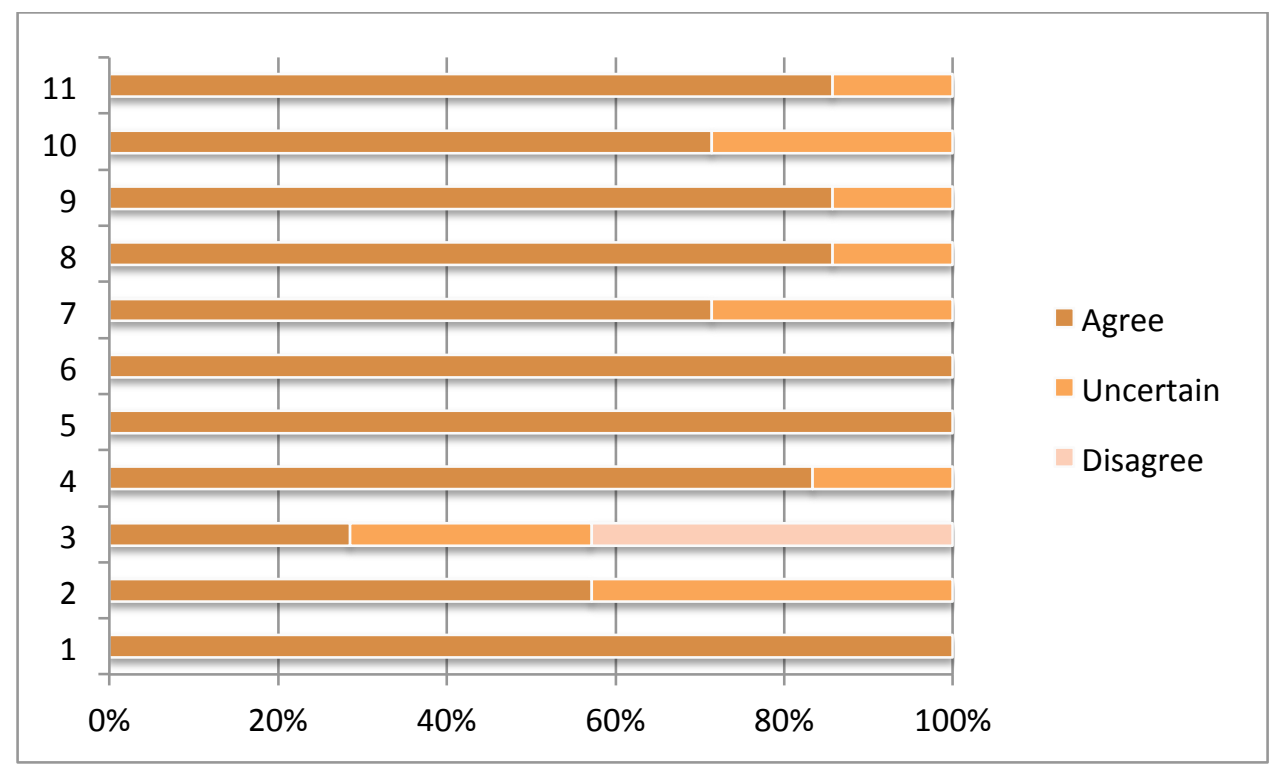

Notes: Only the Undergrad course and Teacher course had both a PRE and POST survey. 11 students participated in the PRE survey, whereas only 7 participated in the POST. 


\section{Graduate 2010}

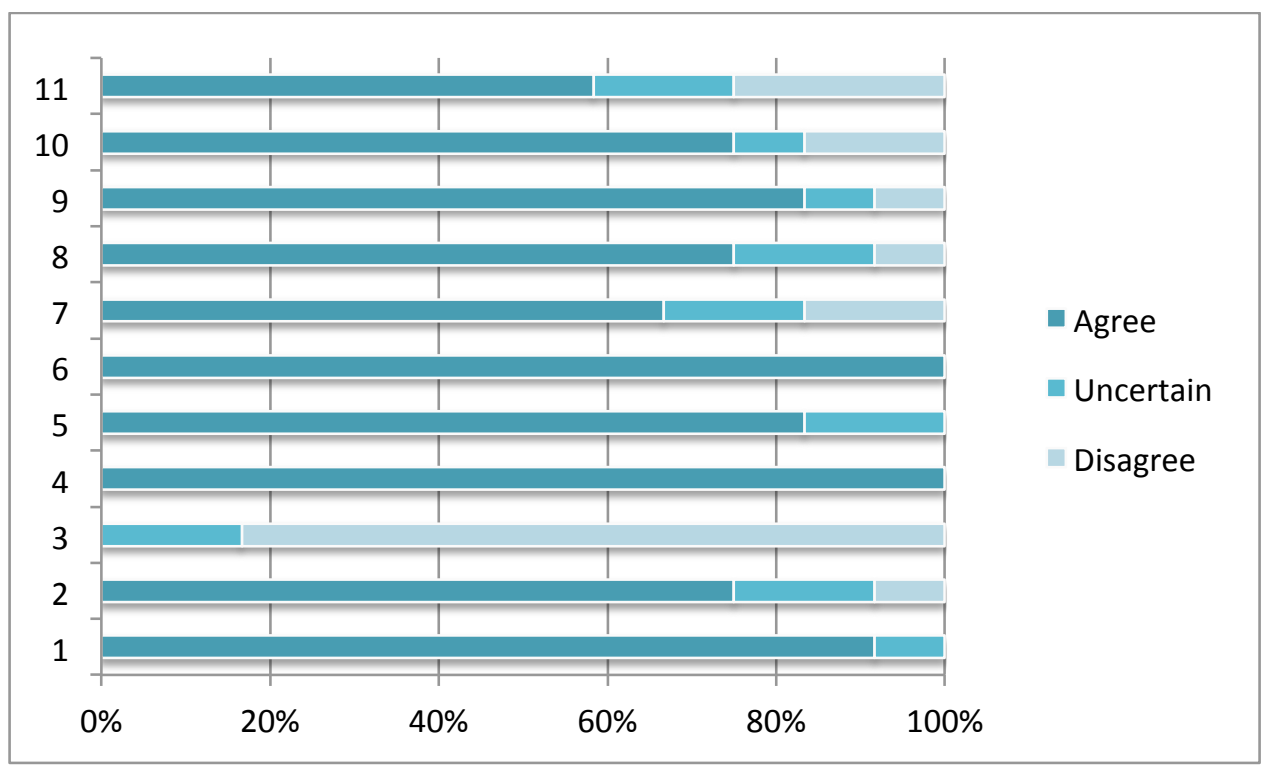

Note: There were a total of 12 respondents for this survey 


\section{Teacher 2011 PRE}

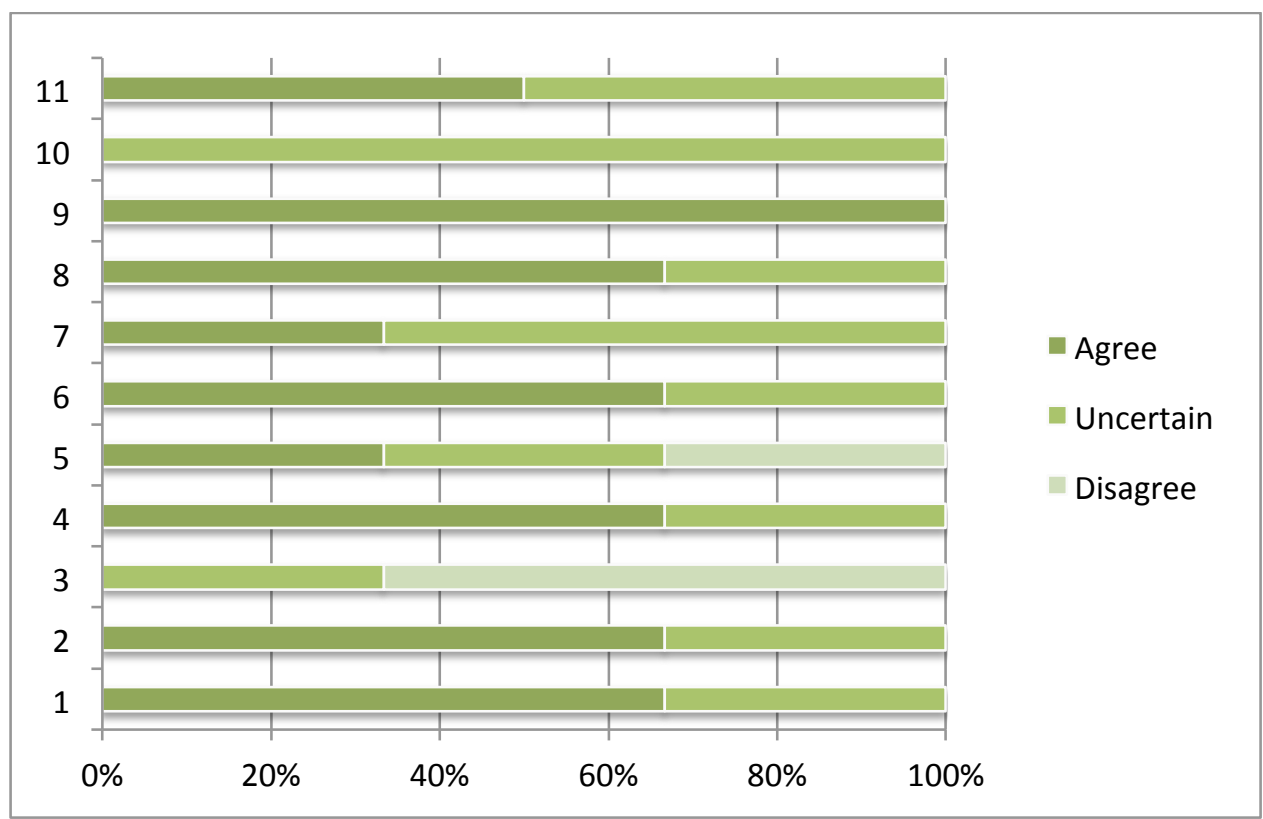

\section{Teacher 2011 POST}

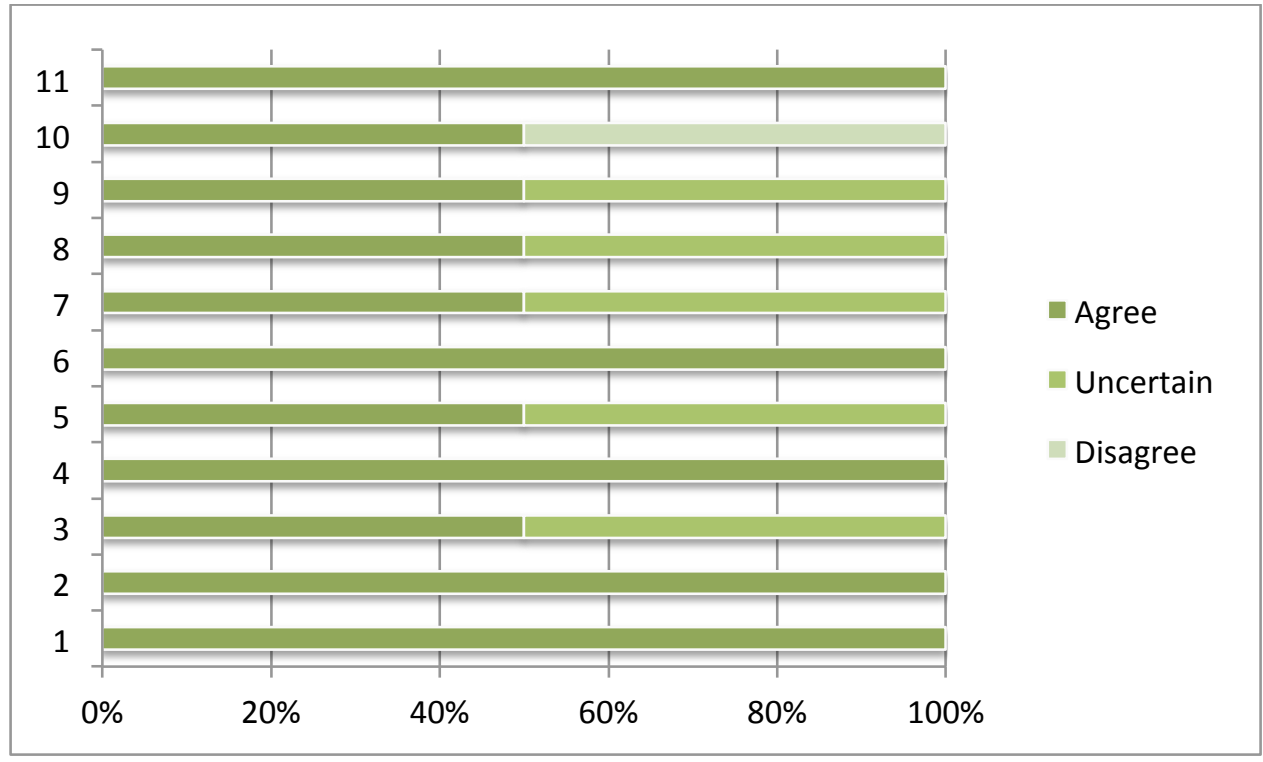

Note: This course had very limited respondents. 3 for PRE, and 2 in POST 


\section{Webinar WADE}

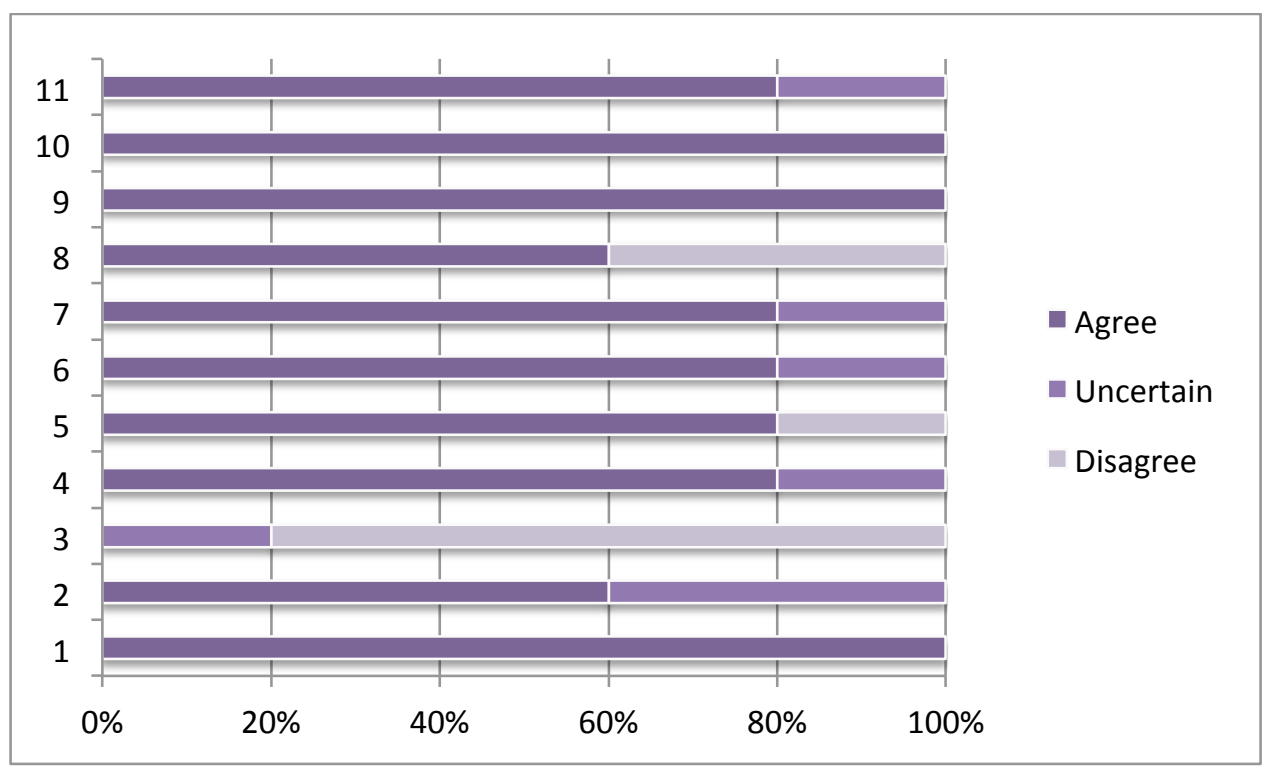

Note: The Wade webinar had 5 respondents. 


\section{Webinar ALMENDRA}

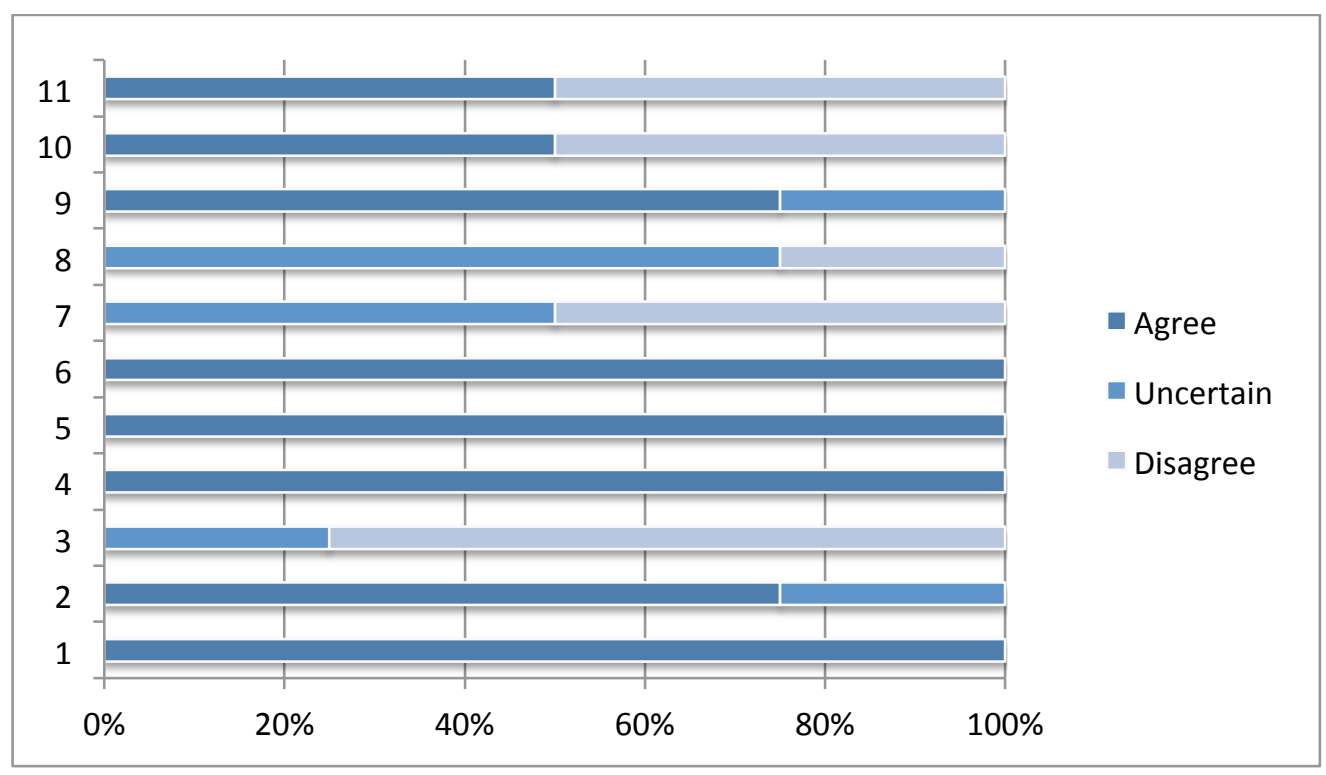

Note: The Almendra webinar had 4 respondents. 


\section{CCS Undergraduate Class Survey}

\section{Educational Background}

1. What is your highest completed level of education?
High School
$\bigcirc$ B.A.
$\bigcirc$ B.S.
M.A.
$\bigcirc$ M.s.
Pr.D.
Professional Degrees (e.g., D.D.S., D.V.M., M.D., J.D.)

2. What is your current department/major?

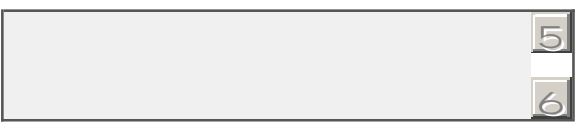

3. Please list any other courses you have taken that have addressed carbon capture and storage (CCS):

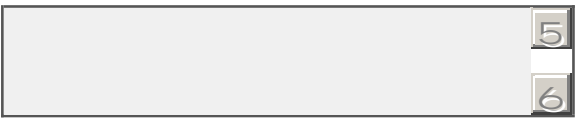

4. Please list any previous experience you have with CCS associated technologies:

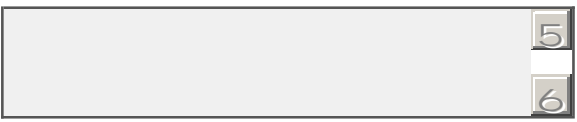




\section{CCS Undergraduate Class Survey}

\section{Course Related Information}

\section{Why did you enroll for this class?}

$\bigcirc$ Department requirement

Suggested by undergraduate advisor

$\bigcirc$ suggested by graduate advisor

Suggested by a professor

Interested in topic

Other (please specify)

2. What do you expect to learn from attending this class?

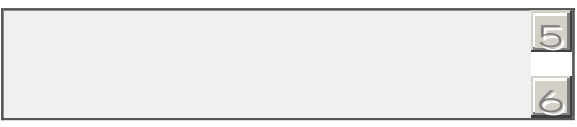

3. What are your career goals after you finish your degree? Please RANK your top 3 preferences:

Industry
International agency
Federal agency
organization
Politics
Primary or secondary
school (teach)
Private consulting firm
Univerearch laboratory
graduate student
University or college - staff
University or college -
faculty

Other (please specify) 


\section{CCS Undergraduate Class Survey}

4. Please RANK the top 5 classes you find most useful for your career goals (based on class syllabus):

Paleoclimate Record and the Great Climate Debate

1st preference

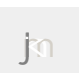

CO2 Capture Technology

Trapping Mechanisms and

Capture Technology

Literature

$\mathrm{P}$-Chem of $\mathrm{CO} 2$

Reservoirs/Seals

Seals and Rock Lab

CO2 Experiments

W/R Interactions

Modeling and Hele-Shaw

Demo

Modeling and Modeling

Software

Geomechanics

Societal Issues/Barriers

MVA and Societal Issue

Debate

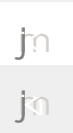

0

0

0

0

0

0

0

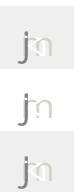

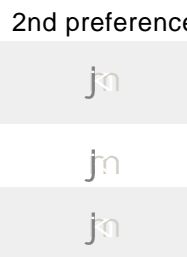

3rd preference
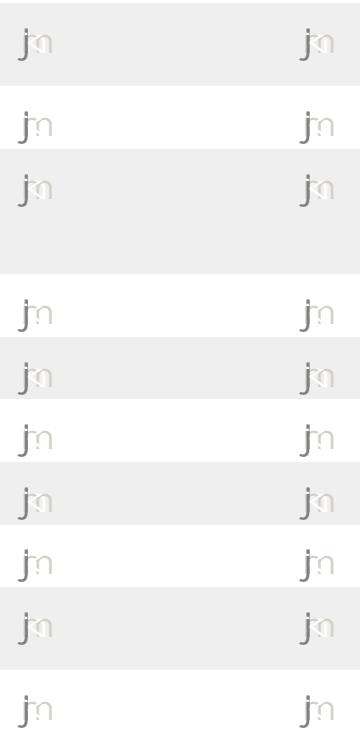

0

$\bigcirc$

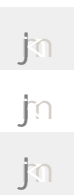

4th preference

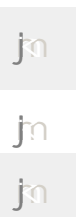

5th preference
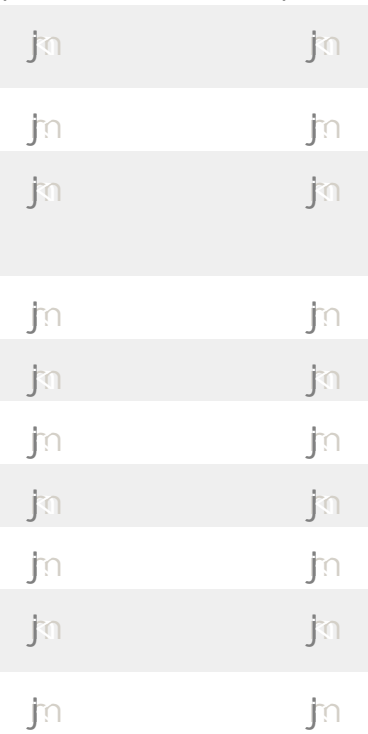

0
0

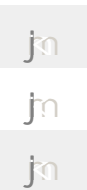

\section{Please RANK the top 5 classes you find most interesting in general (based on class} syllabus):

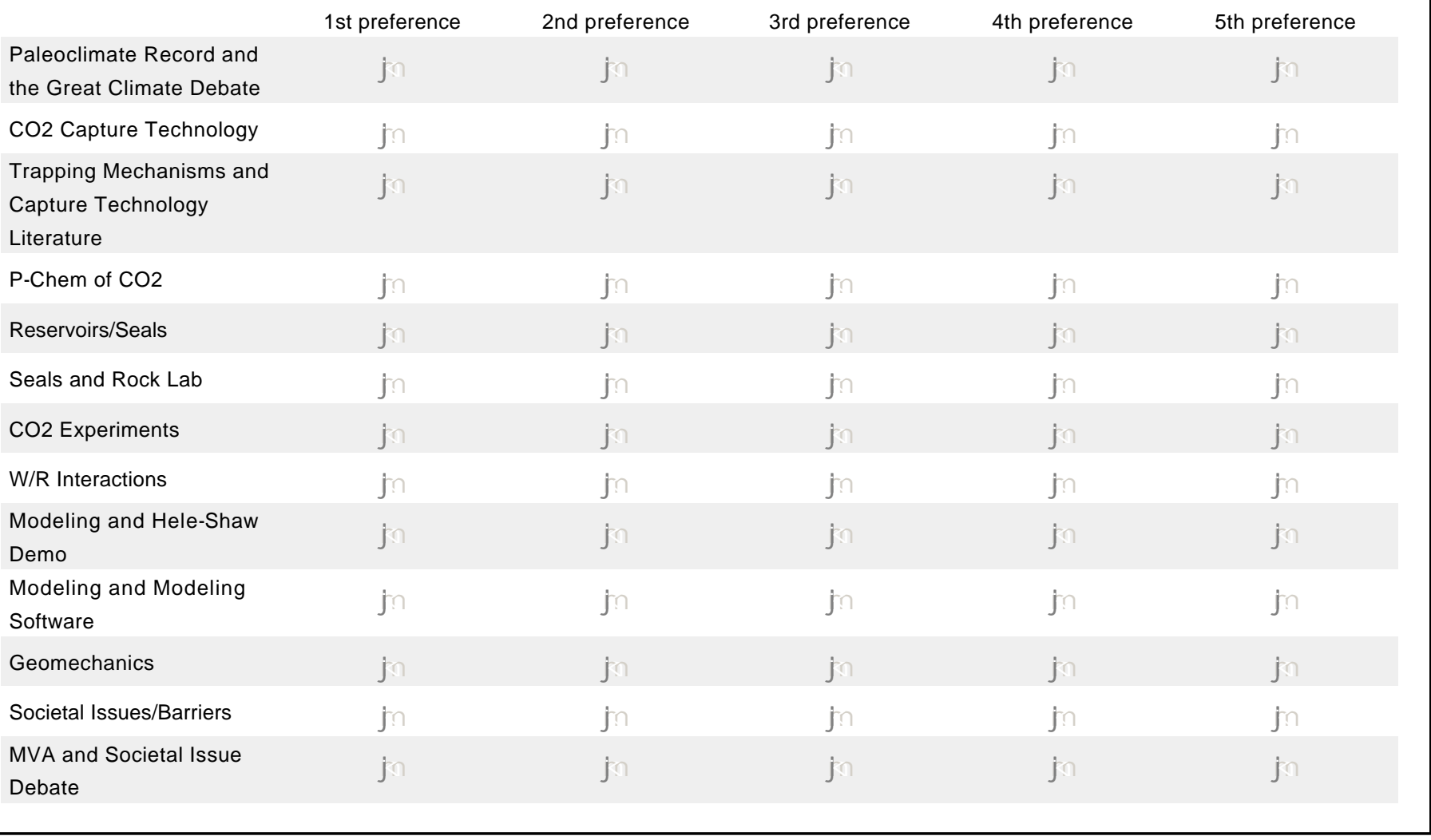




\section{CCS Undergraduate Class Survey}

\section{CCS Knowledge Questions}

1. Please explain your background knowledge on the scientific and technical issues of CCS:

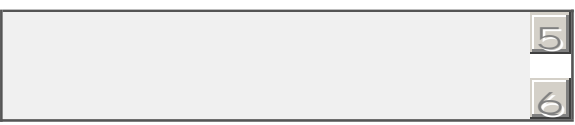

2. Please explain your background knowledge on the social aspects (economic, political, and cultural) of CCS:

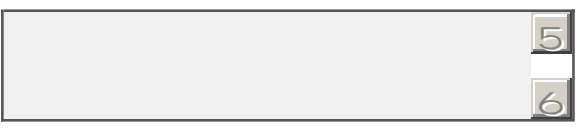

3. Please RATE your knowledge of CCS for the following questions on a scale of $\mathbf{1}$ to $\mathbf{5}$ with 1 being no knowledge and 5 being very knowledgeable (fill in one bubble per row):

How would you rate your

knowledge of climate

change science prior to this class?

How would you rate your knowledge of the social aspects of climate change (i.e., economic, political, cultural) prior to this class? How would you rate your knowledge of scientific and technical aspects of CCS prior to this class?

How would you rate your knowledge of social aspects

(i.e., economic, political, cultural) of CCS prior to this class?

Comments
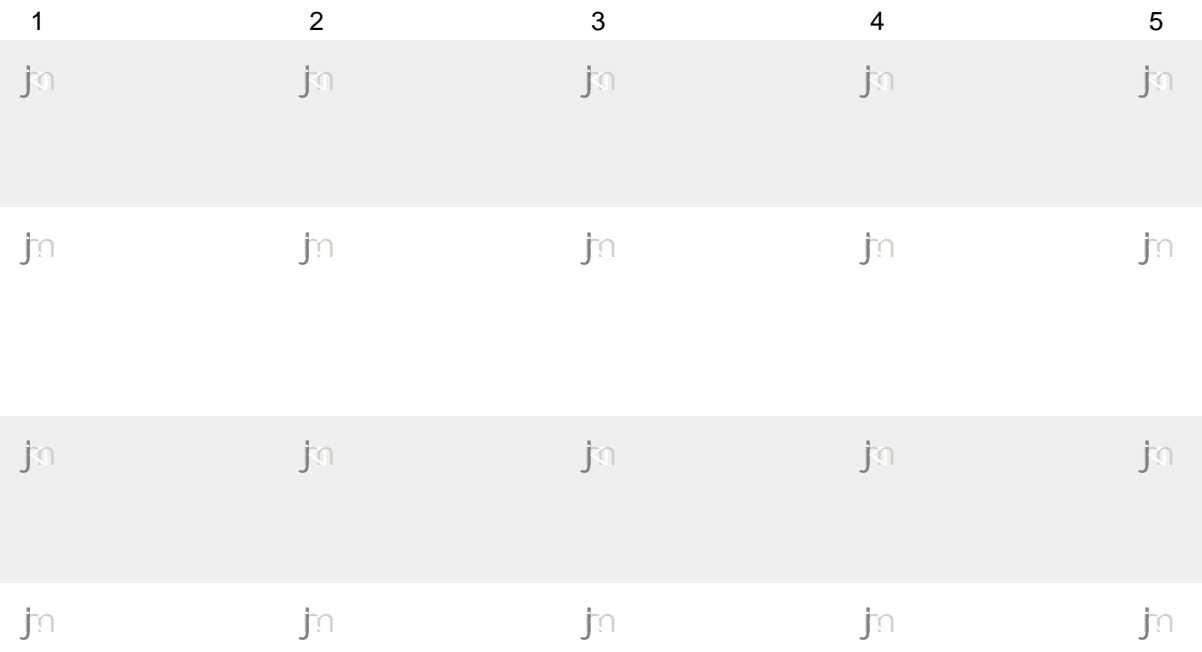

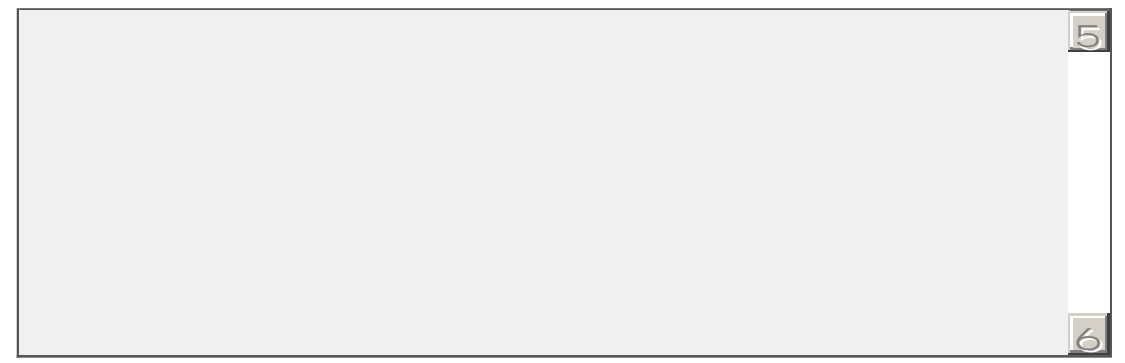




\section{Opinion Statements}

\section{Please RATE how well you agree or disagree with the following statements using the scale listed below (fill in one bubble per row):}

We should learn more about geologic and terrestrial CCS - such as how much would it cost, and is it safe and effective and support more research on this topic. We should encourage landowners to increase the carbon stored in farmlands, forests and open spaces for terrestrial CCS.

We should not support geologic and terrestrial CCS because we need to make a major shift away from using emissioncausing fuels such as oil, coal and gas. CCS will just delay that shift.

Both geologic and terrestrial CCS should be encouraged as part of a larger strategy that includes more renewable energy, higher energy efficiency and other types of energy sources.

We should encourage both geologic and terrestrial CCS because there is evidence to suggest that it will be difficult to transition away from our reliance on fossil fuels such as oil, gas and coal, and CCS provides a way we can keep carbon out of the atmosphere as much as possible during a transition.

We should support efforts to test and develop geologic CCS because new technologies need to be tried before they can be adopted nationally.

We should support geologic CCS because it is an approach that the U.S. Dept. of Energy and oil /gas /power companies are seriously looking at.

We should support geologic and terrestrial CCS because they will aid in climate change mitigation.

We should support energy policies that will better enable the deployment of geologic and terrestrial CCS technologies.

An understanding of the science and technical aspects of CCS are the most relevant consideration for the deployment of such technologies for commercial use. An understanding of the social aspects (i.e., economic, political, cultural) of CCS

Disagree

$\bigcirc$

Somewhat disagree
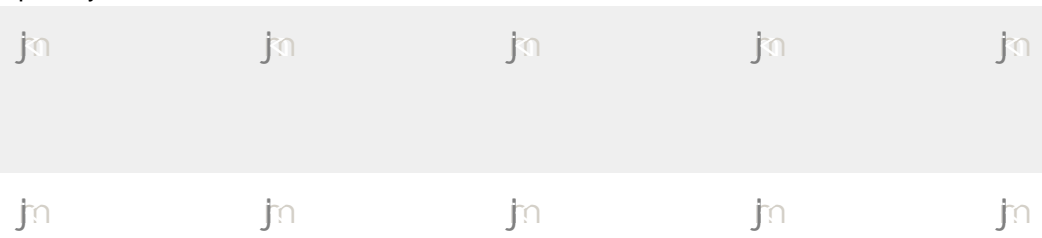

$\bigcirc$
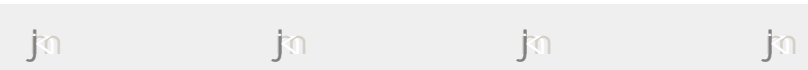

$\bigcirc$
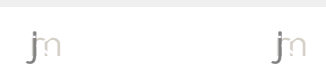

$\bigcirc$
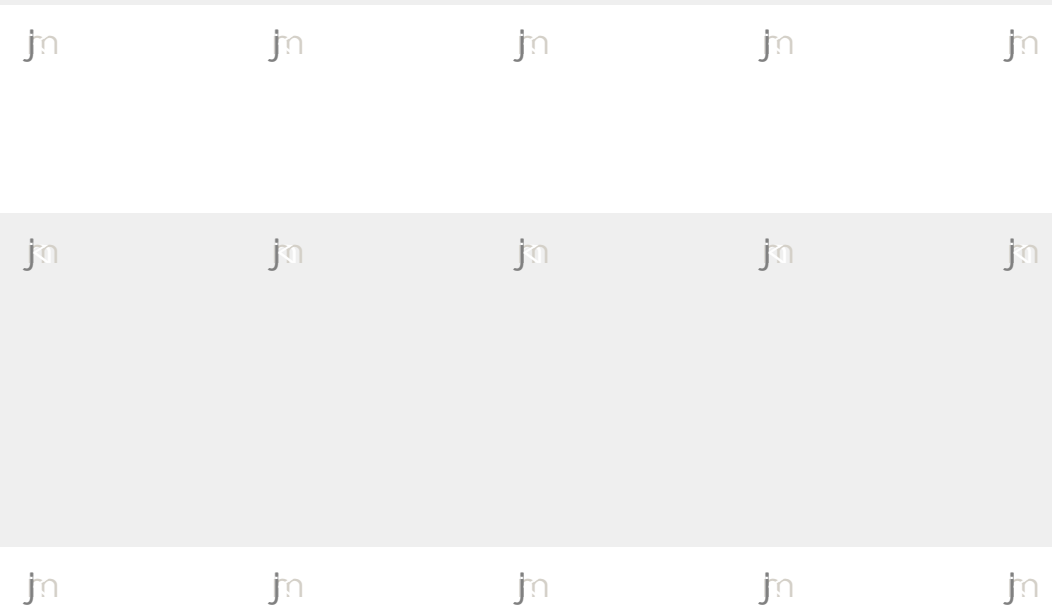

$\bigcirc$
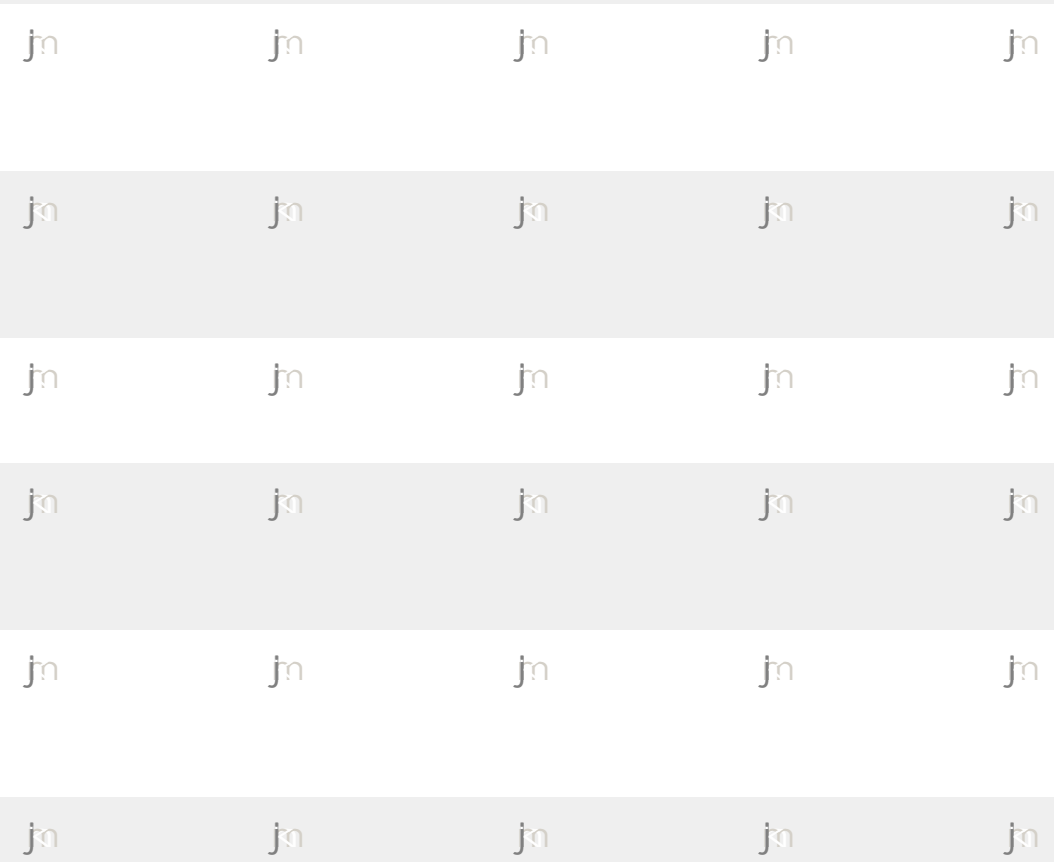


\section{CCS Undergraduate Class Survey}

are the most relevant consideration for

the deployment of such technologies for

commercial use.

Comments

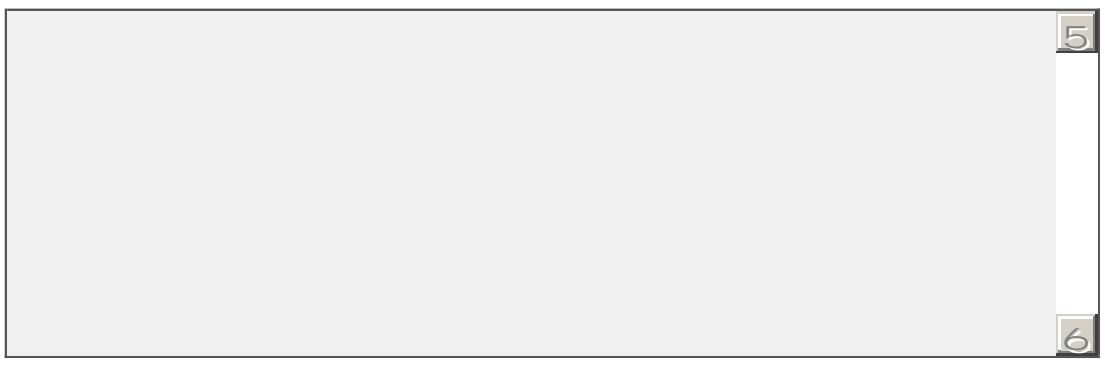

2. How do you think CCS fits into the issue of climate change?

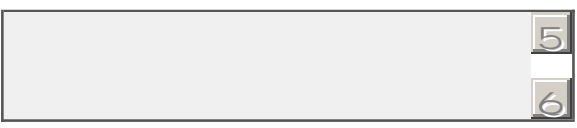

3. How do you think CCS fits into energy policy?

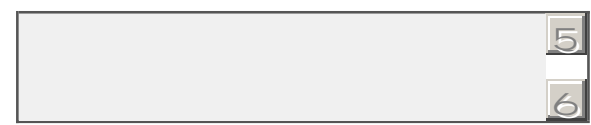




\section{CCS Undergraduate Class Survey}

\section{Demographic Information}

1. What is your sex?

Male

Pemale

2. What is your age?
24 or younger
25-29
30-34
35-39
$\bigcirc 40$ or older

3. How would you define your race/ethnicity? (Please choose all that apply):

Caucasian

Asian

African-American

Hispanic/Latino

Native American

Other (please specify)

\section{What is your country of origin?}




\section{CCS Undergraduate Class Survey}

5. What are your primary sources of information about local and national news? (Please choose all that apply):

Local newspaper

National newspaper

Radio

TV

Internet news sites

Social networking sites (i.e. Facebook, Myspace, Twitter)

Blogs/ individually run internet sites

Other (please specify)

6. What are your primary sources of information about CCS? (Please choose all that apply):

News media (radio, newspapers, internet)

Classes

Professors and/or researchers

ndustrial sources

Government sources

Peer-reviewed publications

Non peer-reviewed publications

Popular magazines (i.e. Scientific American)

Social networking sites (i.e. Facebook, Myspace, Twitter)

Blogs/individually run internet sites

Other (please specify) 


\section{Educational Background}

1. What is your highest completed level of education?

B.A.

B.s.

$\bigcirc M . A$.

$\bigcirc$ M.S.

$\bigcirc$ Professional Degrees (e.g., D.D.S., D.V.M., M.D., J.D.)

Pr.D.

2. What degree are you currently working on?
$\bigcirc M . A$.
$\bigcirc$ M.s.
Pr.D.

3. What is your current department/major?

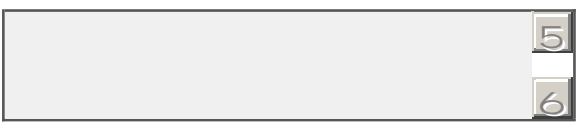

4. What is your current specialty/research interest?

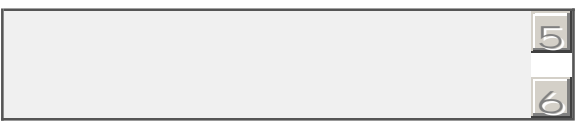

5. What is (are) your past department(s)/major(s)?

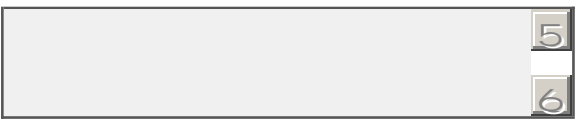

6. What is (are) your past specialty(ies)/research interest(s)?

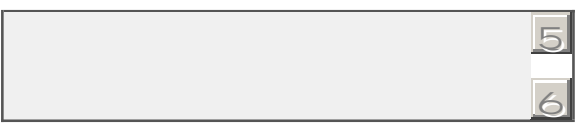

7. Please list any other courses you have taken that have addressed carbon capture and storage (CCS):

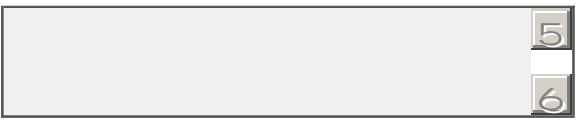

8. Please list any related research or previous experience you have with CCS associated technologies:

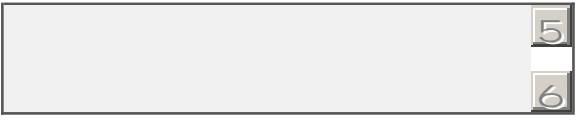




\section{Course Related Information}

\section{Which class section did you attend?}

8:30am (New Mexico Tech)

8:30am (University of Utah)

12:30pm (University of Utah, taped session)

2. To what extent did you attend the discussion section for this course?

Always - required/strongly suggested by major professor

Always - personal choice

Sometimes

Whenever I could

$\bigcirc$ Never - not interested

Never - unable due to schedule

\section{Why did you enroll for this class?}

Required by major professor

Suggested by major professor

Interest in topic

Other (please specify)

4. What did you expect to learn from attending this class?

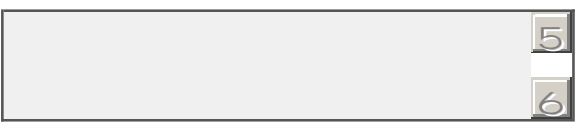

\section{Did the class meet your expectations?}

$\bigcirc$ Yes

$\bigcirc \mathrm{No}$

Comments

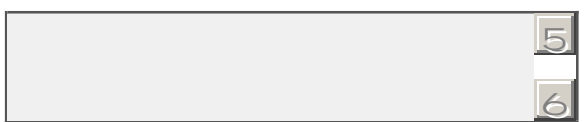


6. What are your career goals after you finish your degree(s)? Please RANK your top 3 preferences:

Industry
International agency
Federal agency
State agency
Non-governmental
organization
Politics
Primary or secondary
school (teach)
Private consulting firm
Research laboratory
University or college -
faculty member
University or college - staff

2nd preference

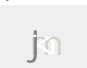

0

0

0

O

$\bigcirc$

0

O

0

$\bigcirc$

0 3rd preference

$\bigcirc$

O

0

O

O

$\bigcirc$

$\bigcirc$

O

$\bigcirc$

0

Other (please specify) 
7. Please RANK the top 5 class topics you found most useful toward your career goals (based on class syllabus):

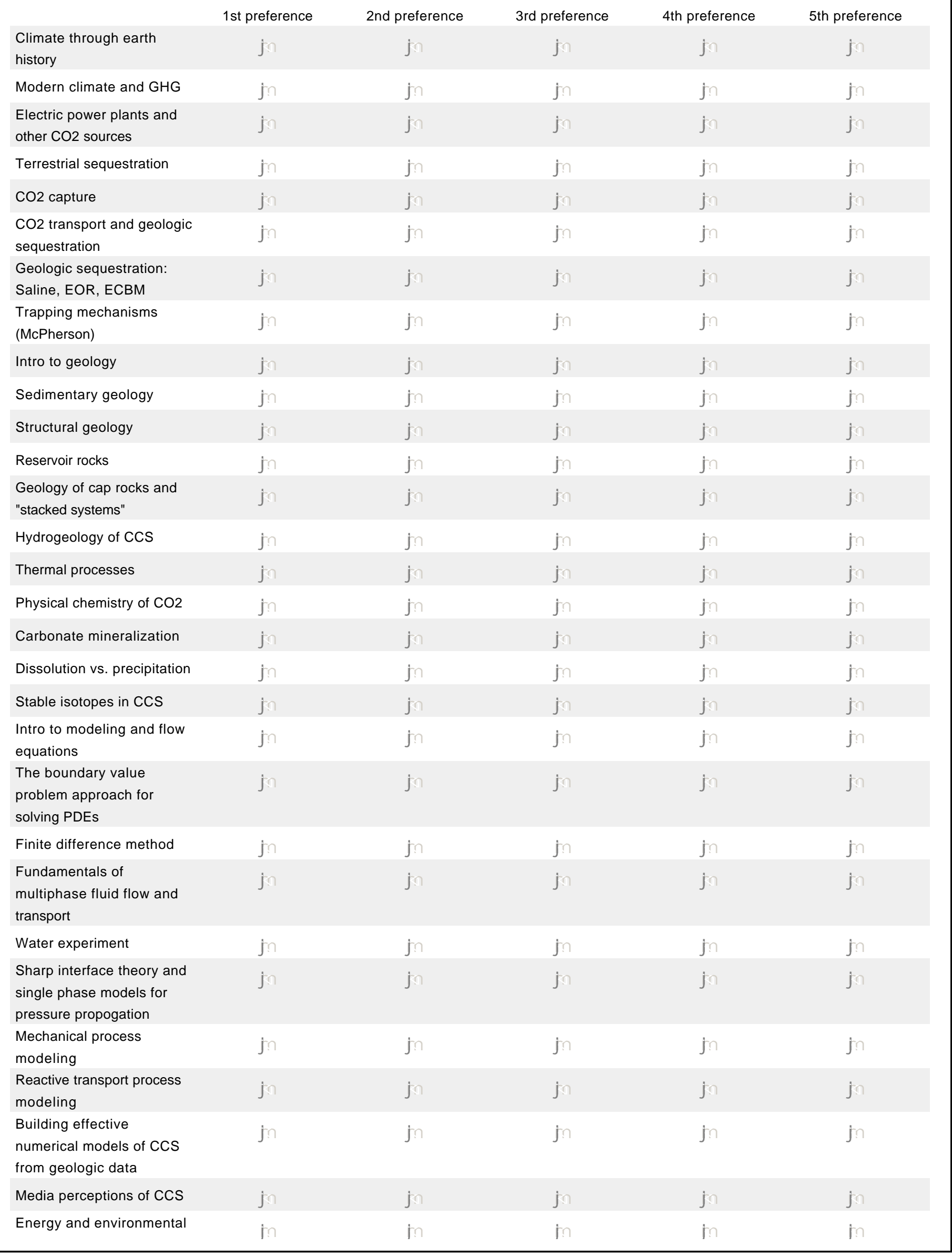




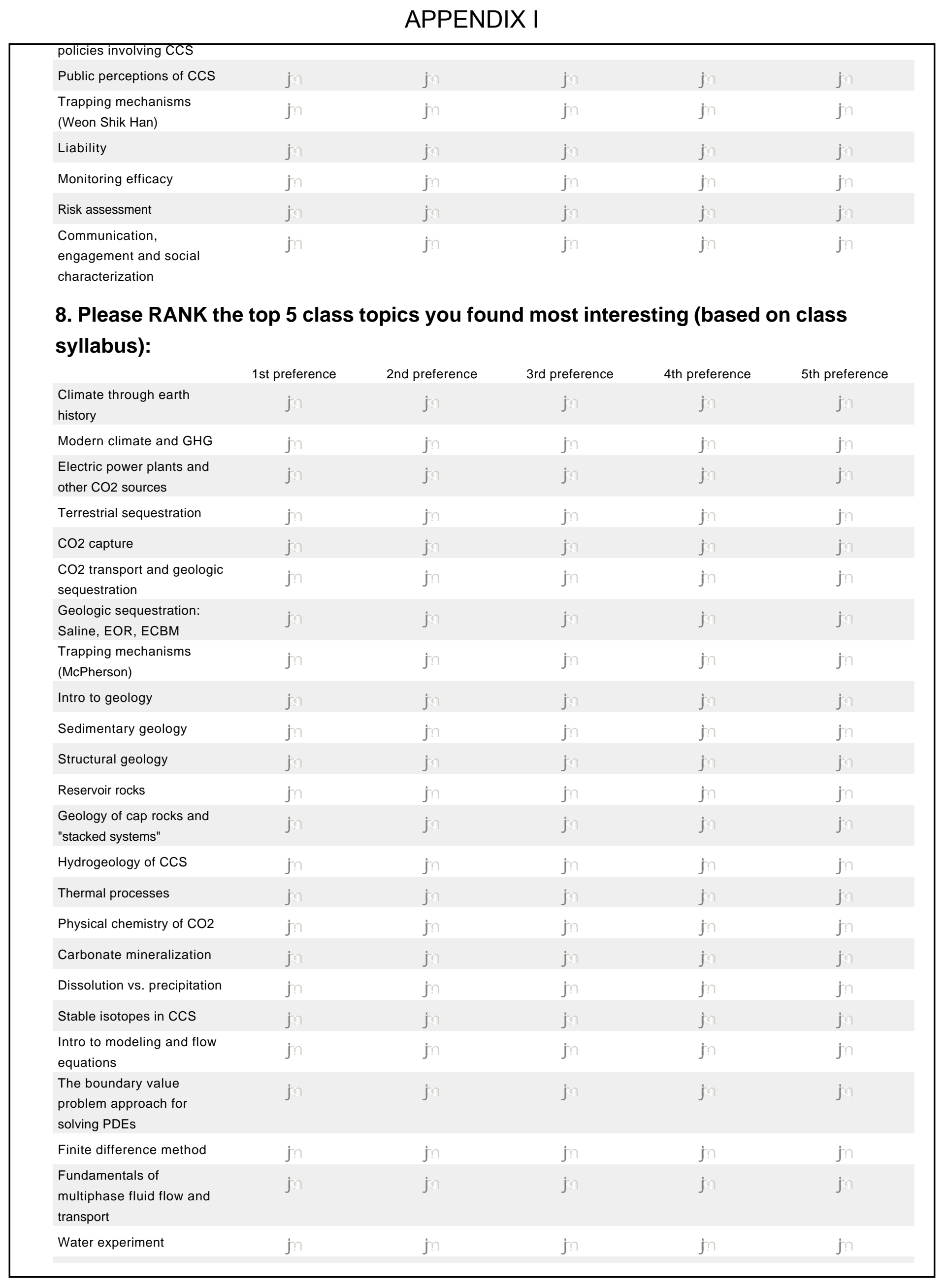




\section{APPENDIX I}

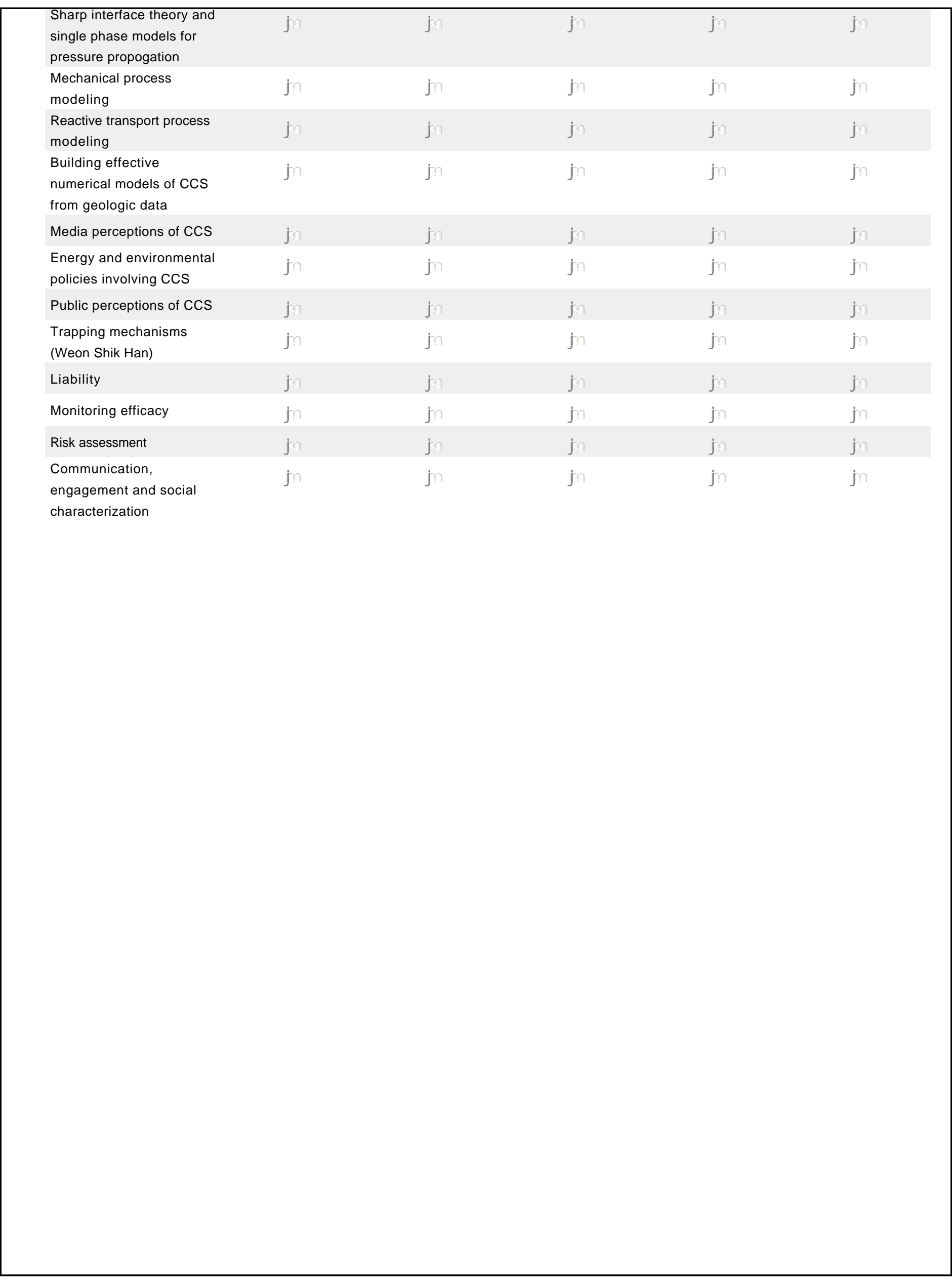




\section{CCS Knowledge Questions}

1. Please explain your background knowledge on the scientific and technical issues of CCS PRIOR to attending this class:

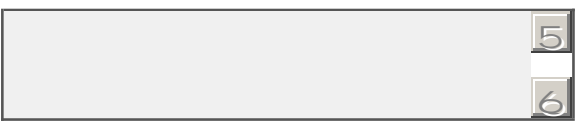

2. Do you feel that your knowledge of the scientific and technical issues of CCS has improved because of this class?

Yes

No

Comments

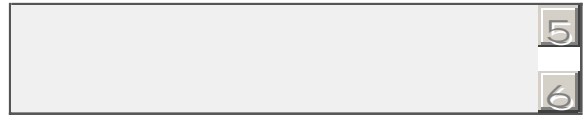

3. Please explain your background knowledge on the social aspects (economic, political, and cultural) of CCS PRIOR to attending this class?

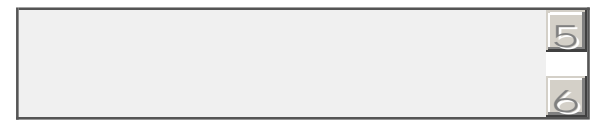

4. Do you feel that your knowledge of the social aspects (economic, political, and cultural) of CCS has improved because of this class?

Yes

No

Comments

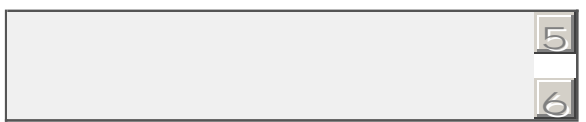


5. Please RATE your knowledge of CCS PRIOR to this class for the following questions on a scale of 1 to 5 with 1 being no knowledge and 5 being very knowledgeable (fill in one bubble per row):

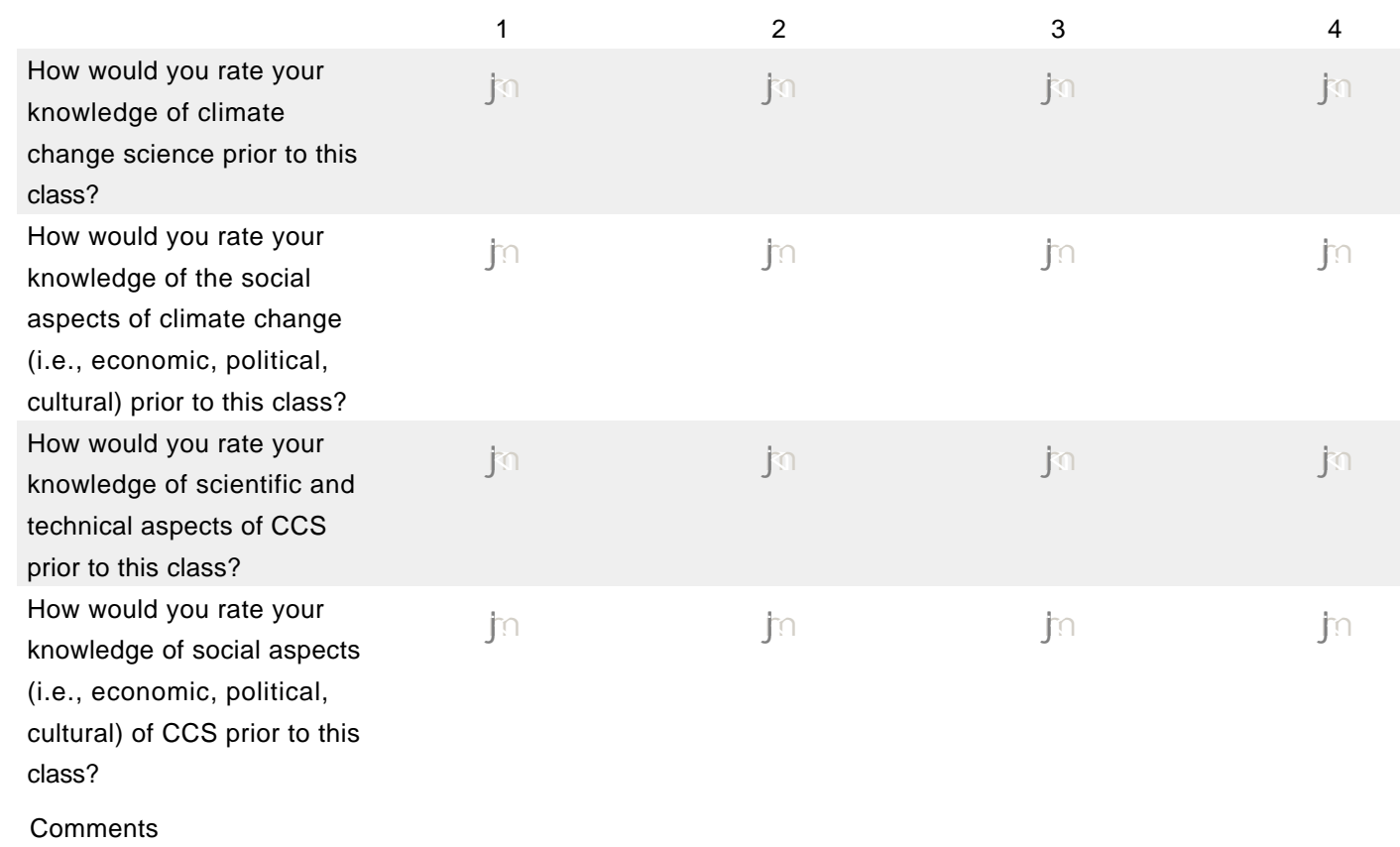




\section{Please RATE your knowledge of CCS AFTER this class for the following questions on} a scale of 1 to 5 with 1 being no knowledge and 5 being very knowledgeable (fill in one bubble per row):

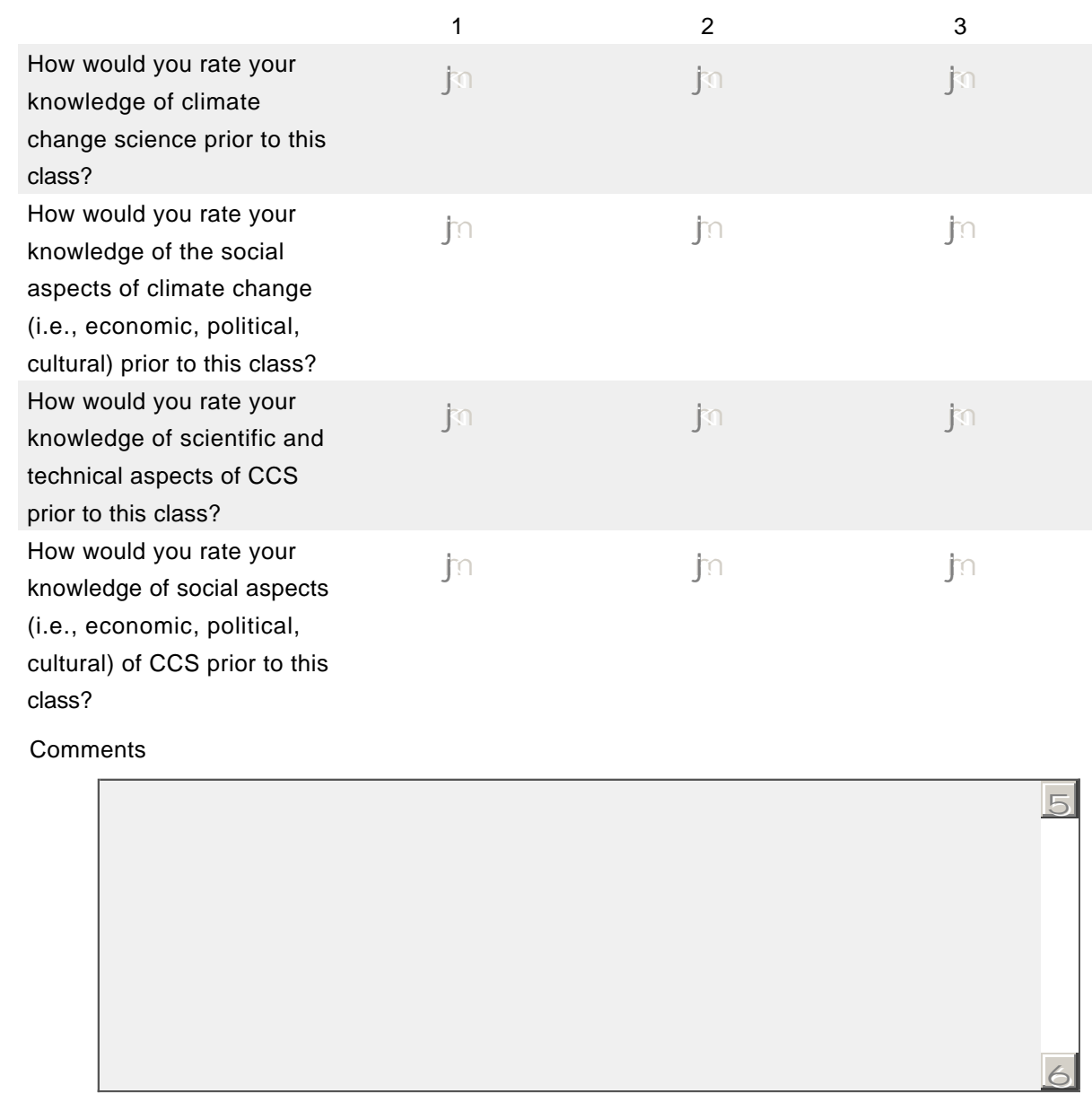




\section{Opinion Statements}

\section{Please RATE how well you agree or disagree with the following statements using the scale listed below (fill in one bubble per row):}

We should learn more about geologic and terrestrial CCS - such as how much would it cost, and is it safe and effective and support more research on this topic. We should encourage landowners to increase the carbon stored in farmlands, forests and open spaces for terrestrial CCS.

We should not support geologic and terrestrial CCS because we need to make a major shift away from using emissioncausing fuels such as oil, coal and gas. CCS will just delay that shift.

Both geologic and terrestrial CCS should be encouraged as part of a larger strategy that includes more renewable energy, higher energy efficiency and other types of energy sources.

We should encourage both geologic and terrestrial CCS because there is evidence to suggest that it will be difficult to transition away from our reliance on fossil fuels such as oil, gas and coal, and CCS provides a way we can keep carbon out of the atmosphere as much as possible during a transition.

We should support efforts to test and develop geologic CCS because new technologies need to be tried before they can be adopted nationally.

We should support geologic CCS because it is an approach that the U.S. Dept. of

Energy and oil /gas /power companies are seriously looking at.

We should support geologic and terrestrial CCS because they will aid in climate change mitigation.

We should support energy policies that will better enable the deployment of geologic and terrestrial CCS technologies.

An understanding of the science and technical aspects of CCS are the most relevant consideration for the deployment of such technologies for commercial use. An understanding of the social aspects (i.e., economic, political, cultural) of CCS are the most relevant consideration for the deployment of such technologies for commercial use.
Disagree

$\bigcirc$

Somewhat disagree
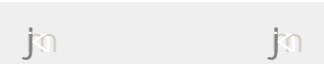

0

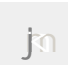

$\bigcirc$

0

0

0

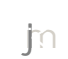

0

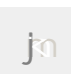

0

0

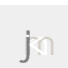

0

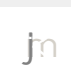

0

0

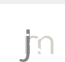

$\bigcirc$

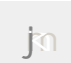

0
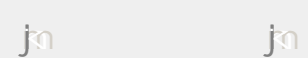

0

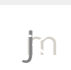

0

0

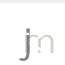

0

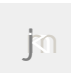

0
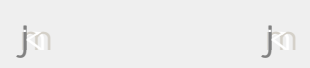

0

0

0

0

0

0

0

0

0

0

0

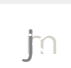

0
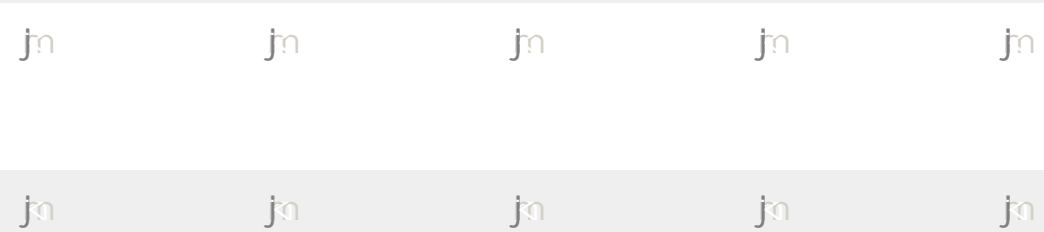
APPENDIX I

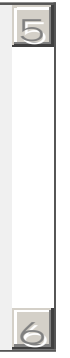

2. How do you think CCS fits into the issue of climate change?

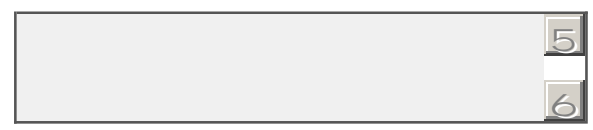

3. How do you think CCS fits into energy policy?

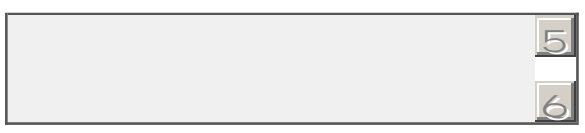




\section{Demographic Information}

1. What is your sex?

$\bigcirc$ Male

$\bigcirc$ Female

2. What is your age?
24 or younger
25-29
(30-34
35-39
$\bigcirc 40$ or older

3. How would you define your race/ethnicity? (Please choose all that apply):

Caucasian

Asian

African-American

Hispanic/Latino

Native American

Other (please specify)

\section{What is your country of origin?}

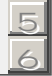

5. What are your primary sources of information about local and national news? (Please choose all that apply):

Local newspaper

National newspaper

Radio

TV

Internet news sites

Social networking sites (i.e. Facebook, Myspace, Twitter)

Blogs/ individually run internet sites

Other (please specify) 


\section{What were your primary sources of information about the technical/scientific aspects of CCS PRIOR to this class? (Please choose all that apply):}

News media (radio, newspapers, internet)

Classes

Professors and/or researchers

Industrial sources

Government sources

Peer-reviewed publications

Non peer-reviewed publications

Popular magazines (i.e. Scientific American)

Social networking sites (i.e. Facebook, Myspace, Twitter)

Blogs/individually run internet sites

Other (please specify)

7. What are your primary sources of information about the technical/scientific aspects of CCS AFTER this class? (Please choose all that apply):

News media (radio, newspapers, internet)

Classes

Professors and/or researchers

Industrial sources

Government sources

Peer-reviewed publications

Non peer-reviewed publications

Popular magazines (i.e. Scientific American)

Social networking sites (i.e. Facebook, Myspace, Twitter)

Blogs/individually run internet sites

Other (please specify) 
8. What were your primary sources of information about the social/cultural aspects of CCS PRIOR to this class? (Please choose all that apply):

News media (radio, newspapers, internet)

$\square$ Classes

Professors and/or researchers

Industrial sources

Government sources

Peer-reviewed publications

Non peer-reviewed publications

Popular magazines (i.e. Scientific American)

Social networking sites (i.e. Facebook, Myspace, Twitter)

Blogs/individually run internet sites

Other (please specify)

9. What are your primary sources of information about the social/cultural aspects of CCS AFTER this class? (Please choose all that apply):

News media (radio, newspapers, internet)

Classes

Professors and/or researchers

Industrial sources

Government sources

Peer-reviewed publications

Non peer-reviewed publications

Popular magazines (i.e. Scientific American)

Social networking sites (i.e. Facebook, Myspace, Twitter)

Blogs/individually run internet sites

Other (please specify) 


\author{
APPENDIX J \\ Putting the $\mathrm{U}$ in Carbon Capture and Storage: \\ Performances of Rupture within the CCS Scientific Community \\ Danielle Endres, Associate Professor, University of Utah \\ Brian Cozen, Doctoral Student, University of Utah \\ Megan O'Byrne, Doctoral Candidate, University of Utah \\ Andrea Feldpausch-Parker, Assistant Professor, SUNY-ESF
}

\begin{abstract}
This paper examines a rhetorical framing shift from CCS to CCUS within science and technology professionals' communication, particularly how the professional community responded to this framing shift. Drawing from participant observation, we describe and evaluate the moments of rupture caused by putting the $\mathrm{U}$ in carbon capture and storage. Drawing from the theories of terministic screens, rhetorical boundary-work and the cultural performance of social drama, we argue that the framing shift is a breach or rupture in the boundaries of the CCS professional community that calls forth cultural performances of confusion, acquiescence, and resistance to the framing shift. This theoretical framework has the potential to serve as a powerful heuristic for examination of similar inter-scientific framing shifts. In addition, this paper contributes to contemporary research in rhetoric of science (RoS), social dimensions of CCS, and environmental communication.
\end{abstract}

Keywords: CCS, Social Drama, Boundary-Work, Framing, Rupture 
Carbon Capture and Storage (CCS, also known as carbon sequestration) technologies are a significant facet of international deliberation about energy policy, particularly in the face of the impending climate crisis. In 2005 the Intergovernmental Panel on Climate Change wrote a report on the potential of CCS as a strategy for climate change mitigation (IPCC, 2005). CCS incorporates a wide variety of technologies for the reduction of $\mathrm{CO}_{2}$ emissions from the coal-dependent energy sector and other stationary industrial sources (e.g., cement plants, ethanol plants, refineries, and iron and steel mills; Feldpausch-Parker et al, in press; IPCC, 2005). Clean coal technology serves as one suite of technologies included in the carbon capturing side of CCS (Feldpausch-Parker et al., 2011). Though research into CCS technologies has been underway since the late 1980s, coordinated national and international efforts did not start until the early 2000s (Herzog, 2001). These more comprehensive efforts included researchers in both the biophysical and social sciences. Individually the authors of this paper have been involved with research on the social and cultural dimensions of CCS for between two and nine years. Our research and meeting attendance has allowed us to observe a variety of venues where CCS-oriented science and technology professionals (e.g., academic, industry, agency, and NGO scientists and engineers) gather. This includes our yearly attendance of the annual spring CCS conference in Pittsburgh, Pennsylvania, home to the coal industry and one of three main offices for the U.S. Department of Energy's National Energy Technology Laboratory. 
In this paper, we turn our attention to rhetorical dynamics of naming and framing within the CCS professional community. We use the term CCS professionals to refer to people with scientific and technical training who engage in work related to research, development and commercialization of CCS. This includes people from academic, industry, federal and state agency (e.g., NETL, DOE), public utility, and NGO organizations. Drawing from ethnographic participant observation within the CCS professional community, we focus in particular on an attempted framing shift from CCS to CCUS (Carbon Capture Utilization and Storage) that occurred during the course of our research. Utilization refers to using the captured $\mathrm{CO}_{2}$ for an additional purpose before storing it, such as enhanced oil recovery (EOR), or a displacement method for extracting more oil from fields. When we arrived at the first plenary session for the 2012 annual spring CCS conference, we were quickly faced with the ubiquity of this new term. ${ }^{1}$ CCUS appeared prominently in all of the on-site conference materials. The conference organizers emphasized the importance of making the business case for CCUS through the conference theme. Plenary speakers highlighted examples of promising utilization research and successful pilot programs. Through our participant observation, we witnessed an attempt to rhetorically shift the discursive terrain from CCS to CCUS and thus re-map the landscape of CCS research and technology towards pursuing a "business case" for CCUS (by linking CCS with EOR). Yet, we also observed various reactions to the new term by conference attendees.

\footnotetext{
${ }^{1}$ After returning from the conference, we discovered that the conference name had been changed to CCUS in its initial promotional materials. Yet, even though CCUS was in the title of the conference, the call for papers, and other materials, we had not noticed the change until we arrived at the conference. Upon further research we discovered that the framing shift started to appear in documents in 2011.
} 
In this paper, we focus on the rhetorical shift from CCS to CCUS within science and technology professionals' communication. We draw from ethnographic data to study this framing shift as it was happening and reflect on how the professional community-to the extent that it was represented at this conference-reacted to this shift in framing. In particular, we examine how the professional community responded to this framing shift through describing and evaluating the moments of rupture caused by putting the $\mathrm{U}$ in carbon capture and storage. Drawing on Kenneth Burke's concept of terministic screens (Burke, 1966), rhetorical boundary-work (Gieryn, 1999; Taylor, 1996) and the cultural performance of social drama (Turner, 1980), we argue that the framing shift is a breach or rupture in the boundaries of the CCS professional community that calls forth cultural performances of confusion, acquiescence, and resistance to the framing shift.

\section{Performing Resistance in the Boundaries}

While there are numerous academic perspectives on the concept of framing (Burke, 1966; Entman, 1993; Goffman, 1974; Lakoff, 2010), we draw from Kenneth Burke's rhetorical perspective on framing. Burke suggests that terminology creates a terministic screen that frames how it is understood. He states, "even if any given terminology is a reflection of reality, by its very nature as a terminology it must be a selection of reality; and to this extent it must also function as a deflection of reality" (Burke, 1966, p. 45). Any message is, consciously or not, rhetorically constructed to emphasize certain things and deemphasize others. In the case of the shift between CCS to CCUS, the addition of a "utilization" step to the process of carbon capture and storage reframes the technology in interesting ways. Instead of viewing CCS as climate mitigation technology - a way to lessen $\mathrm{CO}_{2}$ emissions from energy production and other 
industrial operations - adding utilization to CCUS changes the frame of the technology such that it is focused on using the captured carbon to facilitate the production of additional fossil fuel energy sources, namely enhanced oil recovery (EOR). As we will demonstrate in our analysis, CCUS refocuses research and technology toward facilitating EOR. Utilization implicates CCS more firmly in industry logics and business imperatives, a shift that foregrounds the interests of some constituents over others.

This framing shift destabilizes several rhetorical boundaries at play within the CCS professional community. Studies of boundary-work (Gieryn, 1999) or rhetorical demarcation (Taylor, 1996) examine the construction of boundaries between science and non-science as well as within science through discourse. Through analysis of a messy interdisciplinary scientific community made up of scientists and engineers from academic, industry, and political sectors, we are particularly interested in the boundary work that happens within science (as opposed the boundary between science and public for example). In this case, adding the U to CCUS not only creates a boundary between CCS and CCUS, but also breaks down a boundary between coal and oil (EOR) technologies. Gieryn (1999) suggests that "boundary-work is strategic practical action. As such, the borders and territories of science will be drawn to pursue immediate goals and interests of cultural cartographers, and to appeal to the goals and interests of audiences and stakeholders" (p. 23) As we demonstrate in our analysis, the framing shift represents an attempt to re-map the landscape of CCS research and technology towards pursuing a "business case" for CCUS that makes the technology viable through its association with EOR. 
In order to study the boundary-work at play in the framing shift from CCS to CCUS, we focus our attention on performances of confusion, acquiescence and resistance to the framing shift within CCS professionals at the Eleventh Annual Carbon Capture, Utilization, \& Sequestration Conference. Expanding from Heath's (1998) examination of performances of knowledge co-construction at academic science conferences, we see the responses to the framing shift as performances of boundary negotiation at CCS professional conferences. Victor Turner's $(1980 ; 1995)$ theory of the cultural performance of social drama illuminates the process through which societies attend to conflict. Viewing the community of CCS professionals as a society, Turner's theory highlights how the attempted framing shift from CCS to CCUS represents a "breach" in the norms of the community. This breach is potentially troubling for the community because it destabilizes accepted boundaries. As such, CCS professionals were faced with how to respond to this rupture. For some, the response was confusion. Others complied with the shift. And others took more active forms of resistance. It is these moments of response to the framing shift that we can see cultural performances of the boundaries created and destabilized through the attempted framing shift.

\section{Method}

Latour (1988) argues that science can only be understood through its practice (see also Woolgar, 1982). Our study draws from three years of qualitative data collected from CCS professional conferences in which CCS scientists and engineers talk (informally and formally) about CCS. Science happens in multiple sites beyond the laboratory (Hine, 2007; Lorenz-Meyer, 2011). We argue that while CCS scientists' discourse travels to, localizes, and constitutes anew around such artifacts as scientists' websites, journal 
articles, and government documents, professional conferences are a particularly important site of localization for the CCS professional community. We build on the insights of Heath (1998) and Krauss $(2011 ; 2009)$ to argue that professional conferences are a relatively understudied site of science in practice. These conferences serve as a proving ground for presenting, discussing, and developing new scientific ideas and advancements, as well as for negotiating norms and boundaries. Hine (2007) promotes the choice of ethnographic sites that capture the "heterogeneous audiences comprising diverse sets of peers, policy makers, funders, bosses, and research contacts" (657). Henke and Geiryn (2008) point to the importance of face time and chance encounters in the transference of knowledge. Conferences are an integral space for co-presence and where mobile, cross-disciplinary subjects converge. According to Krauss (2011), conducting research at conferences follows "migratory scientists" where they coalesce (Krauss, 2011, p. 155). For a topic as interdisciplinary as CCS, conferences serve as a crucial localized site of knowledge and, as Heath (1998) argues, act as performance settings.

We use rhetorical field methods (Middleton, Senda-Cook, \& Endres, 2011) to conduct participant observation of science rhetoric in action at CCS professional meetings. Our participant observation yielded fieldnotes (e.g., Emerson, Fretz, \& Shaw, 2011), transcribed plenary speeches, and conference materials. Our fieldnote data was supplemented by analysis of relevant documents, including journal articles and DOE documents that use the term CCUS. We employ rhetorical criticism to analyze the data described above. The theoretical framework described above emerged inductively from an analysis of our data.

\section{Confusion, Acquiescence \& Resistance}


In this section we offer some brief examples of moments of confusion, acquiescence, and resistance to the framing shift. The name shift caught numerous participants by surprise. Our analysis will consider moments that exposed the rupture caused by the framing shift including how panelists and speakers introduced their topics in relation to these changes, how the topic came up in interpersonal conversations, and how people asked questions about the new terminology. For example, we observed that plenary speakers often commented on the new terminology and how the conference organizers encouraged the use of CCUS in titles, sometimes at odds with their own goals for their presentation. In interpersonal conversation, one academic scientist discussed how the name change was surprising but ultimately inconsequential to her own research focus, thus acquiescing to the shift. She described her response as putting faith in smart people to implement her work in productive ways as being more important than the new name. Her comments reflect nuances in conceptualizing the conference space as one where different constituents negotiate conceptual boundaries amongst each other, and one where boundary work may demarcate self-segregation between constituents. In the larger analysis, we will consider the roles of these divergent constituents, as well as the boundary work both conducted and conscientiously avoided.

\section{Conclusion}

This paper has several important implications for scholarship. First, the theoretical framework that emerged from our analysis has the potential to serve as a powerful heuristic for examination of similar inter-scientific framing shifts. In addition, this paper also contributes to contemporary research in rhetoric of science (RoS), social dimensions of CCS, and environmental communication. RoS scholarship focuses on the 
rhetorical dynamics of science, scientists, and scientific controversy. While research in RoS tends to be focused either on academic science or on the relationship between scientists and the public (Ceccarelli, 2001; Wander, 1976) our project uniquely offers insight into the relationship between academic scientists, industry scientists, and agency scientists when they come together to interact at a professional conference. Second, previous research on social cultural dimensions of CCS focused on public perceptions and knowledge of CCS technologies (Bradbury et al. 2009; Feldpausch-Parker et al., 2011; Johnsson, 2011; Moutenet et al., 2012), in addition to policy efforts for technology implementation (Pollak \& Wilson, 2009). These studies have demonstrated limited knowledge of industry and government efforts toward the commercialization of CCS with varying degrees of acceptance, or in some cases, outright protest against operations. Similarly, policy creation and implementation have been slow to arise, stemming from issues over pore space ownership, liability and a slew of other issues economic and cultural in nature (Feldpausch-Parker et al., in press). Expanding on this research, our study shifts the focus from public perceptions to professional perceptions of CCS, an often-overlooked area of study in the social and cultural dimensions of CCS. Finally, this paper contributes to environmental communication and scholarship, more generally through its focus on the importance of understanding the rhetoric of CCS professionals to controversies over climate mitigation strategies and energy policy (e.g., Moser \& Dilling, 2007; Nerlich \& Koteyko, 2009, 2010). 


\section{References}

Bradbury, J., Ray, I., Peterson, T., Wade, S., Wong-Parodi, G., \& Feldpausch, A. (2009). The role of social factors in shaping public perceptions of CCS: Results of multistate focus group interviews in the U.S. Energy Procedia, 1, 4665-4672.

Burke, K. (1966). Language as symbolic action: essays on life, literature, and method. University of California Press.

Ceccarelli, L. (2001). Rhetorical Criticism and the Rhetoric of Science. Western Journal of Communication, 65(3), 314-29.

Emerson, R. M., Fretz, R. I., \& Shaw, L. L. (2011). Writing Ethnographic Fieldnotes (Chicago Guides to Writing, Editing, and Publishing) 2nd (second) edition. University Of Chicago Press.

Entman, R. M. (1993). Framing: Toward Clarification of a Fractured Paradigm. Journal of Communication, 43(4), 51-58. doi:10.1111/j.1460-2466.1993.tb01304.x

Feldpausch-Parker, A. M., Ragland, C. J., Melnick, L. L., Chaudhry, R., Hall, D. M., Peterson, T. R., Stephens, J. C., \& Wilson, E. J. Spreading the news on carbon capture and storage: A state-level comparison of US media. Environmental Communication, In Press.

Feldpausch-Parker, A.M., Chaudhry, R., Stephens, J.C., Fischlein, M., Hall, D.M., Melnick, L.L., Peterson, T.R., Ragland, C.J., \& Wilson, E.J. (2011). A comparative state-level analysis of carbon capture and storage (CCS) discourse among U.S. energy stakeholders and the public. Energy Procedia, 4, 6368-6375.

Gieryn, T. F. (1999). Cultural Boundaries of Science: Credibility on the Line. University of Chicago Press. 
Goffman, E. (1974). Frame analysis: an essay on the organization of experience. Harper \& Row.

Heath, D. (1998). Locating genetic knowledge: Picturing Marfan Syndrome and its traveling constituencies. Science, Technology \& Human Values, 23(1), 71-97.

Henke, C. R., \& Gieryn, T. F. (2008). Sites of Scientific Practice: The Enduring Importance of Place. In E. J. Hackett, O. Amsterdamska, M. E. Lynch, J. Wajcman, \& W. E. Bijker (Eds.), The Handbook of Science and Technology Studies (Third ed., pp. 353-76). Cambridge, MA: The MIT Press.

Herzog, H. J. (2001). What future for carbon capture and sequestration? Environmental Science \& Technology, 35, 148-153.

Hine, C. (2007). Multi-Sited Ethnography as a Middle Range Methodology for Contemporary STS. Science, Technology, \& Human Values, 32(6), 652-671.

Intergovernmental Panel on Climate Change (2005). IPCC special report on carbon dioxide capture and storage. Cambridge, NY: Cambridge University Press.

Johnsson, F. (2011). Perspectives on $\mathrm{CO}_{2}$ capture and storage. Greenhouse Gases: Science and Technology, 1(2), 119-133.

Krauss, W. (2011). Migratory birds, migratory scientists, and shifting fields: The political ecology of a northern coastline. In S. Coleman \& P. von Hellerman (Eds.), Multisited ethnography: Problems and possibilities in the translocation of research methods (pp. 146-160). New York: Routledge.

Krauss, W. (2009). Localizing climate change: A multi-sited approach. In M.-A. Falzon (Ed.), Multi-Sited Ethnography: : Theory, praxis and locality in contemporary research (pp. 149-164). Abingdon, UK: Ashgate. 
Lakoff, G. (2010). Why it Matters How We Frame the Environment. Environmental Communication: A Journal of Nature and Culture, 4(1), 70-81.

doi:10.1080/17524030903529749

Latour, B. (1988). Science in Action: How to Follow Scientists and Engineers through Society. Harvard University Press.

Lorenz-Meyer, D. (2011). Locating Excellence and Enacting Locality. Science, Technology \& Human Values. doi:10.1177/0162243911409249

Middleton, M. K., Senda-Cook, S., \& Endres, D. (2011). Articulating Rhetorical Field Methods: Challenges and Tensions. Western Journal of Communication, 75(4), 386-406. doi:10.1080/10570314.2011.586969

Moser, S. C., \& Dilling, L. (2007). Creating a Climate for Change: Communicating Climate Change and Facilitating Social Change. Cambridge University Press.

Moutenet, J.P., Bedard, K. \& Malo, M. (2012) Public awareness and opinion on CCS in the province of Québec, Canada. Greenhouse Gases: Science and Technology, 2(2), 126-135 (2012).

Nerlich, B., \& Koteyko, N. (2009). Carbon Reduction Activism in the UK: Lexical Creativity and Lexical Framing in the Context of Climate Change. Environmental Communication: A Journal of Nature and Culture, 3(2), 206-223. doi:10.1080/17524030902928793

Nerlich, B., \& Koteyko, N. (2010). Carbon Gold Rush and Carbon Cowboys: A New Chapter in Green Mythology? Environmental Communication: A Journal of Nature and Culture, 4(1), 37-53. doi:10.1080/17524030903522389 
Pollak, M. F., \& Wilson, E. J. (2009). Regulating geologic sequestration in the United States: Early rules take divergent approaches. Environmental Science \& Technology, 43, 3035-3041.

Taylor, C. A. (1996). Defining Science: A Rhetoric of Demarcation. Madison: University of Wisconsin Press.

Turner, V. (1980). Social Dramas and Stories about Them. Critical Inquiry, 7(1), 141168.

Turner, V. W. (1995). The Ritual Process: Structure and Anti-Structure. Transaction Publishers.

Wander, P. C. (1976). The rhetoric of science. Western Speech Communication, 40(4), 226-235. doi:10.1080/10570317609373907

Woolgar, S. (1982). Laboratory Studies: A Comment on the State of the Art. Social Studies of Science, 12(4), 481-498. 


\title{
APPENDIX K
}

\section{The Use and Utility of YouTube Videos as an Outreach Medium for Carbon Capture, Utilization and Sequestration Information}

\author{
Study by Charles Milewski, B.S., SUNY ESF
}

In a study examining the use and effectiveness of posting Carbon Capture, Utilization and Sequestration (CCUS) videos to YouTube, I reviewed 60 videos created mainly by government, academia and industry groups to determine (1) how CCUS is communicated to the public, either as educational or persuasive material, and (2) what reaction it is receiving based on number of views and posted comments. I found a somewhat even distribution of posts between the three main sources of videos, with government providing slightly more videos than either industry or academia. The majority of these videos $(78 \%)$ focused on geologic sequestration only (15\% focused on terrestrial and $8 \%$ including both sequestration types in their content).

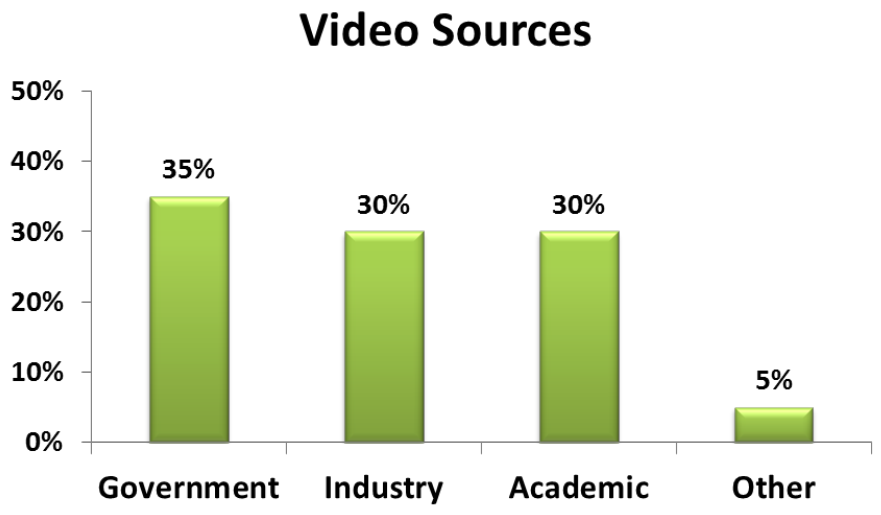

I also found a higher prevalence of educational videos, though persuasive videos and those incorporating both persuasive rhetoric and educational information were also well represented. Persuasive material was characterized as using language that would attempt to sway opinion of such technologies through rhetorical appeals. For example, videos that invoked a sense of urgency in the viewers to take action and support CCUS before the catastrophic consequences of climate change occur were determined as persuasive. Educational material, on the other hand, was characterized as attempts to describe the CCUS process or technology while avoiding any emotional appeals, apocalyptic narratives, or persuasive framing.

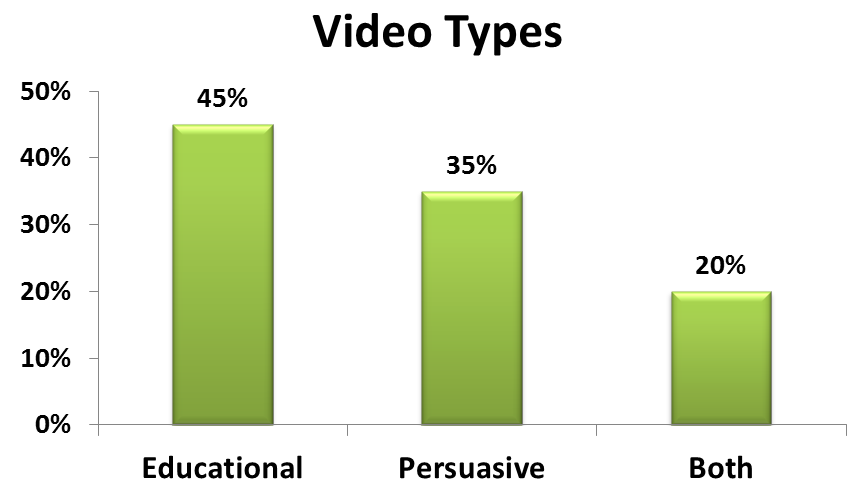




\section{APPENDIX K}

Findings examining viewer response $(n=479)$ showed that most viewers were positive toward the videos with an overwhelming number of likes $(86 \%)$ to dislikes $(14 \%)$. Comments posted below the videos $(n=199)$ were also relatively positive. Positive comments were those characterized as supportive of the content discussed in the videos and were generally complimentary of CCUS technology. For example, comments that positively discussed CCUS from an economic, environmental or social sense describing potential jobs, social justice considerations or environmental prosperity that CCUS could potentially offer were coded as positive. Conversely, negative comments were those which were critical or denounced the usage of CCUS, such as comments describing CCUS as insufficient, a waste of taxpayer's money, impractical, or all together unnecessary based on the commenter's position concerning the larger issue of climate change. Finally, ambiguous comments were recorded as those which could not be discerned as either supportive or critical of the content within the videos. These comments were typically in response to other comments and oftentimes had little to do with the actual content portrayed in the videos.

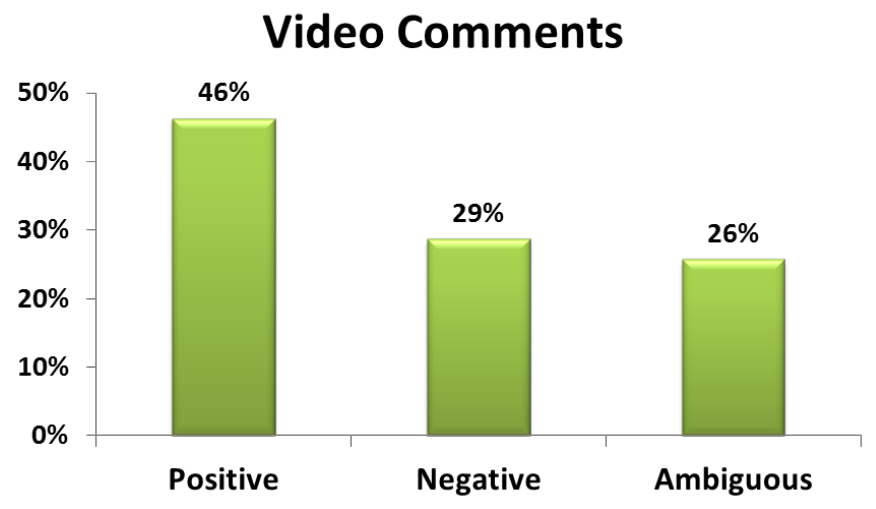

When examining the number of views for these videos, I found that the 60 videos had approximately 150,000 views averaging roughly 2,500 views per video. Overall, it appears that CCUS is not reaching an exceptionally large audience through this form of online media. Regardless of video source, most of the videos had a similarly small quantity of views. The most watched CCUS video on YouTube had approximately 19,500 while roughly half of the videos failed to reach 1,000 views.

Based on this analysis, it appears that the message of CCUS is not reaching a great percentage within the public sphere. Public feedback from the videos does demonstrate, however, a higher level of support for such ventures than criticism. 


\section{Appendix L}

\section{South West CCUS Training Center}

\section{Documentation of PDU and CEU offerings}

\section{Undergraduate Class}

Spring semester 2011, an upper-level undergraduate course in geological carbon sequestration was taught at New Mexico Tech by Andrew Campbell and Peter Mozley, together with hydrology professor Mark Person. 10 students finished the class. The course, ERTH 427 (Carbon Sequestration Science), covered a broad range of topics, including: Earth's present and past climate, carbon capture technology, trapping mechanisms, physical chemistry of $\mathrm{CO}_{2}$, reservoirs and seals, water/rock interaction, modeling subsurface migration, geomechanics, and societal issues. Eleven students registered for the course, about evenly split between Earth Science and Petroleum Engineering majors. In addition to lecture material, the students had various lab exercises, gave weekly reports on current CCS events in the news, and prepared for classroom debates. Students in the class produced short videos on CCS related topics of their choosing. Some of these videos are posted on the SWP $\mathrm{CO}_{2}$ Training Center website. The class included a three-day field trip, which visited two SWP Phase II Demonstration Sites: the Aneth EOR and Pump Canyon ECBM pilot sites, as well as outcrop analogs of reservoir and seal lithologies. Lab assignments included identification of important rock properties on reservoir and seal rocks and comparing $\mathrm{CO} 2$ plume growth from experiments and theory

10 students for 3 university credits @ 45 PDH per credit hour is 450 PHD awarded

Carbon Sequestration Science - ERTH 42701 , 3 Credits, Spring Semester 2011

CRN: $\underline{32545}$

Duration: Jan 17, 2011 - May 13, 2011

Student Name

1 Bammidi, Vidya Sagar

2 Benally, Craig T.

3 Chaves, German

4 Currie, Neil D. 
5. Withdrew

6 Geist, Jay N.

7 Hutton, Ashley

8 Myers, Heidi P.

9 Ololo, Peter U.

$10 \underline{\text { Tian, Hongyu }}$

11 Zhang, Guoyin

Graduate Level CCS Class A major activity of the SWTC this quarter was development and completion of a graduate course entitled "Carbon Capture and Storage," offered simultaneously at both the University of Utah and New Mexico Tech. The course is graduate level at both schools, but undergraduates were permitted to enroll. It was offered as Civil and Environmental Engineering 7920 at the University of Utah, and as Geology 571 at New Mexico Tech. The total enrollment of 14 students included 10 at the University of Utah and 4 at New Mexico Tech, with approximately $50 \%$ M.S. students and 50\% Ph.D. students. Classes began Monday, August $23^{\text {rd }}, 2010$, and the final class was held on Friday, December $10^{\text {th }}, 2010$.

A unique aspect of this course is that it was co-taught at two regional universities, the University of Utah and New Mexico Tech, and was broadcasted live via the Internet.

The goals of this course were to (1) create a broad academic foundation of carbon capture and sequestration (CCS), with the primary emphasis on geologic sequestration, that prepares students for continuing education, leading to greater professional competency, and (2) provide students with the fundamental knowledge and tools necessary to perform design of CCS systems for professional practice.

14 students for 3 university credits @ 45 PHD/credit hour = 630 PDH

New Mexico Tech

Climate and Carbon - GEOL 571 01, Fall Semester 2010, 3 Credits

CRN: 24112

Duration: Aug 23, 2010 - Dec 16, 2010

1 Oh, Yong Jae $\underline{A}$

2 Payne, William G.

3 Petersen, Michael T.

4 Zhang, Yipeng

Office of the Registrar University of Utah -- Official Grade Roster, Fall 2010 Generated: Feb 08, 2012 


\section{Instructor Subject Cat.\# Sect. Cmpt. Title Days Time Location}

MCPHERSON, B. J. CVEEN 7920003 Special Topics Carbon Capture \& Storage M,W,F 08:35 AM-09:25 AM JFB 210

\section{Emplid Student Units Roster Grade Official Grade Date of Official Grade}

Registration Date

$1 \mathrm{CHOI}, J E O N G D O N G$

2 COSTANZO,MARIO VINCENT

3 FRANZ,RICHARD J 4 LEE,SEONG JUN 3.0 A A Dec 22, 2010 Aug 05, 2010

5 LI,XINHUA MERRILL

6 OLSEN,ADAM 30, 2010

7 OPARA,ALEKSANDRA

8 PATIL,VIVEK VIDYADHAR

9 WRIEDT,JUSTIN

10 ZABALA,OSCAR

Grad class Fall 2012

New Mexico Tech Carbon Sequestration - GEOL 571D 01

CRN: $\quad 53539$

Duration: Aug 20, 2012 - Dec 14, 2012

Summary Class List

\begin{tabular}{|c|c|c|c|c|c|}
\hline $\begin{array}{l}\text { Record } \\
\text { Number }\end{array}$ & Student Name & ID & Reg Status & Level & Credits Final Grade Detail \\
\hline 1 & ABDALLAH, ISSAH & & $* *$ Registered $* *$ & Graduate & 3.000 \\
\hline 2 & $\begin{array}{l}\text { Butler, David L. } \\
\text { Confidential }\end{array}$ & & $* *$ Registered ${ }^{* *}$ & Graduate & 3.000 \\
\hline 3 & Cudjoe, Sherifa E. & & $* *$ Registered $* *$ & Graduate & 3.000 \\
\hline 4 & Czoski, Paige A. & & $* *$ Registered $* *$ & Graduate & 3.000 \\
\hline 5 & Gallagher, Sara R. & & $* *$ Registered $* *$ & Graduate & 3.000 \\
\hline
\end{tabular}




\begin{tabular}{|c|c|c|c|c|}
\hline 6 & Gonsalves, Charlene & $* *$ Registered ${ }^{* *}$ & Graduate & 3.000 \\
\hline 7 & Hubbling, Jessica & $* *$ Registered $* *$ & Graduate & 3.000 \\
\hline 8 & Kurnia, Ivan & $* *$ Registered** & Graduate & 3.000 \\
\hline 9 & Nauer, Catherine E. & $* *$ Registered $* *$ & Undergraduate & 3.000 \\
\hline 10 & Raduha, Stefan P. & $* *$ Registered $* *$ & Graduate & 3.000 \\
\hline & Rosandick, Benjamin. & & & \\
\hline
\end{tabular}

\section{University of Utah Students Grad Class 2012}

Blayde Mclntire

Amanda Varland

Rick Lyons

Andy Jensen

Sarah Kissel

Dan Stout

Zac Jones

Logan Riley

Ting Xiao

UTEP Students Grad Class 2012

Paul M. Delgado

Alay G. Gebregiorgis

Afshin Gholamy Salehabady

Felix Dziedzorm D. Ziwu

Teacher Training, Salt Lake City, December 9-10, 2010. This activity was funded by both the Southwest Training Center and the Southwest Partnership. Funding to pay the Keystone center was from Phase II of the Southwest Partnership and personnel to organize the training was from the Training Center. We contracted with the Keystone Center (Keystone, $\mathrm{CO}$ ) to offer a "Climate Status Investigations" teacher training in Salt Lake City, UT at the McGillis School. The Climate Status Investigations is a curriculum for middle-high school students designed to "broaden the scope and quality of national science education with a balanced, non-biased, comprehensive, and interdisciplinary approach to the study of an issue 
pivotal to our students' generation - global climate change" (Keystone Center, 2009). The curriculum was developed in partnership with the U.S. Department of Energy and the National Energy Technology Laboratory.

All 30 students received 13 hours of re-licensure points (for the state of Utah). Eleven of them (marked with an X in the last column of the spreadsheet) received one semester of University Credit (issued from Utah State University).

13 hours $\times 1$ CEU $/ 10$ hours $=1.3$ CEU per student $\times 30$ studnets $=39$ CEU

\begin{tabular}{|c|c|c|c|}
\hline Name & & Re-licensure & University credit \\
\hline Michael & Archibald & $X$ & \\
\hline Tyler & Blain & $x$ & \\
\hline Matthew & Blake & $x$ & \\
\hline Delilah & Brinkerhoff & $x$ & \\
\hline $\begin{array}{l}\text { Kenton } \\
\text { S. }\end{array}$ & Bustin & $x$ & \\
\hline Cabot & Carlston & $x$ & $x$ \\
\hline Paul K. & Chung & $x$ & $x$ \\
\hline Colleen & Cobia & $x$ & \\
\hline Lisa & Craig & $x$ & $x$ \\
\hline Melissa & Decker & $x$ & $x$ \\
\hline Carlyn & Grossaint & $x$ & \\
\hline Andrea & Harris & $x$ & \\
\hline Daloy & Harris & $x$ & $x$ \\
\hline Mark & Harris & $x$ & \\
\hline Tom & Herret & $\mathrm{X}$ & \\
\hline David & Houle & $x$ & \\
\hline \begin{tabular}{|l|} 
Phil \\
\end{tabular} & Johnson & $x$ & \\
\hline \begin{tabular}{|l} 
Joshua \\
\end{tabular} & Lord & $x$ & \\
\hline Daniel & Melville & $x$ & \\
\hline
\end{tabular}




\begin{tabular}{|c|c|c|c|}
\hline John & Moon & $x$ & \\
\hline Jason & Paige & $x$ & \\
\hline Brenda & Raccuia & $x$ & $x$ \\
\hline Jen & Roddick & $x$ & \\
\hline $\begin{array}{l}\text { Robert } \\
\mathrm{J} .\end{array}$ & Rooley & $x$ & $x$ \\
\hline LeeAnn & Salisbury & $X$ & $x$ \\
\hline Mark & Schiszler & $x$ & \\
\hline Marc & Small & $x$ & \\
\hline Richard & Statler & $x$ & \\
\hline Aaron & Tesch & $x$ & \\
\hline Michael & Valdez & $x$ & $x$ \\
\hline
\end{tabular}

SWTC Professional Short Course 1: October 26-27 2010

A CCS simulation professional short course was held at the University of Utah on October 26-27, 2010. The training course was convened by Dr. Brian McPherson (b.j.mcpherson@utah.edu) and taught by code development staff from the Pacific Northwest National Laboratory. This short course provided an introduction to CCS model simulation analysis. For sake of simplicity, we offered training with only one simulation package, STOMP, a multifluid subsurface flow and reactive transport simulator, developed at the Pacific Northwest National Laboratory (PNNL). Through a combination of lectures and computer 
laboratory exercises, students were guided through a series of problems, designed to demonstrate specific CCS scenarios. Students were taught how to prepare input files for flow and reactive transport problems and interpret simulation results, by working with sample problems that vary in complexity and structure. The sample problems were designed to emphasis specific operational modes of CCS and to serve as prototypes and templates for applications for the students after the course. Lectures described the mathematical models, numerical solution approaches, and code structure, but also covered a series of case study examples.

1 Sanjay Mawalkar Battalle

2 Guoping Tang ORNL

3 Jun Yin Oregon State

4 Chu-Lin Cheng University of Tennessee

5 Kenneth Carroll Pacific Northwest National Laboratory

6 Casie Davidson Pacific Northwest National Lab

7 Si-Yong Lee Energy \& Geoscience Institute Utah

8 Weon Shik Han Energy \& Geosciences Institute Utah

9 Brian McPherson University of Utah

10 Imam Raharjo University of Utah

11 Richard Franz University of Utah

12 Adam Olsen University of

13 Seong-Jun Lee University of Utah

14 Vivek Patil University of Utah

15 Wei Jia University of Utah

16 Justin Wriedt University of

17 Katrina Von Kamrath University of Utah

18 Paul Gettings Geology \& Geophysics, U Utah 
Climate Change \& CO2 Seq. - ST 58903

2 Credits CRN:

17590

Duration:

Jun 20, 2011 - Jul

01,2011

A Masters of Science Teaching class ST 589-03 Climate Change and CO2

Sequestration was taught over a two week period in the summer. The class met

from $9 a m$ to $5 \mathrm{pm}$ each day.

The first few days were taken up covering the geological, chemical and atmospheric science underlying $\mathrm{CO} 2$ sequestration and a discussion of the evidence for climate change. Lectures were usually held in the morning, and field or lab studies in the afternoon.

All the students in the class are currently active class room teachers and so we looked at the NM Middle School science standards and common curriculum to find where it was possible to incorporate discussion of climate change and $\mathrm{CO} 2$ sequestration information in the classroom.

The final week lab periods the students developed lesson plans on climate change and $\mathrm{CO} 2$ sequestration for $6^{\text {th }}, 7^{\text {th }}$, and $8^{\text {th }}$ grade students.

class List 2011

1 Banddy, Kirsten

2 Bardy, Marcia

3 Larsen Scott 


\section{Class List 2012}

Liz Monroy, (El Paso-General Science),

Esti Guiterrez (Los Lunas-General Science \& Math),

Lu Boren, (Durango- Biological Sciences),

Ian Geib (South Valley- Chemistry),

Earl Reynolds (Belen=-Math),

Angelica Lopez (Rio Rancho-Biology),

Geizi LLanes (Shiprock-general Science).

\section{Resvr Caprock Field 8/15-8/17 - ERTH 49101}

Course Information

This class was offered to university and professionals alike. It consisted of a 4 day field trip to Southeastern Utah to examine evidence of fluid flow in reservoir and caprock lithologies to better understand the nature of seal by-pass in sequestration reservoirs. Instructors were Peter Mozley and Andrew Campbell

CRN:

53560

Duration:

Aug 15, 2012 - Aug 17,

Summary Class List

$\begin{array}{cccccccc}\text { Record } & \text { Student } & \text { ID } & \text { Reg Status } & \text { Level } & \text { Credits } & \text { Final } & \begin{array}{c}\text { Grade } \\ \text { Dumber }\end{array} \\ \text { Name } & & & & & \end{array}$

1 Blom, Lukas $900304826^{* *}$ Registered** Undergraduate 1.000

$2 \quad$ Butler, David $900275258 * *$ Registered** Graduate $\quad 1.000$

$3 \quad$ Currie, Neil $900297256^{* *}$ Registered** Undergraduate 1.000

$4 \quad$ Gallagher, $\quad 900302678 * *$ Registered $^{* *}$ Graduate $\quad 1.000$ 
Sara

$5 \quad \frac{\text { Lafferty, }}{\text { John N. }} \quad 900295843 * *$ Registered $* *$ Undergraduate 1.000

$6 \quad \frac{\text { Nauer, }}{\text { Catherine E. }} 900285696 * *$ Registered ${ }^{* *}$ Undergraduate 1.000

$7 \quad \underline{\text { Raduha, }} \quad 900300711^{* *}$ Registered** Graduate $\quad 1.000$

$8 \quad \begin{aligned} & \text { Rosandick, } \\ & \text { Benjamin }\end{aligned} 900302130 * *$ Registered ${ }^{* *}$ Graduate 1.000

$9 \quad \frac{\text { Salaz, }}{\text { Kenneth }} \quad 900177929 * *$ Registered ${ }^{* *}$ Graduate $\quad 1.000$

$10 \quad \frac{\text { Towery, }}{\text { Andrea C. }} \quad 900295915 * *$ Registered ${ }^{* *}$ Graduate $\quad 1.000$ 


\section{Conversion of professional development credits.}

\section{Equivalency of credits.}

According to the Society of Petroleum Engineers the following definitions are used.

I hour spent in professional-development activities = $1 \mathrm{PDH}$

10 hours of continuing education $=1 \mathrm{CEU}$

So $1 \mathrm{CEU}=10 \mathrm{PHD}$

From this we can calculate the conversion of university credits to PDH and CEU.

1 university credit is 1 hour per week for a 15 week semester.

So 1 university credit $=15 \mathrm{PDH}$ or $1.5 \mathrm{CEU}$.

So a 3 credit university course $=45 \mathrm{PDH}$ or $4.5 \mathrm{CEU}$ 